Running head: ANALYZING STUDIO CLASSROOM PRACTICES AND CULTURE

\title{
ANALYZING THE PHYSICAL AND VIRTUAL INTERIOR DESIGN STUDIO CLASSROOM PRACTICES AND CULTURE
}

A Dissertation
presented to
the Faculty of the Graduate School
at the University of Missouri-Columbia
In Partial Fulfillment
of the Requirements for the Degree
Doctor of Philosophy
by
LORI KINLEY
DECEMBER 2018
Dr. Ruth Brent Tofle, Committee Chair
DEC


Running head: ANALYZING STUDIO CLASSROOM PRACTICES AND CULTURE

The undersigned, appointed by the dean of the Graduate School, have examined the dissertation entitled

\section{ANALYZING THE PHYSICAL AND VIRTUAL INTERIOR DESIGN STUDIO CLASSROOM PRACTICES AND CULTURE}

Presented by Lori Kinley, a candidate for the degree of doctor of philosophy, and hereby certify that, in their opinion, it is worthy of acceptance.

Ruth Brent Tofle, PhD

Benyamin Schwarz, PhD

Joi Moore, $\mathrm{PhD}$

Laura Cole, $\mathrm{PhD}$ 
Running head: ANALYZING STUDIO CLASSROOM PRACTICES AND CULTURE

\section{DEDICATION}

For my loving and supportive husband.

For my loving and patient sons. 
Running head: ANALYZING STUDIO CLASSROOM PRACTICES AND CULTURE

\section{ACKNOWLEDGEMENTS}

Although this journey has taken much longer than I anticipated, the time yielded significant and constructive interactions with many people.

I would like to thank Dr. Ruth Brent Tofle for assuming the role as my committee chair at a crucial time. She picked up the pieces and placed all back together effortlessly. I am grateful for her guidance, support, suggestions, and questions that pushed my research and writing.

In addition, I would like to thank Dr. Benyamin Schwarz. As my co-advisor, I value the many meaningful conversations, debates, and banter. The discussions were vital to the development and success of my research.

Thank you to Dr. Joi Moore as she challenged me to look at my research from a different perspective. With that, she has inspired my next research projects.

And, Dr. Laura Cole. I appreciate her time, questions, and comments.

To my colleagues and peers, Dan Harper, Donna Pennella, Dr. Gloria Stafford, and Dr. Lori Anthony. They all were a tremendous support system.

And, to the instructors and students that participated in my research. I am thankful for their insight, honesty, and contributions.

Lastly, to my family - for their continued encouragement. 
Running head: ANALYZING STUDIO CLASSROOM PRACTICES AND CULTURE

\section{TABLE OF CONTENTS}

Acknowledgements

List of Illustrations $\quad$ V

Abstract vi vi

I. CHAPTER ONE: INTRODUCTION 01
A. Overview
01
B. Purpose
02
C. Goals of the Study

II. CHAPTER TWO: BACKGROUND 04

A. History of the Design Studio 04

$\begin{array}{ll}\text { B. Studio Pedagogy } & 06\end{array}$

C. Physical Studio Learning Environment $\quad 11$

$\begin{array}{lr}\text { D. Virtual Studio Learning Environment } & 18\end{array}$

E. Studio Culture $\quad 29$

F. Social Learning Theory $\quad 32$

G. Research Questions 34

III. CHAPTER THREE: RESEARCH DESIGN 35

A. Epistemology and Theoretical Framework 35

B. Constructionism $\quad 35$

C. Theoretical Perspective: Interpretivism and Symbolic Interactionism 35

D. Grounded Theory Methodology 36

$\begin{array}{ll}\text { E. Purposive Sample } & 37\end{array}$

F. Data Collection $\quad 38$

G. In-Depth Interviews 38

H. Observations and Document Review 41

I. Interview Coding 41

J. Validity Issues $\quad 44$

$\begin{array}{ll}\text { K. Ethical Issues } & 47\end{array}$

IV. CHAPTER FOUR: FINDINGS 49

A. Physical Interior Design Studio Classroom 52

i. Studio Practice $\quad 52$

ii. Critique $\quad 59$

iii. Studio culture $\quad 62$

iv. Collaboration $\quad 68$

$\begin{array}{ll}\text { v. Outcomes } & 70\end{array}$

vi. Environment influence, impact, and control 72

B. Virtual Interior Design Studio Classroom $\quad 76$

i. Studio Practice 76 
Running head: ANALYZING STUDIO CLASSROOM PRACTICES AND CULTURE

ii. Critique $\quad 81$

iii. Studio culture $\quad 87$

iv. Collaboration $\quad 92$

v. Outcomes $\quad 95$

vi. Environment influence, impact, and control 100

V. CHAPTER FIVE: DISCUSSION 110

A. Limited collaborative interaction among faculty, students, project clients, and experts

B. Limited creativity associated with the fluid and open-ended nature of stimulation, trials and exploration in the design process

C. Limited personal and individualized interaction in building engaged relationships and networks

D. Limited teaching and learning expectations for iterative on-going reflection and continuing improvements in projects evolving in time

E. Limited investment in building a studio culture with real-time presence and interaction among a tightly formed group of 16 or less colleagues to address dynamic complexities in the problem-solving design process

F. Other Aspects for Consideration

i. Dedication of instructor and student

123

ii. Technical skills and design process

125 iii. Course design

127

G. Limitations of Study

131

H. Final Thoughts

133

i. Advantages and Disadvantages

133

ii. Beyond Classroom Influences

134

I. Conclusion

VI. REFERENCES

VII. APPENDICES

Appendix A: Discussion Guides for In-Depth Interviews 
Running head: ANALYZING STUDIO CLASSROOM PRACTICES AND CULTURE

\section{LIST OF ILLUSTRATIONS}

Figure or Table

Figure 1: Example of student collaboration $\quad 17$

Figure 2: Example of pin-up critique of student work 18

Figure 3: Example of Human Factors course $\quad 22$

Figure 4: Example of Space Planning lecture 23

Figure 5: Example of online help $\quad 24$

Figure 6: A video demonstration of sketching techniques 25

Figure 7: Example of "Welcome Announcement" 26

Figure 8: Example of "Course Closing Announcement" 27

Figure 9: Example of juror critique 28

Figure 10: Example of pin-up and/or desk critique 30

Figure 11: Example of an instructor using redlines within PDF tools 31

$\begin{array}{lr}\text { Figure 12: The research design framework } & 50\end{array}$

Table 1: Comparison of the Two Instructional Models 111 
Running head: ANALYZING STUDIO CLASSROOM PRACTICES AND CULTURE

\author{
ANALYZING THE PHYSICAL AND VIRTUAL INTERIOR DESIGN \\ STUDIO CLASSROOM PRACTICES AND CULTURE \\ Lori Kinley \\ Dr. Ruth Brent Tofle, Committee Chair
}

\begin{abstract}
Studio courses are the heart of the undergraduate interior design programs in the United States. Traditionally, studio courses are offered in a physical classroom where the instructor and students meet together for several hours each week. With the emergence of technology, few institutions are offering studio courses in a virtual environment. Although instructors and students interact with one another within the virtual classroom, they do not meet together in the same physical space. The practices within each environment can determine its success. Therefore, the examination of the experience of both the interior design instructors and students, as well as studio classroom practices, is required to gain an understanding of the studio environment and culture within a physical learning classroom and a virtual learning classroom.

Guided by grounded theory methodology, data collection was triangulated with 19 personal interviews of instructors and students familiar with both environments, classroom observations, and documents that pertained to the classroom. Virtual environments have the potential to be a productive learning space with the current technologies available, however, it was determined that the examined virtual interior design studio environment did not equate to the rich experiences, practices, or culture of the physical environment. Established course design, studio practices, and the use of collaborative technology were not implemented in the virtual studio classroom to produce
\end{abstract}


Running head: ANALYZING STUDIO CLASSROOM PRACTICES AND CULTURE

the teaching and experiential learning outcomes of real-time intensive studio culture. Specifically, the study found serious limitations in (1) Collaborative interaction among faculty, students, project clients, and experts, (2) Creativity associated with the fluid and open-ended nature of stimulation, trials and exploration in the design process, (3) Personal and individualized interaction in building engaged relationships and networks, (4) Teaching and learning expectations for iterative on-going reflection and continuing improvements in projects evolving in time, and (5) Investment in building studio culture with real-time presence and interaction among a tightly formed group of 16 or less colleagues to address dynamic complexities in the problem-solving design process. 
Running head: ANALYZING STUDIO CLASSROOM PRACTICES AND CULTURE

\section{Chapter One: Introduction}

\section{A. Overview}

The concept of teaching students with studio instruction as the central focus of the curriculum is used within architecture and interior design programs (Bender, 2006). Learning by doing is the recommended approach. "Within the basic design studio environment, students are guided to transfer their abstract thoughts into visual concrete decisions under the supervision of design educators" (Nikanjam, 2016, p. 1565).

All four-year interior design programs in the United States utilize both lecture and studio courses. Although lecture courses in design provide valuable information, the studio courses are the backbone of the program. "In interior design, studio often comprises a quarter to a third of the number of hours of the entire curriculum. This studio educational experience typically begins at the freshman level and continues each term through graduation" (Ankerson \& Pable, 2008, p. 144).

The studio classroom is known as a physical location where instructors meet with their students to discuss and review design projects. However, within the past 25 years, technology has provided another avenue, and today students can meet with their instructor and peers in a virtual environment. Institutions that offer the interior design degree online typically only provide lecture courses in a virtual environment, although a few institutions are offering both lecture and studio courses virtually.

With the use of virtual studio emerging, identifying how the physical and virtual studio classrooms operate is important. There is a deep tradition attributed to the physical studio practices, however, the use of virtual studio practices is on the cusp of transpiring. Using the lens of interior design educators and students, an investigation of 
Running head: ANALYZING STUDIO CLASSROOM PRACTICES AND CULTURE

both physical and virtual studio experiences is necessary to not only further understand how instructors and students function in these environments, but also to determine the success of the environments in regards to the development of studio culture and learning outcomes.

\section{B. Purpose of the Study}

As an online instructor for almost twelve years, people often asked me, "How do you teach online?" With the many institutions that offer online courses in numerous disciplines, the question is not as common as it once was. However, the answer to the question can be challenging when applied to interior design.

In the physical studio classroom, instructors and students interact in real time in the same physical space. Studio courses depend on constant interaction between the instructor and student. "Studios (where drawing, debate, and analysis of design take place) are considered more of an active learning experience than a lecture-style classroom" (Bender \& Vredevoogd, 2006, p. 115). When the studios are hosted within a virtual learning environment, the interactions change as instructors and students do not necessarily interact in real time and are not located together in a physical classroom. Only a few institutions have attempted to offer studio courses online. Therefore, it is important to expand the question and ask, "How do you teach studio courses online?" There is a struggle to find the best answer to the question. Not only does interior design education rely on concepts that are physical, tangible and measurable, the courses exist in a studio environment. The approach of studio courses is completely different from lecture courses when comparing the instructor delivery techniques and the student outcomes.

The purpose of this study, therefore, is to examine the experience of both the 
Running head: ANALYZING STUDIO CLASSROOM PRACTICES AND CULTURE

interior design instructors and students to gain an understanding of the studio

environment within a physical learning classroom and a virtual learning classroom.

\section{Goals of the Study}

The goals of this study are to:

1. Understand the interior design instructor experience, as well as the interior design student experience, of the physical studio and virtual studio classrooms.

2. Identify how the physical and virtual studio classrooms operate.

3. Discover the nature of the interaction and outcomes of the physical and virtual environments. 
Running head: ANALYZING STUDIO CLASSROOM PRACTICES AND CULTURE

\section{Chapter Two: Background}

Unlike traditional educational programs where students learn in classrooms or lecture halls, art and design educational programs provide another approach. Art and design students gather in a studio space and learn by doing, an educational theory proposed by John Dewey. Dewey (1933) explained that students should be learning skills that are relevant and applicable, not theoretical.

As a learning environment, the studio is the physical site for learning and teaching, where active interaction between students as well as with faculty takes place. The studio is where the enculturation of students into the profession occurs, and where students undergo a transformation that influences the way they related to the built environment, to their peers, and to their tutors. (Tumusiime, 2013, p. 1)

This research investigates the physical studio, a familiar educational space, as well as the virtual studio, an alternative educational space that has emerged in the last 25 years.

\section{A. History of the Design Studio}

In the early 1700 s, wealthy Americans sent their sons to Europe for study and the Grand Tour. No formal education programs existed for architects in America, however, many men identified themselves as practitioners upon their return to the States. Many notable American architects, including H. H. Richardson, Charles McKim, Louis Sullivan, Bernard Maybeck, and Julia Morgan, attended the Ecole des Beaux-Arts (School of Fine Arts) in Paris, but an American program was not established until 1853 when Richard Morris Hunt, another student of the Ecole des Beaux-Arts, founded a 
Running head: ANALYZING STUDIO CLASSROOM PRACTICES AND CULTURE

formal program in America (Cuff, 1992). When Hunt and Richardson returned from Europe, they each established American ateliers (1857 and 1866 respectively), that eventually became known as architectural centers. "Their emphasis on art, intellect, and theory stood in sharp contrast to the ad hoc training in skills and construction acquired by less aristocratic practitioners of the time" (Cuff, 1992, p. 28). Kuhn (2001) indicates "the Architecture studio, an American adaption of the atelier-based training at the Ecole des Beaux-Arts in Learning from the Architecture Studio $19^{\text {th }}$ Century Paris, offers us a teaching model from a design discipline in which the function and the structural, the social and the technical, must be successfully blended" (p. 349).

The Arts and Crafts movement sparked interior design programs. "The earliest mention of an interior design school was at the Women's Institute of Technical Design in New York in 1883" (May, 2017, p. 14). Although, it appears that the courses focused more on painting and decorating skills (May, 2017).

Interior design formal education programs began in the late $19^{\text {th }}$ and early $20^{\text {th }}$ century. "Interior design educational programs have been traditionally situated in one of the following: (1) an art department in connection with art practice, (2) home economics schools which evolved into human ecology programs; or (3) within established architectural programs" (Cho \& Schwarz, 2015, p. 492).

From the 1870 s to the 1930 s, there were many documented interior decoration programs categorized by May, the author of "Lessons in Diversity: Origins of Interior Decoration Education in the United States." Categories included Universities (Home Economics), Universities (Architecture), Universities (Art/Fine Art), Universities (Teacher Colleges), Evening Schools, and Correspondence Courses. As expected, the 
Running head: ANALYZING STUDIO CLASSROOM PRACTICES AND CULTURE

programs that closely relate to those today are Universities (Architecture) and Universities (Art/Fine Art). Both programs included courses such as drawing and drafting, design, history of architecture and furniture, color theory, and textiles (May, 2017). The interior design programs that were aligned with architectural programs followed the foundation studio with lecture courses as supplemental instruction. "As interior decoration transitioned into interior design and educational and professional standards developed, some of the early diversity in training methods, such as selfeducation, became obsolete or was integrated into interior design curriculums, including art training, apprenticeships (now internships) and the correspondence course (now online)" (May, 2017, p. 21). Today, programs not only focus on residential design, but also emphasize commercial spaces such as office, healthcare and hospitality applications.

Since studio courses are the heart of the interior design program; institutions create curriculum with the studio at the center. "Design studio is a core component in design education as a pedagogical approach that emphasizes student-centered learning in design disciplines such as interior design, architecture, and industrial design (Bunch 1993; Chen and You 2010; Cuff 1992)" (Cho and Cho, 2014, p. 473). A small percentage of lecture courses are also required. "In many architectural schools, teaching is divided between the design studio, where the design projects are 'tutored' and lecture-based modules where the historical and technical subjects are "taught"' (Ghaziani, 2013, p. 2).

For the purpose of this research, the approach of the lecture courses will not be discussed.

\section{B. Studio Pedagogy}

Studio teaching allows instructors to provide students with real world design problems and work through the many steps to discover the most appropriate design 
Running head: ANALYZING STUDIO CLASSROOM PRACTICES AND CULTURE

solution. In the physical studio classroom, the instructor allows the student to investigate, fail, and succeed all the while prodding, challenging, and guiding to the project end.

Students within the studio model learn through practice, research, and discovery

(McWhinnie \& Peterson, 2017). “This constructivist and open-ended approach is aligned with recent learning sciences research, which has found that such pedagogies are more effective at fostering higher-level learning outcomes" (Sawyer, p. 106, 2017). Allowing students to work through problems reinforces the many skills necessary in the professional setting.

As a pedagogical model, studio represents a continuum for participants from education to industry practice. Since "work ready" graduate attributes may be seen as a point of difference for professionally and vocationally oriented higher education institutions, it is important to reflect upon the influence of research and theoretical frameworks on creative outcomes, in both education and industry studio. It is also important to reflect upon ways in which communication, collaborative problem-solving, technology skills, initiative, and self-management can be strengthened in studio (McWhinnie \& Peterson, 2017, p. 3).

Within a studio environment as a learning space, collaboration and social interaction are supported by the physical space. (McWhinnie \& Peterson, 2017). The students are allowed to move about, interact with others, or collaborate during the informal class time. The success of the student can be dependent on the community they establish. 
Running head: ANALYZING STUDIO CLASSROOM PRACTICES AND CULTURE

Studio teaching in the physical space allows the instructors to interact with students and students to interact with one another frequently or spontaneously. Within the studio, instructors have varying approaches however, in all cases, the instructor provides a design project that the student must complete within a designated timeframe. The design problem typically includes specifics; this could include a variety of aspects including requirements of the project, cost, period of time/due dates, etc. The creative process can flourish in this type of environment.

Instructors complete desk critiques, students conduct oral presentations, and both students and instructors continue to consider multiple solutions until the best solution is found.

A successful path through the creative process requires students to reflect on and articulate their process. Students' intensions should be clear in the work, and students should be articulate about the meaning. Instructors ask to 'Explain process, not just the product' (Dabbeksm 2005, p.149) (Sawyer, 2017, p. 108).

The interactions change week to week based on the requirements and demands of the project, or student.

Good instructors are able to modify their conversational approach to match each student's needs: 'goals and content are left very open, and are assumed to emerge through the work of the student ... it cannot be decided beforehand by anyone else or even the student' (Swensson \& Edstom, 2011, p. 23) (Sawyer, 2017, p. 106). 
Running head: ANALYZING STUDIO CLASSROOM PRACTICES AND CULTURE

Although the overall project requirements are the same for the physical studio and virtual studio, the pedagogical approach is different. In most cases, the instructor and the students are located in separate physical locations. With this, the issues of time, place and channels need to be reviewed (Kvan, 2001). "Most obviously, communication channels change. Sitting adjacent to a tutor [instructor], listening to their comments as they work, the students observe the acts of knowing-in-action and reflection-in-action which Schon identifies" (Kvan, 2001, p. 348). Instructors and students must modify their actions to accommodate the virtual environment, and act as if they are part of one physical space while using computer mediated spaces. Timing and presence are altered.

Under certain circumstances, given the nature of the schools and classrooms as we have them today, it may be easier to foster the dimensions of interest, involvement, imagination, and interactivity through computers or other technologies; they do have certain advantages in this regard. Online education can be just as vivid, meaningful, and dynamic as face-to-face interactions in a classroom-or even more so. Each domain has its own unique qualities and advantages for this reason; to me, the question is not a matter of which is better or which should substitute for the other, but rather what is the distinct capability of each to support immersive learning experiences (Haythornthwaite \& Kazmer, 2004, p. 12-13).

With one particular study, the responsibilities of the instructor and student of the virtual environment were identified. 
Running head: ANALYZING STUDIO CLASSROOM PRACTICES AND CULTURE

In a Virtual Design Studio, the role of teachers and students acquire new nuances. This is because students' learning does not depend so much on the dialogue between the two sides but on the methods and resources used to perform the learning activities. The teachers' role as transmitters of knowledge (a feature of the conventional Design Studio) passes into the background since their main responsibility now is to boost the learning processes in the virtual environment. For example, $[\ldots]$, teachers assumed the role of the client to reinforce distance relationships with students to help them identify their learning needs through a process of self-review (without imposing their professional beliefs) and to enhance students' participation and cooperation in the differently designed learning activities (Masdeu, 2017, p. 13)

Students of the virtual studio learning environment must take responsibility and accountability for their learning with a more active role. "Students have to learn to selfmanage their own learning, to use the right information to achieve their goals and to plan their study time" (Masdeu, 2017, p. 13). This occurs not only with individual work, but also with group or team project work. Therefore, the virtual environment must also support the opportunity to collaborate and interact with others. In the following two sections, the specifics of each learning environment, the physical and virtual, will be explored. 
Running head: ANALYZING STUDIO CLASSROOM PRACTICES AND CULTURE

\section{Physical Studio Learning Environment}

Al-Qawasmi (2006) indicates that the studio offers a holistic learning approach

for the students as they can work through both aesthetics and construction. This "learning by doing" is essential in the interior design curriculum.

Problem based learning models offer a number of potential advantages in a search for solutions of this kind: it is problem driven, not discipline driven; it encourages hands-on experience with due regard to the 'critical importance of situated learning' (Fincham, Georg, \& Nielsen, 2005, p. 28), thereby engendering an interest in addressing real life problems. (Al-Qawasmi, 2006, p. 456) According to Kuhn (2001), the following are essential characteristics of architectural studio teaching:

1. Student work is organized primarily into semester length projects, responding to complex and open-ended assignment.

2. Students' design solutions undergo multiple and rapid iterations.

3. Critique is frequent, and occurs in both formal and informal way, from faculty, peers, and visiting experts.

4. Heterogeneous issues - ranging from structural integrity to the social impact of the design - are considered, often in the same conversation.

5. Students study precedents (past designs) and are encouraged to think about the big picture.

6. Faculty help students to impose appropriate constraints on their design process in order to navigate a complex and open-ended problem and find a satisfactory design solution. 
Running head: ANALYZING STUDIO CLASSROOM PRACTICES AND CULTURE

7. The appropriate use of a variety of design media over the course of the project significantly supports and improves students' insight and design (Kuhn, 2001, p. 351-352).

The studio instructors, many with professional practice experience, develop the session long project that meets the goals, objectives, and competencies of the course. "Studios are typically organized around manageable projects of design, individually or collectively undertaken, more or less closely patterned on projects drawn from actual practice" (Schon, 1987, p. 43). This type of instruction allows for the students to embrace the design process by working through it phase-by-phase with guidance.

The concept of studio-based learning refers to the active participation in solving specific given problems and finding the most appropriate solutions. Design studio, as the core of architecture education, aims to equip students with certain skills that are the pre-determined objectives of each design studio in the academic year (Nikanjam, 2016, p. 1565).

Just as any instructor manages their classroom with particular techniques, each studio instructor maintains their own distinct approach to the studio process.

They [instructors] have evolved their own rituals, such as master demonstrations, design reviews, desk crits, and design juries, all attached to a core process of learning by doing. And because studio instructors must try to make their approaches to design understandable to their students, the studio offers privileged access to designers; reflections on designing. It is at once a living and a traditional example of a reflective practicum. (Schon, 1987, p. 43) 
Running head: ANALYZING STUDIO CLASSROOM PRACTICES AND CULTURE

Studio size is typically 14-16 students, and the group typically meets two times per week for three to four hours each session. Ankerson, College of Architecture Dean at the University of Nebraska-Lincoln, concurs, "Studio classes may range from four to twelve hours per week, during which the instructor works with each learner independently for short periods of time (Ankerson \& Pable, 2008, p. 144). Courses are written by each instructor and follow the course competencies and accreditation standards.

The instructors ask the students to continue to refine their work; never accept the first solution as the most successful solution. Many times, instructors will require students to quickly sketch potential solutions and analyze each with a discerning eye. It is not uncommon for students to produce multiple solutions, partial solutions, or stop with unsuccessful approaches. "Design creativity almost invariably includes some degree of risk taking among students, and particularly in the problem-based process" (Al-Qawasmi, 2006, p. 459).

With this studio model, students also typically learn within a cohort program. A cohort is a group of students that start the program together and continue their education enrolling in the same courses.

Research on cohorts (e.g. Brooks 1996; Chairs et al 2002; Lawrence 1997; Maher 2001; Norris and Barnett 1994) reveals that successful cohorts balance the needs of the group with those of the individual member by fostering a sense of belonging, creating an environment in which mutual respect flourishes, supporting risk taking, providing a place for critical reflection and the 
Running head: ANALYZING STUDIO CLASSROOM PRACTICES AND CULTURE

developments of shared understanding, and encouraging and sustaining multiple perspectives. (Imel, 2002, p. 24)

The interior design students may have an even more intensified experience compared to students in other disciplines due to the number of hours spent in the physical studio. The project-based environment provides the space for students to create a sense of belonging and develop respect for varied perspectives.

Instructors take the opportunity to gather students spontaneously during studio to discuss project considerations, review a technical skill, denote potential pitfalls, provide real world experience, or address other topics that may arise. Students also take time to research similar projects throughout history or within the same community to use as a guide or reference. Instructors present information through lectures, videos, or demonstrations. The students learn technical skills such as drafting (via hand or computer), color rendering, or creating presentation boards by directly applying them to the assigned project. On occasion, instructors may also create student teams. Teams may be required to research a design problem together and then finalize with individual solutions, or the teams may be engaged in the entire session and complete a project together. The studio is a place where students gather to engage with one another as well as with their instructor about the design project. Studio learning utilizes one-on-one communication between faculty and students, peer-to-peer interactions, Socratic methods of discourse, all while placing emphasis on learning by doing (Ockman, 2012). 


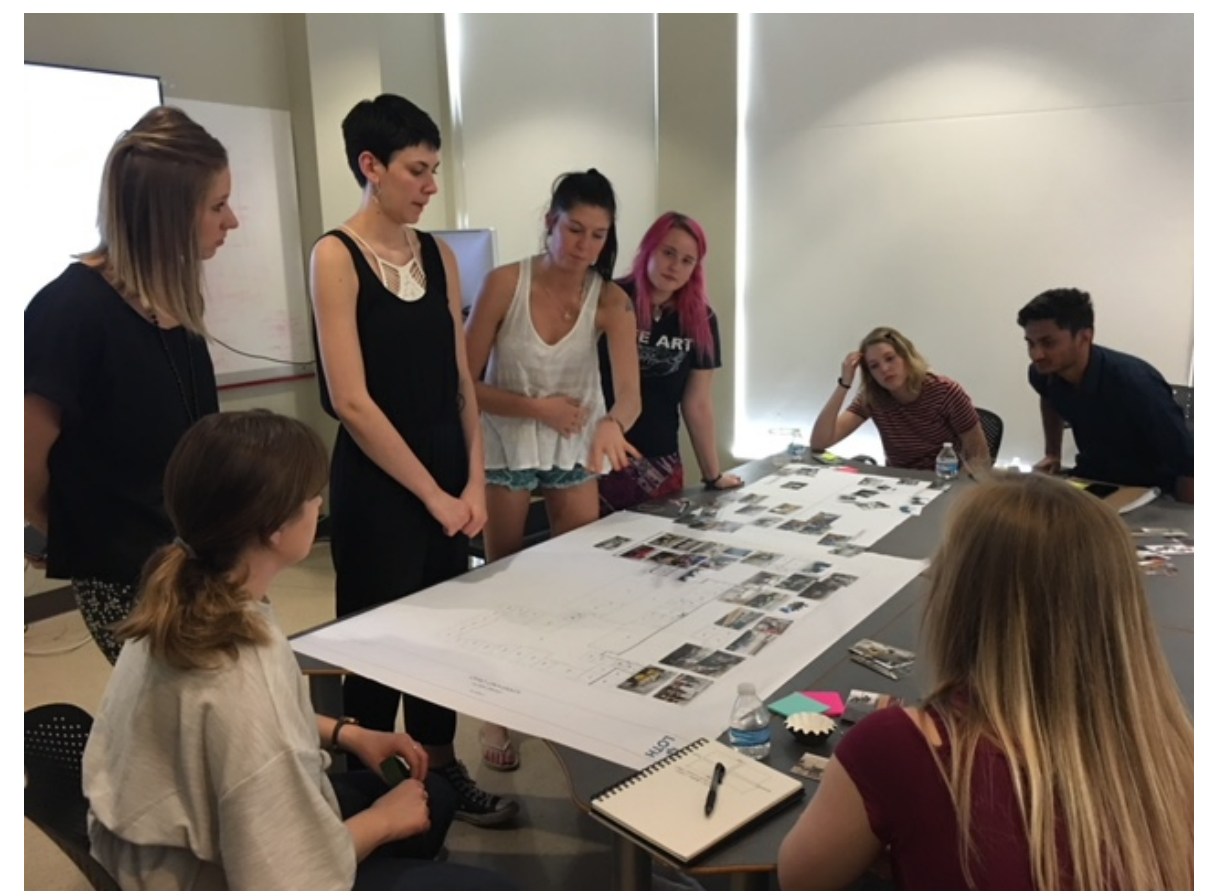

Figure 1: Example of student collaboration; students gathered around student project. (Private Source)

Studio learning also offers many critiques of the work. Throughout the session, a student will receive feedback or critiques from the instructor and their peers.

Communication between the students and the instructor is a necessary component for the studio course to work well. "Students and instructors work jointly to develop the initial design ideas and appropriate design solutions by means of revising and monitoring and also highlighting the problematic parts of the student's design project by the instructors" (Nikanjam, 2016, p. 1566). Studio interaction typically involves one student and one faculty member discussing a project with feedback or direction (Bender \& Vredevoogd, 2006).

The format of a critique is as follows:

1. Pin-up critique: There are typically two times a pin-up critique occurs: at the middle of the project and upon completion of the project. During the project, the 
student literally pins up their work on the wall and their peers and instructor provide a critique of the work (shown in Figure 2). At the project's end, the students present their work to the instructor, their peers, and jurors. During this formal presentation, students may be asked to explain and/or defend their decision making or project solutions. With the final project pin-up, the process is more formal as well-respected professionals and jurors are invited to attend the presentation to evaluate student work. "Most guest critics are not only architects, but architect-teachers, rarely are clients, users, engineers, planners, or neighbors invited, even though their evaluation of architectural projects is important to actual practice" (Cuff, 1992, p. 122).

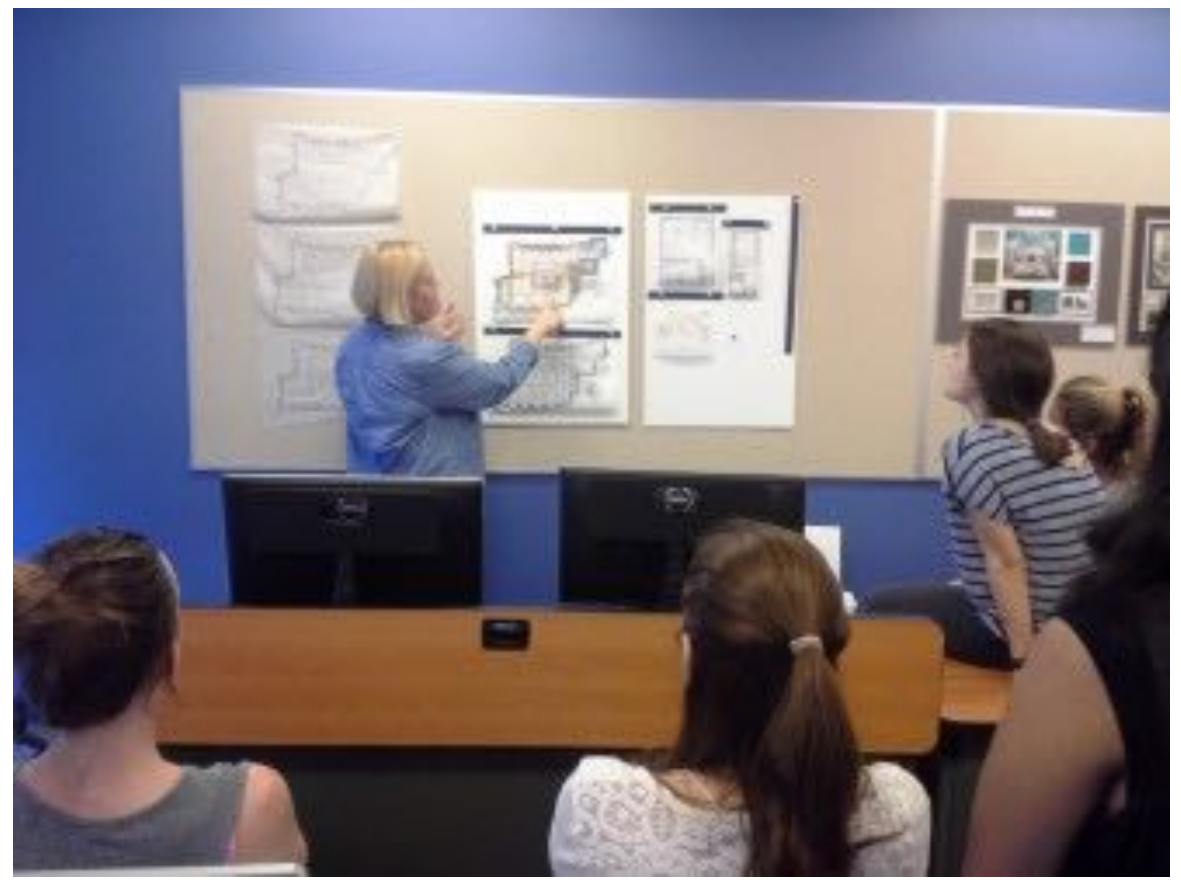

Figure 2: Example of pin-up critique of student work. Instructor and students gather around the work and discuss/critique. Student will use this information to revise the design. (Private Source)

2. Desk critique: With the desk critique, the student receives both audio and visual personal direction from the instructor. "There are desk crits, given to individual 
Running head: ANALYZING STUDIO CLASSROOM PRACTICES AND CULTURE

students at their drawing boards in studio, during which the instructor reviews the progress of the student's project and the student looks for assistance with specific problems and future directions (Cuff, 1992, p. 122).

With this feedback, the student continually revises work seeking the best solution. Schon (1983), a philosopher, "viewed the architecture studio in a relatively positive light, characterizing the desk crit as a dynamic conversation between student and instructor in which the design was made to 'talk back' to the designer" (Ockman, 2012, p. 399). The desk critique is essential to the student's work and growth; using personal interaction with the instructor, the student hones in on the areas of concern or takes note of the project components that are completed well.

The problem-based outcomes provide students with the capability to handle final projects that use critical thinking, reflective thinking, and creativity (Al-Qawasmi, 2006). Dewey maintains that, "reflective thinking, in distinction from other operations to which we apply the name of thought, involves (1) a state of doubt, hesitation, perplexity, mental difficulty, in which thinking originates, and (2) an act of searching, hunting, inquiring, to find materials that will resolve the doubt, settle the disposition of the complexity" (Dewey, 1933, p. 12).

With this approach in the learning environment, students learn how to manage their time, interpret and evaluate the criticism of their work, seek successful approaches, and present their work in a professional atmosphere. This process mimics the professional life of a designer. Students also have opportunities to apply their knowledge to real world issues. "When someone learns a practice, he is initiated into the traditions of 
Running head: ANALYZING STUDIO CLASSROOM PRACTICES AND CULTURE

a community of practitioners and the practice world they inhabit. He learns their conventions, constraints, languages, and appreciative systems, their repertoire of exemplars, systematic knowledge, and patterns of knowing-in-action" (Schon, 1987, p. 36-7).

\section{Virtual Studio Learning Environment}

With the advancement of virtual learning, interior design programs are embracing the use of virtual classrooms for courses such as Design History or Professional Practice. These lecture-based courses appear to be more conducive to the virtual learning environment due to the compatibility of the course competencies. However, a few interior design programs offer studio courses via the virtual learning environment. As expected, there are differences from the physical studio classroom. The studio size is typically the same at 15-18 students. However, the virtual courses are designed as asynchronous therefore there are no formal meeting times as in a physical studio course.

Cohort learning, or a group of students that start a program together and continue their education enrolling in the same courses, is not utilized in the virtual environment as students register for courses at their own pace. For example, with a lack of prerequisites, students may have the ability to register for courses in whatever order they desire. Also, part-time and full-time students are mixed into the program, so one student may complete the degree more quickly than another. These two factors remove the possibility of a cohort learning environment.

Using the physical studio's essential characteristics presented earlier (Kuhn, 2001), the virtual studio attempts to mimic the physical studio. Those seven 
Running head: ANALYZING STUDIO CLASSROOM PRACTICES AND CULTURE

characteristics used for the physical environment are interpreted/applied here within the virtual environment.

1. Studio work is organized into session lengths, as complex and open-ended assignments.

2. Students are asked to compete multiple design solutions, but not necessarily in rapid iterations.

3. Critiques are frequent in informal ways with instructors and other students. A few senior level courses provide live web conferencing presentation opportunities with department instructors as jurors.

4. Heterogeneous issues are present in upper level courses.

5. Students study the history of design and complete case studies for upper level courses.

6. Instructors guide students to find the most appropriate design solutions.

7. A variety of design media are used within the course of the project.

Virtual studio instructors, many with professional practice experience like physical studio instructors, utilize pre-determined, session-long, real-world projects that meet the goals objectives, and competencies of the course. Courses are written by Subject Matter Experts (SMEs) that have the required education and experience pertaining to that particular course. The courses are written with course competencies and accreditation standards in mind. Courses typically are designed with written lectures, assignment/project instructions, tutorials for technology, reading assignments from the electronic textbook or other online sources, and the assignment/project rubrics with expected criteria and attributed points. Figure 3 displays the first page of the written 
Running head: ANALYZING STUDIO CLASSROOM PRACTICES AND CULTURE

lecture; Figure 4 shows a detailed written lecture with a self-check activity on the right panel.

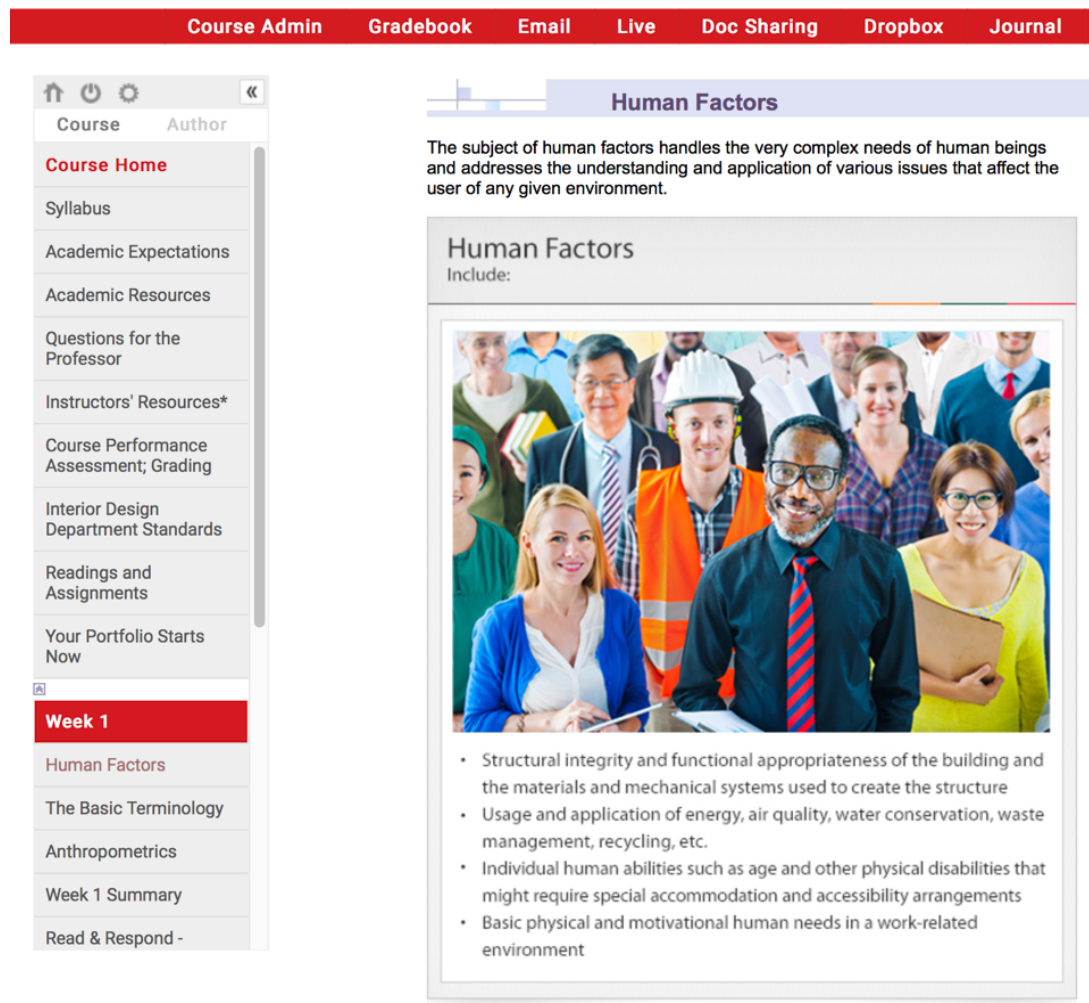

Figure 3: Example of Human Factors course highlighting the first page lecture within the Week 1 online lecture 
Running head: ANALYZING STUDIO CLASSROOM PRACTICES AND CULTURE

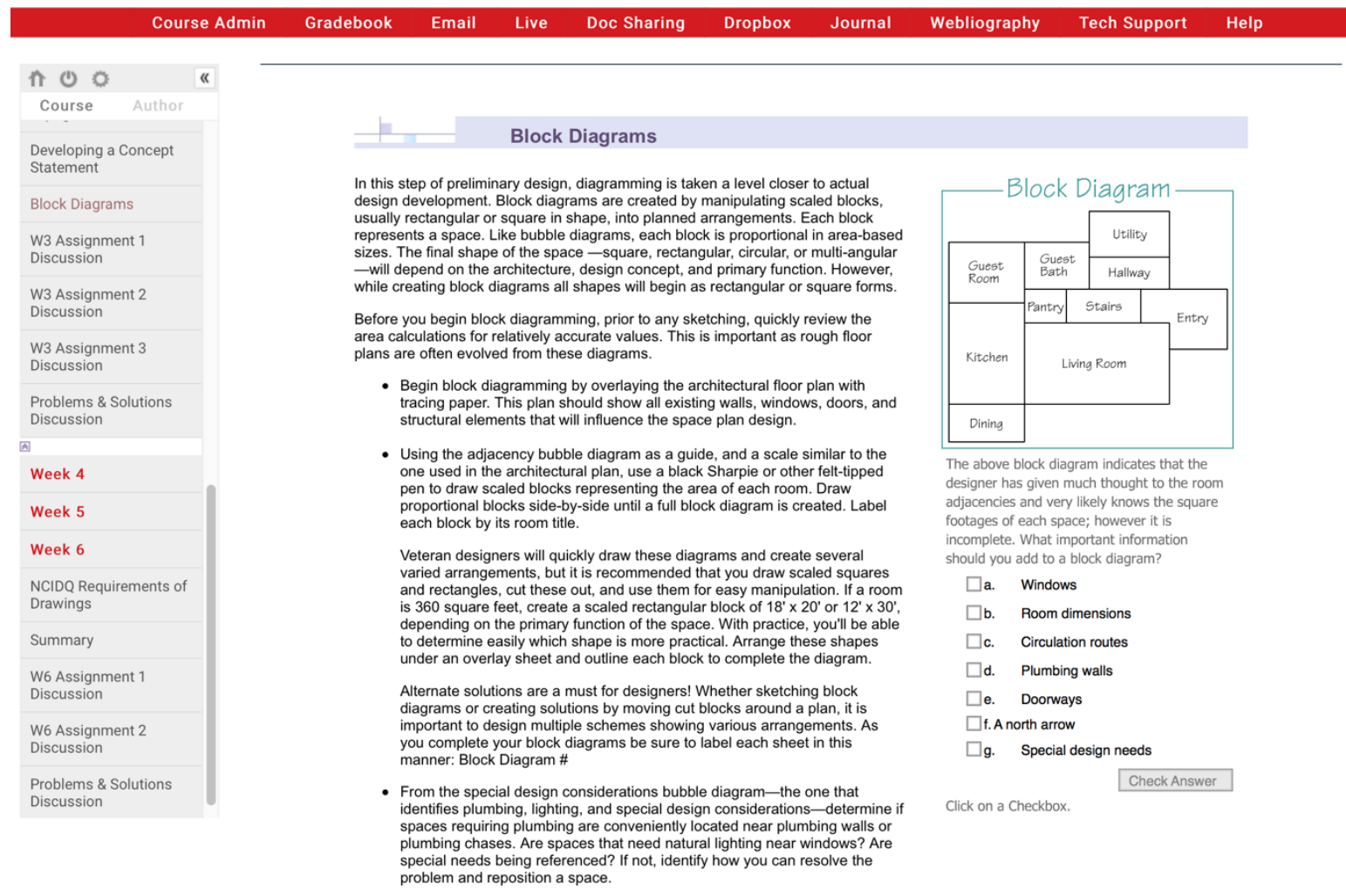

Figure 4: Example of Space Planning lecture with self-check interactive on the right panel.

With virtual courses, students are also provided with links to the online library, or online tutors (available extended hours) if the instructor cannot help or is not available. The tutors provide help with software or writing skills; they do not provide guidance with course content. In this particular course, the "red help button" is displayed at the top of each page in the virtual classroom (see Figure 5). Institutions display the student services section in different formats. 
Running head: ANALYZING STUDIO CLASSROOM PRACTICES AND CULTURE

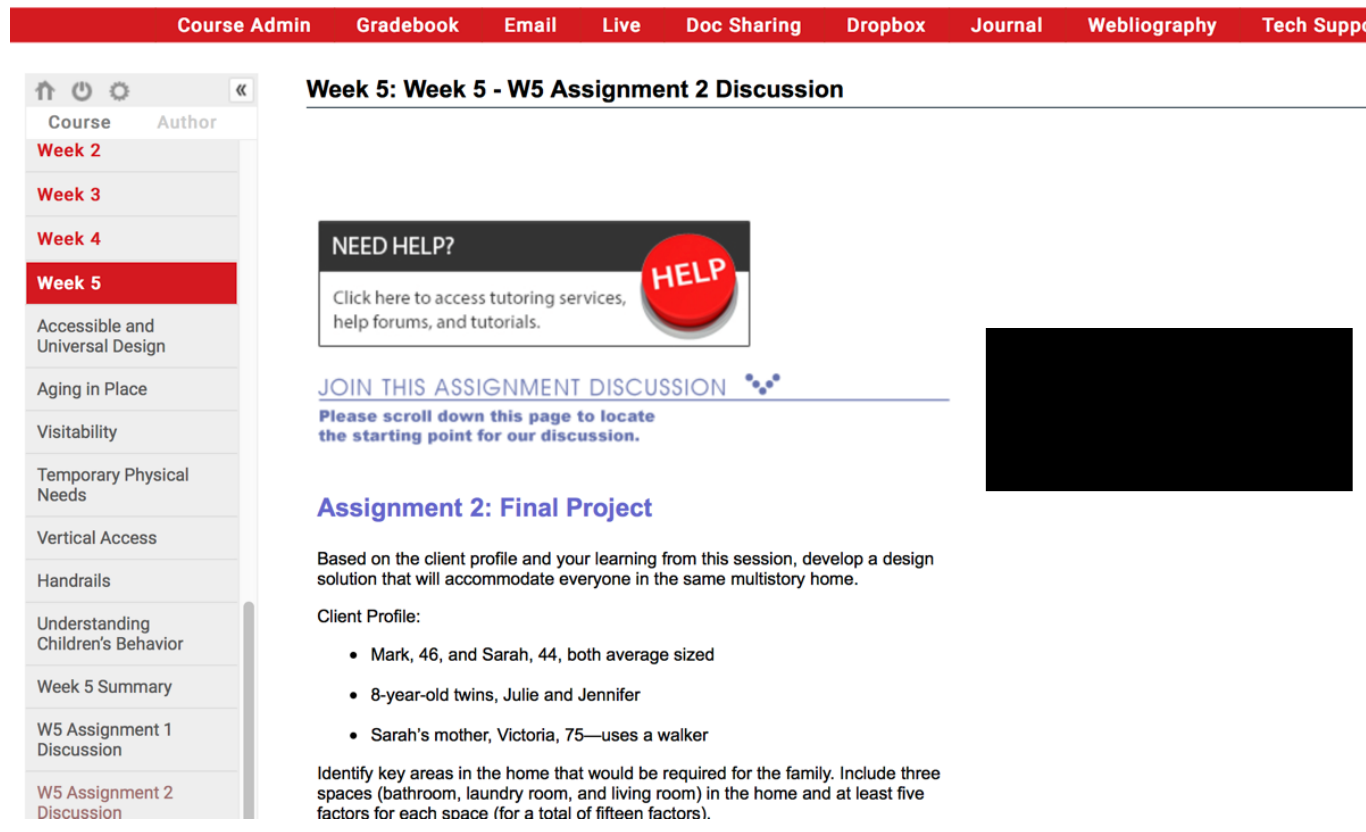

Figure 5: Example of online help: Students can click on the "red help button" to access the online tutors.

Virtual studio courses are uploaded or published to a virtual classroom, providing all virtual studio instructors with the same course information and materials. For example, if there were several sections of a course offered during the same session, the course would be identical.

The virtual instructor can add information to the online classroom. For example, a virtual instructor may add a video demonstration of color rendering, an audio screenshot of a project explanation, or written posts indicating how to approach an assignment/project, as shown in Figure 6. Or, as indicated in Figure 7, the virtual instructor may simply want to add a welcome note. Many times, in the last week of the course, the instructor will post a note regarding the last day of the course, as shown in Figure 8. This helps the student manage the remainder of the time in the course. 
Running head: ANALYZING STUDIO CLASSROOM PRACTICES AND CULTURE

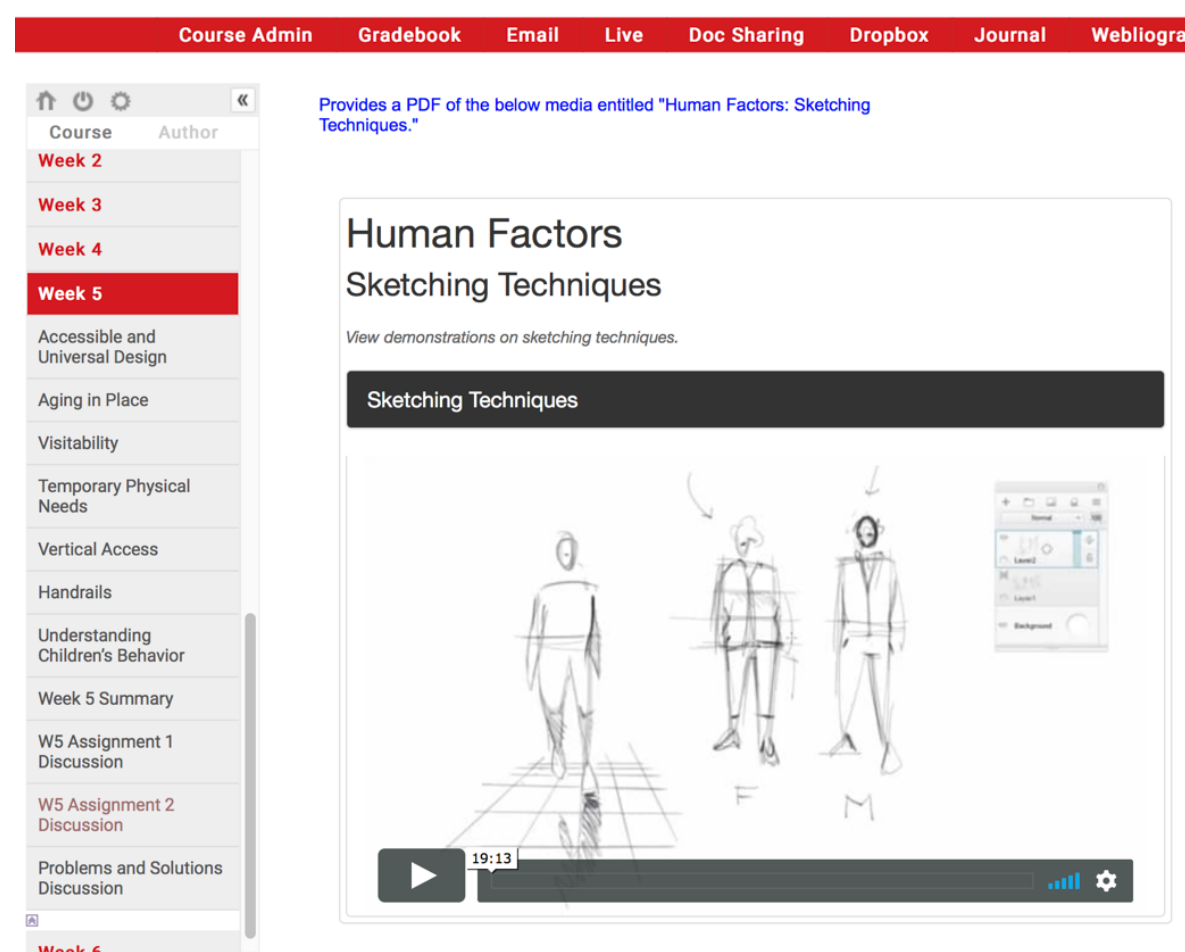

Figure 6: A video demonstration of sketching techniques embedded into the Human Factors online lecture. 
Running head: ANALYZING STUDIO CLASSROOM PRACTICES AND CULTURE

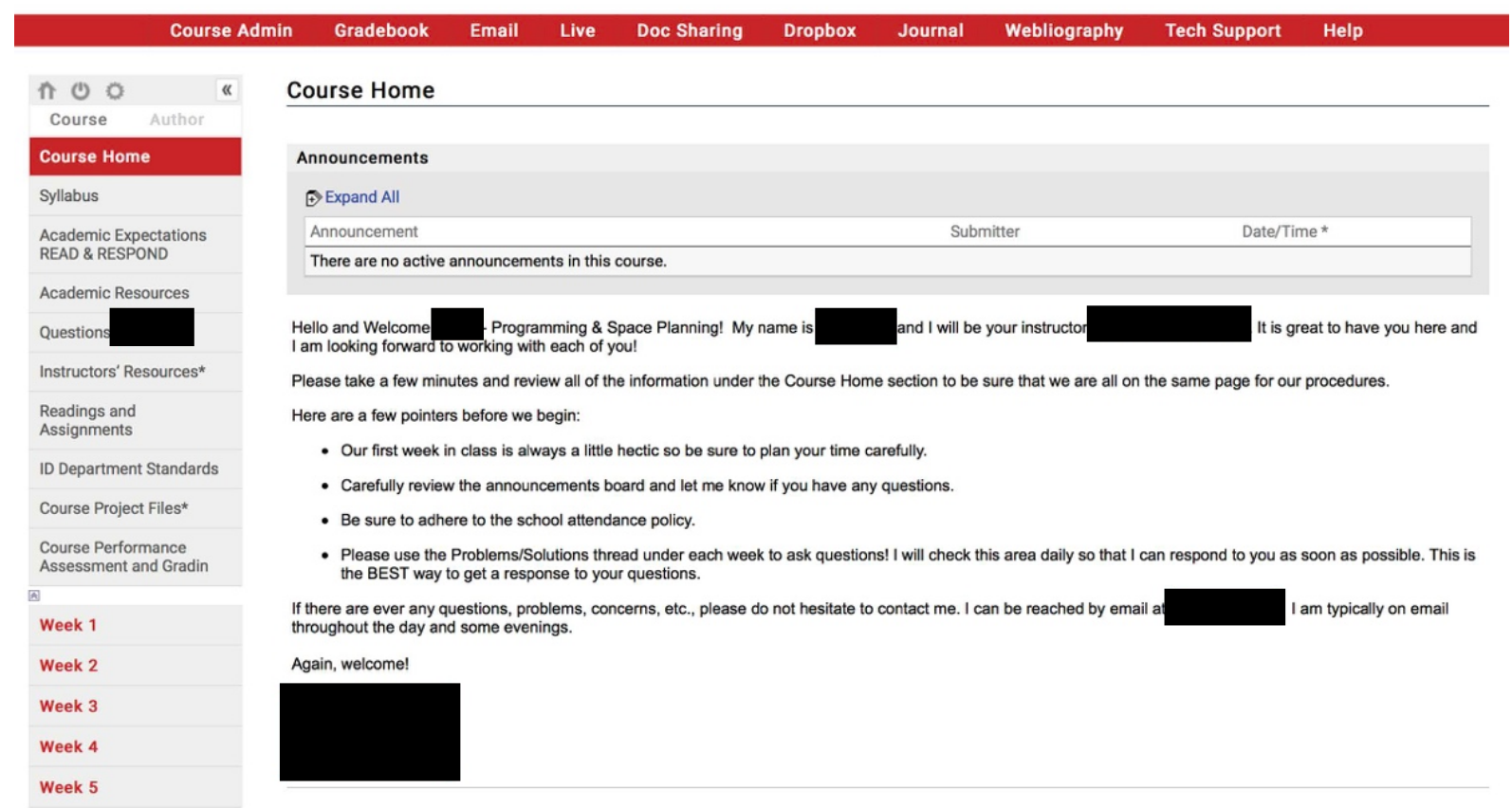

Figure 7: Example of "Welcome Announcement" added by instructor to the home or landing page of the virtual classroom. 
Running head: ANALYZING STUDIO CLASSROOM PRACTICES AND CULTURE

\begin{tabular}{||l|}
\hline Course Author \\
\hline Course Home \\
\hline Syllabus \\
\hline Academic Expectations \\
\hline Academic Resources \\
Questions for the \\
Professor \\
\hline Instructors' Resources* \\
\hline Course Performance \\
Assessment; Grading \\
\hline Interior Design Department \\
Standards \\
\hline Readings and \\
Assignments \\
\hline Your Portfolio Starts Now \\
\hline ⿴囗十 \\
\hline Week 1 \\
\hline Week 2 \\
\hline Week 3 \\
\hline Week 4 \\
\hline Week 5 \\
\hline Week 6 \\
\hline
\end{tabular}

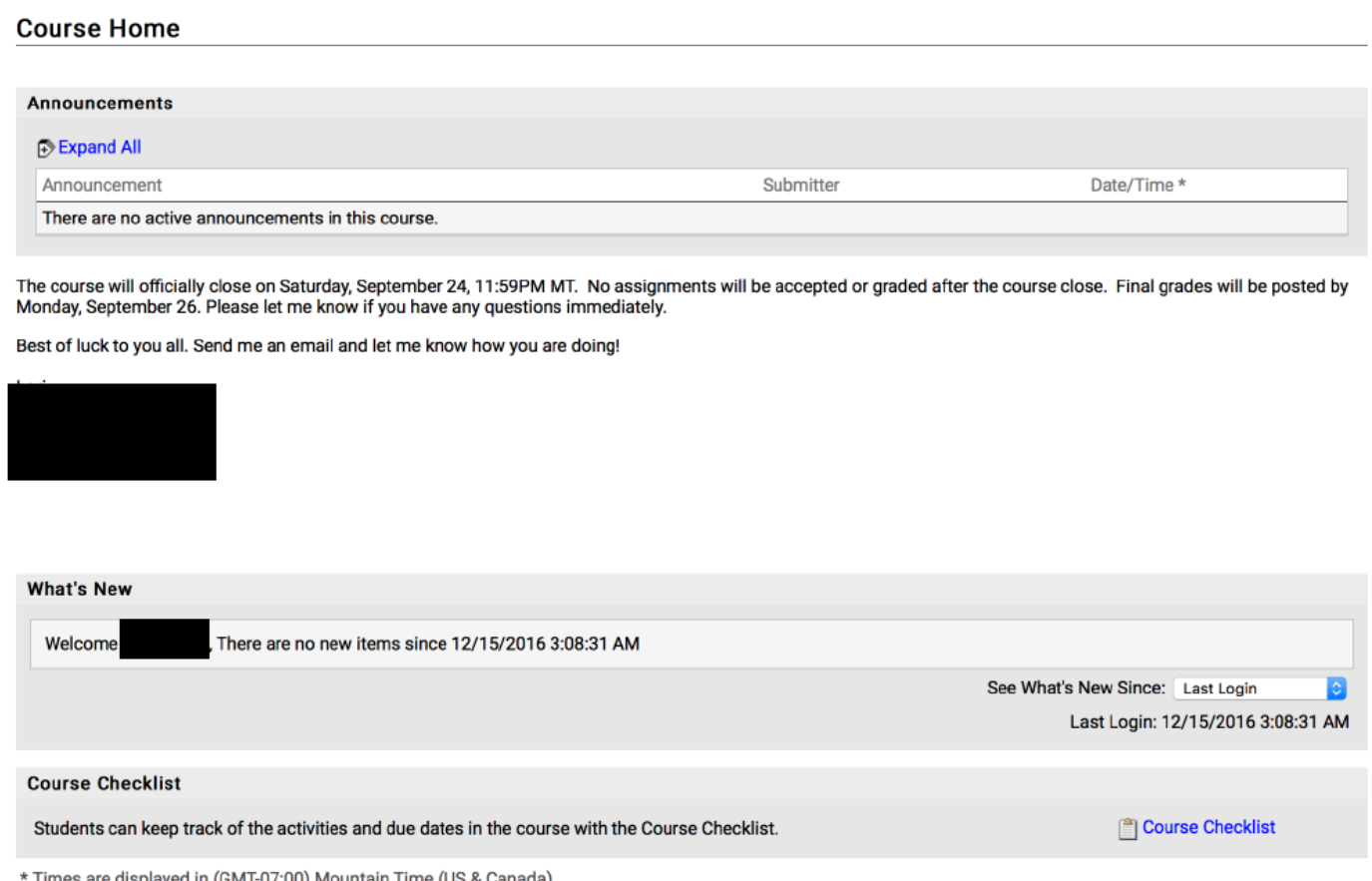

Figure 8: Example of "Course Closing Announcement" added by instructor to the home or landing page of the virtual classroom.

When courses are written by a SME (Subject Matter Expert), this master course can be facilitated by many instructors. No information from the course can be removed due to course outcomes or accreditation standards that need to be met. In my experience, all courses have pitfalls or areas where students tend to ask multiple questions. The instructor can add comments, additional instructions, or examples prior to the assignment instructions to guide the students and reduce confusion. However, there are also instances when an instructor may write a course for their use only. In this case, the instructor would have more control over the content and assignments.

When the design project is presented to the students, there are due dates included with each stage of the project. Since the instructor and student are not in the same 
physical space, the instructor relies on the student to complete the many design solutions on their own, without immediate instructor input or feedback.

The format of the critiques are as follows:

1. Pin-up Critique: Due to the virtual classroom format, instructors do not "gather" the students for pin-up critiques as mentioned in the physical studio. The students post their work in a non- confidential discussion thread with peers providing critiques via written text, audio screenshots, or audio. Strictly written critiques are the most common. Virtual students are required to critique the work of at least two peers. The instructor may provide critique instructions so that students understand the critique process and its purpose. The instructor will also include their own critique. Professionals, jurors, or others are invited to review the students' work in senior level courses. Figure 9 highlights one slide during a student webinar presented to instructors and professionals.

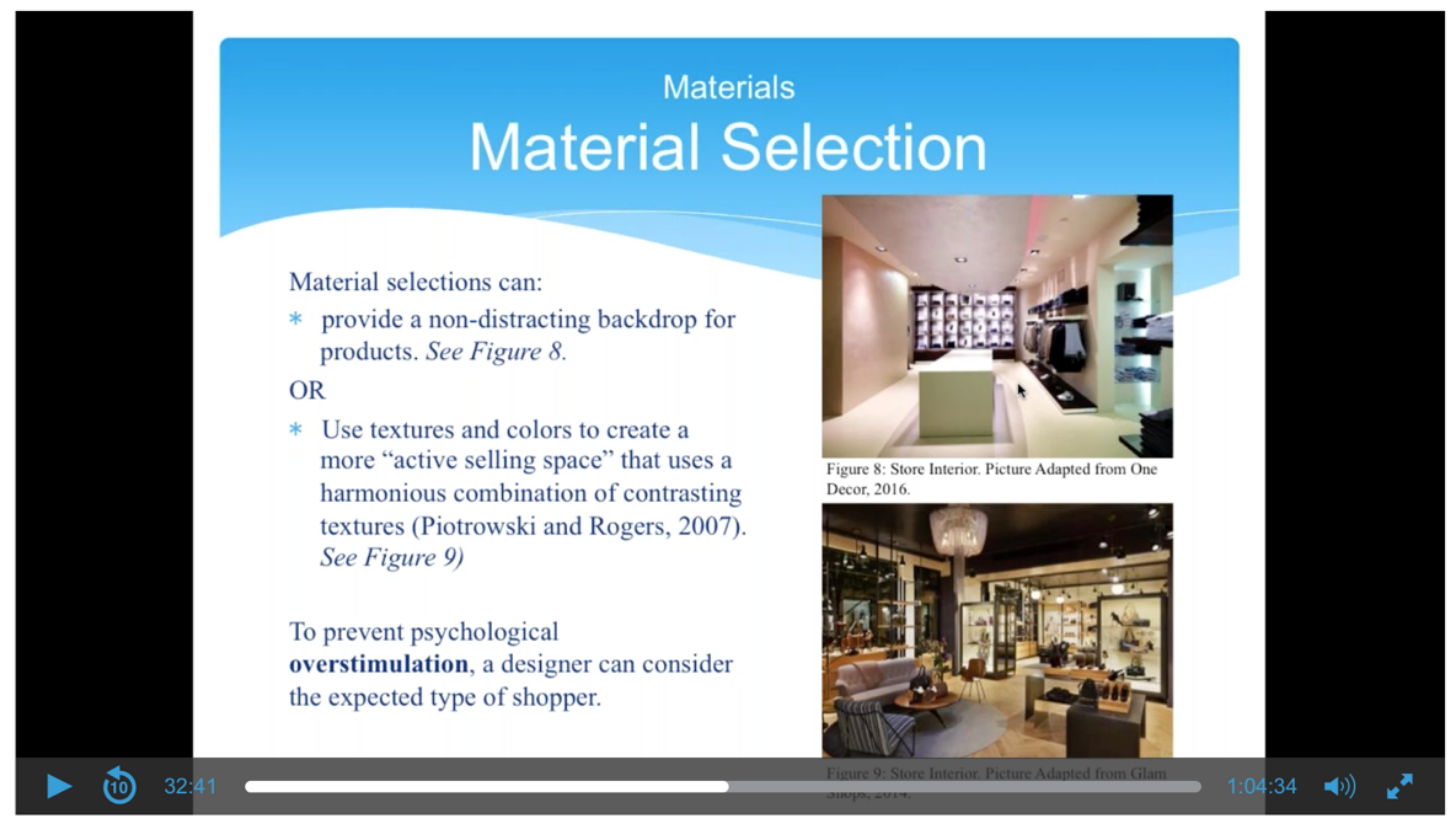


Running head: ANALYZING STUDIO CLASSROOM PRACTICES AND CULTURE

Figure 9: Example of juror critique. One student presenting work to a panel of instructors via live stream audio of desktop digital presentation. (Private source)

2. Desk Critique: The desk critique could be explained in the same way as the pinup critique. Students and instructors review the work posted and provide critiques via the discussion board. Technically, there is not a difference between the two as there was in the physical studio approach. Figure 10 shows a student submitting work, the faculty providing direction as well as asking questions, and the second response from the student. This is a typical exchange. In this example, the assignment is complete and the student would move on to the next assignment in the course. Most frequently, there are two or three assignments per week and in many cases revision of the work is not required; occasionally, a student will revise and resubmit to the original discussion post. 
Running head: ANALYZING STUDIO CLASSROOM PRACTICES AND CULTURE

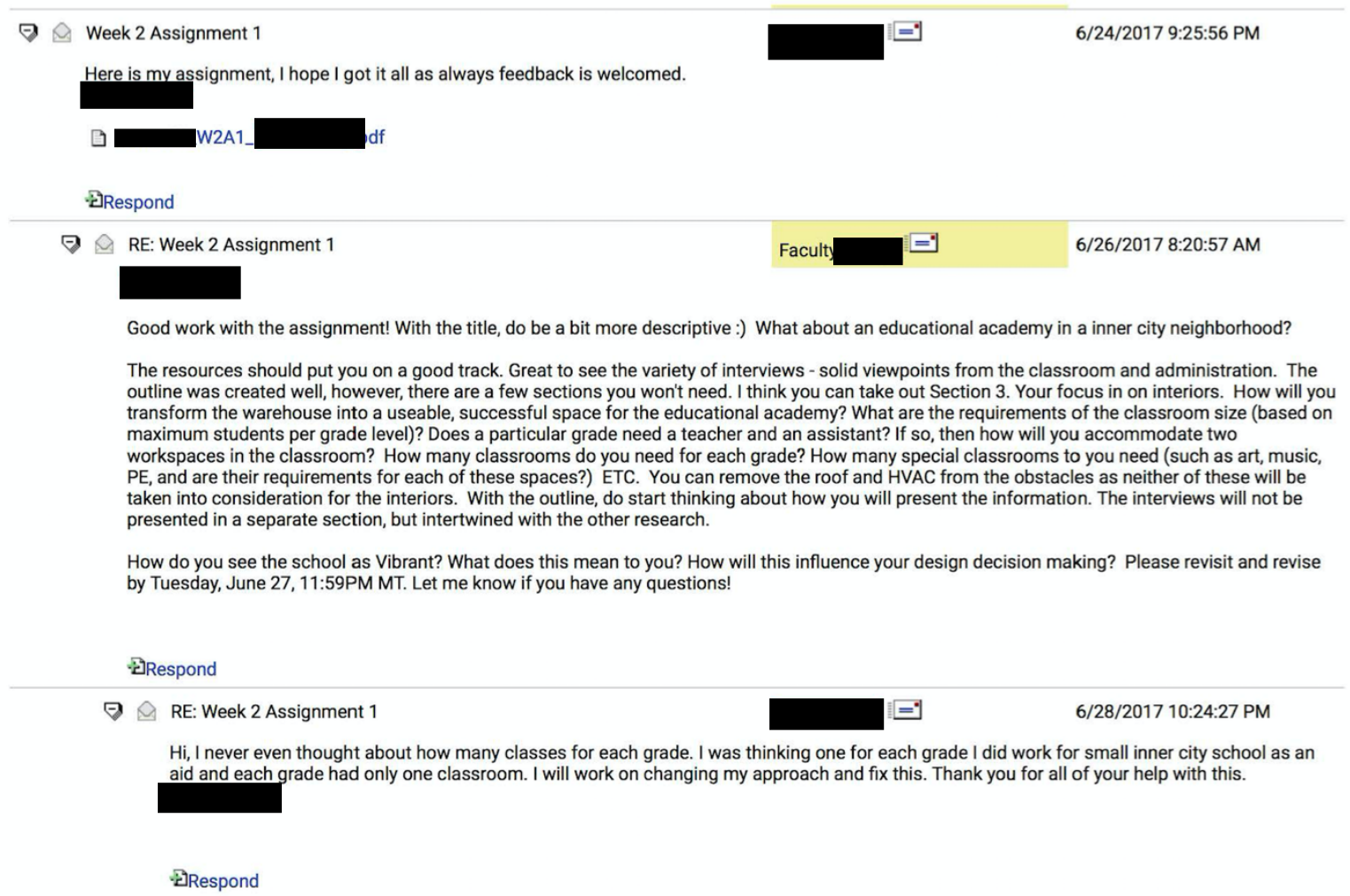

Figure 10: Example of pin-up and/or desk critique. In both cases, the critiques take place within the discussion board of the virtual classroom.

Critiques of the posted work are included with an audio screenshot, written posts

with response, or a PDF with markups as shown in Figure 11. Students learn how to manage a project step-by-step, understand the criticism of their work, and learn the technical skills needed for professional career as a designer. However, as indicated earlier, students have the option of revising work; many, unfortunately do not take the time to do so because the next assignment of the week is due. 
Running head: ANALYZING STUDIO CLASSROOM PRACTICES AND CULTURE

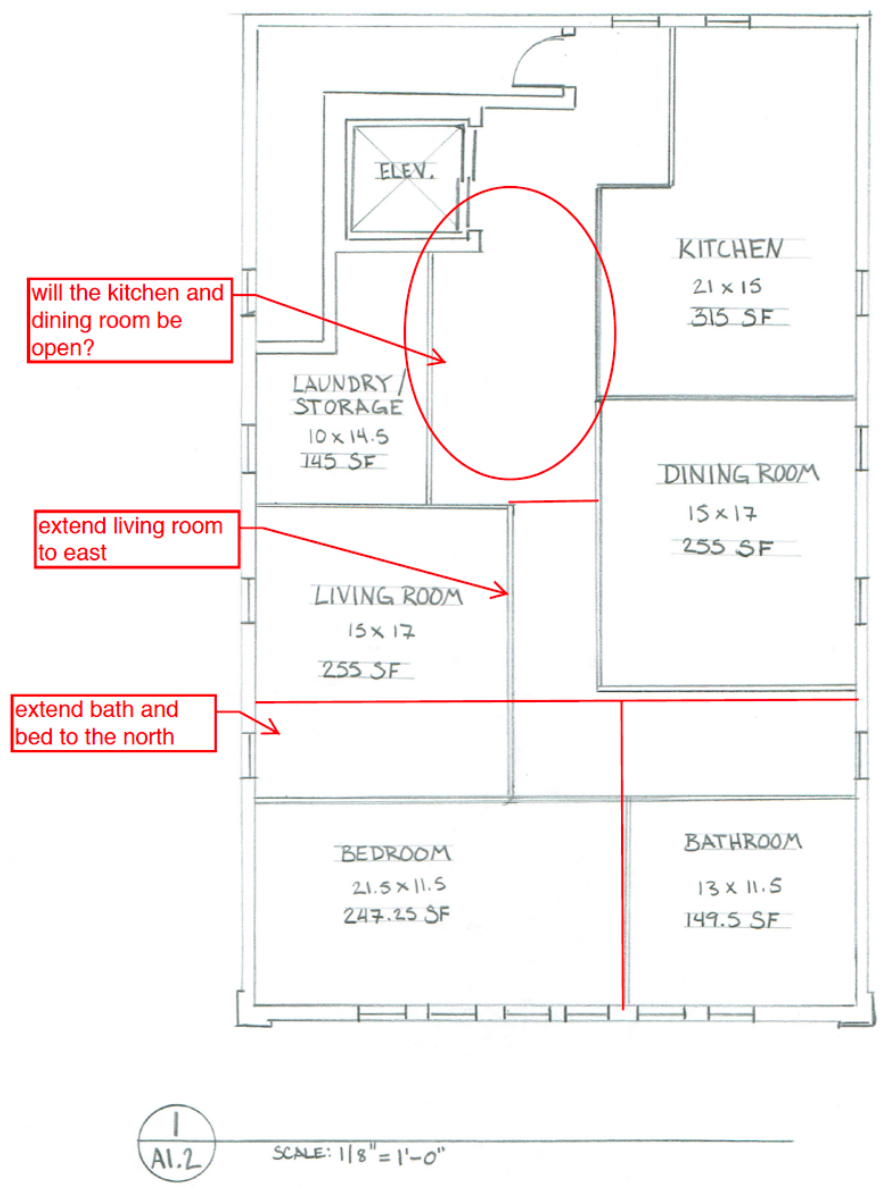

Figure 11: Example of an instructor using redlines within PDF tools to indicate areas of concern and areas for revision to the student.

\section{E. Studio Culture}

In the prior two sections, the focus was on the environment and the actions taken in the physical and virtual space. However, it would be remiss to overlook another element of the studio: studio culture. During formal studio time in the physical environment, the instructor is present, however time is allotted for independent work. When students remain beyond the formal studio time, without the presence of an instructor, a sense of community develops within the group of students. Informal interactions occur, such as one student asking another for advice, one student asking for 
Running head: ANALYZING STUDIO CLASSROOM PRACTICES AND CULTURE

assistance with software, or even personal conversations that create friendships. Programs across the United States have established physical studio culture policies that encourage students to remain in the studio as much as possible and take advantage of the potential collaborations.

Beyond dutifully reporting for studio hours (2:00pm-6:00pm MWF), students are encouraged to spend as much time as possible in the design studio. Studio is offered as a collective, open environment for the sharing of ideas and opinions among both faculty and students, a crucial element in the personal development of each member of the A.UD [Architecture \& Urban Design] community. This world of dialogue can only be fostered through a critical mass of energy, both during and beyond studio hours. Students' participation in this community is as crucial to the success of their colleagues as it is to their own. (Design, 2017) The physical studio policies also highlight the importance of collaborative learning. Some programs provide collaboration opportunities within the department such as student team projects, whereas other programs require students to work with community members that are not necessarily designers or architects, but are professionals that contribute to design projects.

To gain the necessary knowledge and experience for students to be prepared to enter the design profession, collaboration with other disciplines is a necessary addition to design education. Students are given opportunities throughout their academic career to collaborate with many different fields of study including City and Regional Planning, Anthropology, Real Estate Development, and others. This also includes the option of working on community-based research and design 
Running head: ANALYZING STUDIO CLASSROOM PRACTICES AND CULTURE

projects where students can gain a broad range of ability and understanding.

(Department, 2017)

During physical studio time, students also take time to reflect on their own work. With the critiques of the instructor, their peers, and jurors, students can revisit design solutions and constantly revise their work to seek the best solution for the presented problem. With the instructors' guidance, students draw conclusions, make connections, and create projects that are comprehensive. It is this critical reflection that is most beneficial to the student (Ockman, 2012).

The physical studio creates a learning and teaching environment that is unlike the traditional classroom. "The architectural studio has its own culture and values that are as influential in a student's education as the actual projects they complete" (Tumusiime, 2013, p. 2). During the mid-twentieth century, there was a transformation in the studio culture as students were asked to prepare for closed jury presentations (Ockman, 2012). Instead of feedback or critiques strictly from the instructor, the students received detailed feedback from a jury of professionals. Jury sessions often lasted for hours at a stretch, turning into marathons, a practice that persists today. At the same time, as it was in the Beaux-Arts setting, the jury presentation continued to be the culminating moment of the student's many hours of labor. As is still common, architecture students virtually lived in the design studio prior to the jury, cloistered from all else. Not surprisingly, studios often became breeding grounds for strong social bonds among students (Ockman, 2012, p. 399). 
Running head: ANALYZING STUDIO CLASSROOM PRACTICES AND CULTURE

The studio culture is more challenging to cultivate in the virtual classroom as instructors and students are never together in the same space. Although several of the aspects of the studio have attempted to be recreated in the virtual sense, such as juror sessions, group projects, and informal studio time, there are many differences that prohibit the culture from fully developing like one found in a physical space.

\section{F. Social Learning Theory}

Lastly, reviewing the Social Learning Theory will assist in the analysis of the learning environments and the interactions of the students. "Social learning theory approaches the explanation of human behavior in terms of a continuous reciprocal interaction between cognitive, behavioral, and environmental determinants" (Bandura, 1977, p. vii).

Instructors see the benefit of social learning as students can learn by observing others complete tasks in the physical learning environment. In the studio environment, students could watch instructors demonstrate technical skills, or peers solve design problems as they create several prototypes or potential solutions.

By observing peers around you and learning more about those peers and their experiences, you are able to gather information, which could help you later on. [...] As peers exchange thoughts, they may discover new ideas or expand on thoughts that came to mind through the lecture discussion (Williams, 2017, p. 263).

However, direct observations can be more difficult in the virtual learning environment as students are not in the same physical space together. Technology allows the instructors and students to be present in the same virtual classroom, however, since the 
Running head: ANALYZING STUDIO CLASSROOM PRACTICES AND CULTURE

communication is not always live or oral, instructors and students must engage in other ways such as screencaptures, discussion boards, or video feedback.

Online interactions can be more challenging than those that occur face-to-face, however, because there can be less information to guide them. Students in a faceto-face classroom use body language to convey some aspects of their thoughts and feelings, and to monitor how others react to them. In an online learning environment such immediate feedback is not available, so we must be conscious of the online social presence that we choose to portray. It is important to pay careful attention to what we say and do, and how, especially considering that online interactions may not include communication in the form of body language and tone of voice (Spellman-Cann, et al., 2016, p. 112).

Instructors and students need to know the technologies that are available to allow for observations or interactions.

Modeling behavior is another characteristic of the social learning theory. This could be evident when students present their work orally. Students can witness the appropriate approach to presentation and hone their presentation skills. Hill, et al. (2009) also explains that modeling could be found in online discussions. "Some studies have found that when there is a strong example, or model, of how to reflectively interact with others in WBLEs (e.g., discussion board), then the class engages in the learning more effectively" (Hill, et al., 2009, p. 92). 
Running head: ANALYZING STUDIO CLASSROOM PRACTICES AND CULTURE

\section{G. Research Questions}

To completely understand these learning environments and the culture, a thorough investigation of the physical interior design studio classroom and the virtual interior design studio classroom is necessary. The following are the research questions for this study:

1. What are the experiences of instructors and students within the interior design physical studio and virtual studio classrooms, and what are the similarities and differences within the two learning environments?

2. How does either environment influence, impact, or control the learning experience of interior design education within the studio classrooms?

3. What are the operational and outcome differences of the two learning environments? 
Running head: ANALYZING STUDIO CLASSROOM PRACTICES AND CULTURE

\section{Chapter Three: Research Design}

\section{A. Epistemology and Theoretical Framework}

This qualitative study relied on the epistemology of constructionism in that it sought to understand the experiences of both physical and virtual interior design instructors and students.

\section{B. Constructionism}

Constructionism allows the meaning to be constructed, not discovered. Herbert Blumer (1969, p. 2) identifies three basic interactionist assumptions:

- "Human beings act toward things on the basis of the meanings that these things have for them.

- The meaning of such things is derived from, or arises out of, the social interaction that one has with one's fellows.

- These meanings are handled in, and modified through, an interpretive process used by the person in dealing with the things he encounters."

Constructionism allows learners to understand the world around them. "Constructionism is an epistemology embodied in many theoretical perspectives, including symbolic interactionism as this is generally understood" (Crotty, 1998, p. 3).

\section{Theoretical Perspective: Interpretivism and Symbolic Interactionism}

The theoretical perspective symbolic interactionism is a product of interpretivism and allows the construction of meaning. "It [symbolic interactionism] has informed both ethnography and grounded theory" (Crotty, 1993, p. 12). This approach served the research well, as the versatility allowed for modifications during the gathering of information. "Grounded theory methods consist of systematic, yet flexible guidelines for 
Running head: ANALYZING STUDIO CLASSROOM PRACTICES AND CULTURE

collecting and analyzing qualitative data to construct theories 'grounded' in the data themselves (Charmaz, 2006, p. 2).

\section{Grounded Theory Methodology}

The grounded theory methods were established by sociologists Barney Glaser and Anselm Strauss in the mid to late 1960s. "Glaser and Strauss's book The Discovery of Grounded Theory (1967) first articulated these strategies and advocated developing theories from research grounded in data rather than deducing testable hypotheses from existing theories" (Charmaz, 2006, p. 4). As a researcher gathers rich data, the flexibility of this approach allows the discovery of new information by following the leads that emerge (Charmaz, 2006; Crotty, 1998). However, the researcher must continually compare the gathered information, use a variety of viewpoints, visit the data throughout the gathering period, and follow the research guidelines (Babbie, 1999). "An important, distinguishing feature of grounded theory is its use of an intensive, open-ended, and iterative process that simultaneously involves data collection, coding (data analysis), and 'memoing' (theory building)" (Groat \& Wang, 2002, p. 181). In conjunction with observation, data collection, and data structuring, the theory can emerge. (Groat \& Wang, 2002).

Therefore, using the grounded theory method allowed the gathering of qualitative data and interpretation of the two environments in regards to experiences, studio culture development, and learning outcomes. With the information gathered, and using the proper coding and memoing techniques, a theory emerged. 
Running head: ANALYZING STUDIO CLASSROOM PRACTICES AND CULTURE

\section{E. Purposive Sample}

Purposive sampling provides a manageable way to investigate a large population by selecting a subset of that population. A sample can be based on "the knowledge of the population, its elements, and the purpose of the study" (Babbie, 1999, p. 207). As a member of this identified population, I was able to connect with the instructors and students that partake in both the physical and virtual learning environments. Through snowball sampling (existing participants identifying potential participants), I contacted 13 potential instructor participants, and 10 instructor participants agreed to the one-on-one interview. After identifying studio classes that were offered both in the physical and virtual studio classroom, I recruited student participants by asking instructors to post an announcement in the virtual studio classroom. Students that were interested in speaking to me one-on-one contacted me via my email. Thirteen students contacted me via email, however, only nine of those met the desired experiences.

This group, both the instructors and the students, offers considerable knowledge about the physical and virtual studio classroom as each has experience in both environments. To obtain unlimited information regarding the research and participants for the interviews, the two parameters listed below were used for each group. Since the large population consists of both full-time and part-time instructors and students, including all members was appropriate. Also, experiences of full-time respondents and part-time respondents could be different, therefore, it was important to capture the whole range. As common practice in qualitative studies, Babbie (1999) suggests the continuation of refinement of the parameters to be taken into consideration. However, after a few interview sessions were conducted, it was determined that the original 
Running head: ANALYZING STUDIO CLASSROOM PRACTICES AND CULTURE

parameters were appropriate for the information needed. It is imperative in this study that instructors and students have experienced both the physical and virtual studio classrooms so that they can explain, compare, and contrast their interactions in each environment.

Instructors:

1. Instructors with experience in teaching physical interior design studio courses and $100 \%$ virtual interior design studio courses

2. Full-time and adjunct instructors were included

Students:

1. Students that have participated in at least one physical interior design studio course and at least one $100 \%$ virtual interior design studio course

2. Full-time and part-time students were included

\section{F. Data Collection}

In-depth interviews were utilized for this study. "Intensive interviewing permits an in-depth exploration of a particular topic or experience and, thus, is a useful method for interpretive inquiry" (Charmaz, 2006, p. 25). With this approach, the interviewee had the opportunity to express their experiences one-on-one.

\section{G. In-depth Interviews}

In-depth interviewing is a data gathering method used in qualitative studies. With the use of open-ended questions, the researcher can ask specific questions while eliciting a detailed recounting of the interviewee's experience (Charmaz, 2006). This approach is the most practical and precise, and allowed participants to explain their experiences without others present. There were a set of pre-determined questions (Appendix A), 
Running head: ANALYZING STUDIO CLASSROOM PRACTICES AND CULTURE

however it was used as a guide only; the researcher asked for further clarification or devised questions not within the guide based on interviewee responses.

The use of an explanatory qualitative study design allowed the participants to answer open ended questions and the researcher to probe into the participants' perspectives. Ten instructors and nine students were interviewed. The experience of the instructors allowed a comprehensive overview of their involvement in facilitating both physical and virtual interior design studio classrooms. As interviews were conducted, many of the same statements and remarks were repeated from both instructors and students. Not only does this indicate saturation, but also quality of data. Respondents could not be prompted or agree with others as the interviews were conducted on an individual basis.

As indicated earlier, it was decided to interview instructors that were familiar with both the physical and virtual studio classrooms. This segment of instructors was able to compare their experiences in both environments, as well as explain or indicate the nuances of each. A total of 10 instructors were interviewed in a one-on-one setting via telephone or Skype. A majority of the instructors have over 10 years of physical studio experience and over 10 years of virtual studio experience. The instructors, with experience in years, are indicated below:

- Rob, Instructor 1: 20 years physical; 14 years virtual

- Emma, Instructor 2: 3 years physical; 10 years virtual

- George, Instructor 3: 26 years physical; 12 years virtual

- Ryan, Instructor 4: 11 years physical; 3 years virtual

- Eric, Instructor 5: 11 years physical; 11 years virtual 
Running head: ANALYZING STUDIO CLASSROOM PRACTICES AND CULTURE

- Ginny, Instructor 6: 9 years physical; 4 years virtual

- Ethan, Instructor 7: 11 years physical; 11 years virtual

- Sally, Instructor 8: 13 years physical; 12 years virtual

- Bill, Instructor 9: 32 years physical; 5 years virtual

- Andy, Instructor 10: 18 years physical; 12 years virtual

The ages of the instructors range from mid-30s to mid-50s and possess advanced degrees in Fine Art, Human Environmental Sciences, Education, Interior Design, Technical Education, and Architecture. A majority of the instructors have the same virtual studio classroom experience from the same institution, however, their experiences vary in the physical studio classroom. Several have experience teaching at level R2: Doctoral Universities. Finally, the group consisted of seven males and three females.

In a like manner, nine students were also selected with experiences in both the physical and virtual studio classrooms from the same institution as this allowed the capture of information that focused on the delivery and exposure to both environments. The students attended the same virtual studio classrooms, however, could have attended different physical studio classrooms; all experiences were from the same institution. With this approach, the capabilities of the students would be similar and they could compare and contrast their experiences without comparing different institutions. The students encountered different instructors, however this was taken into consideration with the oneon-one interviews as many students referenced several course experiences. The ages of the students range in age from early-20s to mid-50s, and were all female.

Data was collected and organized by each interview session. No other persons were involved in the collection of the data. Logistical details, such as interview dates, 
Running head: ANALYZING STUDIO CLASSROOM PRACTICES AND CULTURE

interview locations, length of meeting, and any other details such as difficulties

encountered, were also included. Meetings extended between 30 minutes and 90

minutes. All interviews were conducted via telephone or Skype. A few interviews were rescheduled due to meeting conflicts; however, no issues were encountered during the interviews. Lastly, with the permission of the participant, all interviews were recorded.

\section{H. Observations and Document Review}

Observations of the classrooms, and review of documents were conducted. Due to the physical and virtual nature, photos captured furniture arrangement and equipment of the physical environment, whereas screenshots documented classroom practices within the virtual environment. Lastly, in the virtual studio classroom, interactions between instructor-student, student-student, and any additional posts/announcements by the instructor were reviewed.

Completed student work and other classroom materials from both environments, and demonstration and critique videos from the virtual classroom were reviewed. Student work included items such as process drawings, specification sheets, formal drawings, and final projects, from the same course, but offered via the physical environment and the virtual environment. The course competencies and syllabi for each course offered in both environments were also reviewed for consistency.

\section{Interview Coding}

Interviews were transcribed at the end of each interview session. This allowed for modifications to the questions, when necessary. The information was coded and checked for similar themes or topics. According to Saldana (2012), there are two stages within the coding process. Grounded theory typically relies on in vivo coding, process coding, and 
Running head: ANALYZING STUDIO CLASSROOM PRACTICES AND CULTURE

initial coding in the first cycle. With the second cycle, focused coding, axial coding, and theoretical coding were utilized.

Using a manual coding process, in vivo coding allowed the capture of the exact verbiage that the participants used, specifically words or phrases used in each particular environment. Also, initial coding methods were utilized to compare for similarities and differences, especially between the two environments. I indicated the codes on the hardcopy of the interview transcripts; then, compiled all codes in a spreadsheet. Codes were separated by instructor interviews and student interviews, and by physical studio and virtual studio thereby creating four lists.

Example instructor interviews with codes are indicated below.

Instructor: "I can see their projects. I can see their face. They can see my face. I like that aspect of it where you have that personal interaction either as a group or be one-on-one with a student in the studio." PHYSICAL STUDIO PERSONAL INTERACTION

Instructor: "I think it is pretty clear, at least it feels like to me, that on ground I truly feel like and I think I'm viewed as an educator versus online I'm viewed as a facilitator." PHYSICAL STUDIO EDUCATOR and VIRTUAL STUDIO FACILITATOR

Instructor: "I think the benefit of on ground is that you have some fluidity with the project, so you can allow the students to come and go and let them explore a little more, versus online.' PHYSICAL STUDIO FLUIDITY

Instructor: "Versus online where you don't really don't have that sense of safety and you're really on your own." VIRTUAL STUDIO LOW SENSE OF SAFETY

With the second cycle, focused coding was used to develop categories with the expectation that each would eventually contribute to the theory. For example, the category, Studio Culture, codes are listed below. Appendix B contains the full list of codes. 
Running head: ANALYZING STUDIO CLASSROOM PRACTICES AND CULTURE

Studio Culture (Instructor - Physical) - 13 codes

Personal interaction, live interaction, genuine, 'educator,' personal experiences, 'organic,' 'fluid,' peer-to-peer interaction, healthy competition, aware of one another, build relationships, engagement extends beyond class time, high sense of comfort

Studio Culture (Instructor - Virtual) - 8 codes

Live interaction, non-personal, 'facilitator,' independent study, lack of personal contact, missing connection with peers, difficult to build relationships, low sense of safety

Analytic memos were written throughout the interviewing process to reflect on the coding selections and choices. Saldana indicates that there is an interrelationship between the coding methods, data collection, and analytic memo writing (Saldana, 2012). During the interviews, I would make connections with prior interviews and note this after its completion. Analytic memos assisted in generating codes and categories. At the conclusion of the process, it was determined that full saturation of information was obtained. Both instructors and students were repeating the same topics with no new information obtained with the final interviews.

Instructors and students are referred to as hypothetical names to protect their identities. Instructors' identifiers also include the years of experience with the physical studio and the virtual studio. For example, Rob who has 20 years of teaching experience in the physical studio classroom and 14 years teaching experience in the virtual studio is referenced as, "Rob, Instructor, 20 physical, 14 virtual." Students are also referred to as a hypothetical name, the title Student and their experience in the studio classroom. For example, "Rebecca, Student, at least one physical interior design studio course and at least one $100 \%$ virtual interior design studio course" indicates that Rebecca is a student with experience in at least one physical studio classroom and at least one virtual studio classroom. 
Running head: ANALYZING STUDIO CLASSROOM PRACTICES AND CULTURE

\section{J. Validity Issues}

Validity in qualitative studies is always a concern. To show that the researcher has exhausted the data sources, saturation is desired. "Data saturation is reached when there is enough information to replicate the study when the ability to obtain additional new information has been attained, and when further coding is no longer feasible" (Fusch \& Ness, 2015, p. 1408).

As indicated previously, interviews were conducted until full saturation of the research questions were reached. With saturation of information, no new information was generated or contributed to new learning concerning the topic of interest, thereby contributing to the validity of the research.

As an instructor of both the physical and virtual classrooms, as well as a student of the physical and virtual classrooms, the researcher has the benefit of specifically identifying with both groups of participants. It is with this lens that in-depth interview questions were developed.

According to Creswell (2009) there are eight primary strategies that can be employed to endure validity with research findings. Five of the eight were utilized in this study.

1. The "triangulation" (Creswell, 2009, p. 191) process draws on several sources to confirm the interpretation of research - meaning that several types of information gathering processes are utilized to formalize the conclusion. In this research, triangulation was achieved by conversing with two groups of participants, observing classrooms, and reviewing student work, classroom materials, and classroom videos. Review of the course materials from the same 
Running head: ANALYZING STUDIO CLASSROOM PRACTICES AND CULTURE

courses, offered both in the physical and virtual studio environment, were conducted. The instructor of the classrooms observed were not instructor interview participants; the student work reviewed was not completed by the student interview participants.

2. "Using rich, thick descriptions" (Creswell, 2009, p.191) of the experiences provides the high level of detail that is needed to fully understand the experiences. Not only were participants asked to provide experience details, these details were also noted in the findings with direct quotes. This allows the participants voice to be heard. Creswell (2009) indicates that full descriptions create a realistic narrative.

3. Including "researcher bias" (Creswell, 2009, p. 192) is another strategy to impart validity to the research. The interpretation of the findings can be based on the researcher experiences or beliefs. "Good qualitative research contains comments by the researchers about how their interpretation of the findings is shaped by their background, such as their gender, culture, history, and socioeconomic origin" (Creswell, 2009, p. 192). Therefore, it is imperative for the researcher to identify any bias allowing the reader to understand the researcher viewpoint or lens. With this research, the following should be noted:

a. Researcher background: I have been an interior design educator for 12 years in both the physical and virtual studio environment. Within this timeframe, I have created, developed, and instructed courses in both environments, mentored faculty in the virtual environment, and created and developed supportive student resources in the virtual environment. 
Running head: ANALYZING STUDIO CLASSROOM PRACTICES AND CULTURE

b. Participants: At the time of the interviews, the instructors were actively teaching and the students were currently taking courses. However, some instructors or students were not active in one environment during the interviews. For example, I may have spoken to an instructor that was actively teaching in the virtual environment but not in the physical. Instructors and students could have responded to interview questions relying on the remembrance of instances within the year.

c. Institution: The instructors have had experiences in a variety of institutions within the physical environment, however a majority of the experiences in the virtual environment were from the same institution. The students, on the other hand, have had virtual and physical studio experiences from one institution.

4. "Spending prolonged time" (Creswell, 2009, p. 192) in the environment under study provides an authentic understanding of the environment. "The more experience that a researcher has with participants in their actual setting, the more accurate or valid will be the findings" (Creswell, 2009, p. 192). Again, as an instructor with 12 years of experience in both the physical and virtual studio classroom, I was able to interpret the findings of the instructors because I could identify with their experiences. Although I did not possess as much experience as a virtual student, I could also interpret and comprehend the experiences the students referenced in the interviews.

5. "Present the negative or discrepant information" (Creswell, p.192) indicates that the findings allowed all participants to explain their experiences. By 
Running head: ANALYZING STUDIO CLASSROOM PRACTICES AND CULTURE

disclosing all perspectives, the research is authentic, as it is not expected that all participants share the same point of view.

6.. The use "of an external auditor" (Creswell, p. 192) provides the researcher with an evaluation of the work. This research was completed with a four-person advisory committee as well as a professional editor not specializing in this field. I met with the committee members on numerous occasions conducting detailed discussions regarding my research. We also exchanged emails and revised written work, when appropriate.

\section{K. Ethical Issues}

Ethical issues can arise at any stage of research including during construction of purpose or research questions, data collection, data analysis and interpretation, and writing and disseminating the information (Creswell, 2009). However, this research project considered all ethical issues prior to conducting interviews. A cover letter outlining the purpose and acknowledging participants' rights was provided prior to the beginning of the interviews. Interview information will be kept for at least five years in a secure location. The interpretation of the research should stay true to the information collected. 
Running head: ANALYZING STUDIO CLASSROOM PRACTICES AND CULTURE

Goals

1. Understand the interior design instructor experience, as well as the interior design student experience, of the physical studio and virtual studio classrooms.

2. Identify how the physical and virtual studio classrooms operate.

3. Discover the nature of the interaction and outcomes of the physical and virtual environments.

\section{Methods}

1. Qualitative study

2. Grounded Theory

\section{Research Questions}

1. What are the experiences of instructors and students within the interior design physical studio and virtual studio classrooms, and what are the similarities and differences within the two learning environments?

2. How does either environment influence/impact/control the learning experience of interior design education within the studio courses?

3. What are the operational and outcome differences of the two environments?

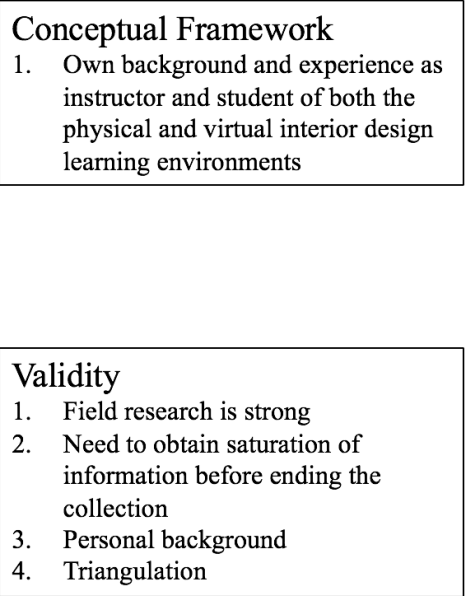

Figure 12: The research design framework. Maxwell interactive model of research design adopted with this research. Reproduced from Maxwell, 2005, p. 5. 
Running head: ANALYZING STUDIO CLASSROOM PRACTICES AND CULTURE

\section{Chapter Four: Findings}

After conducting in-depth interviews with ten instructors and nine students, this section provides perspectives from both groups including similarities and differences in their experiences within the physical and virtual interior design studio classrooms.

Before the findings are discussed, the physical studio and virtual studio classrooms are detailed below based on the information gathered from the interviews. With each classroom, there are distinct approaches and actions taken within the studio environment.

Physical studio classrooms are typically equipped with drafting tables and chairs for approximately 15 students, a whiteboard, a projector, and an area for the instructor to present. Some physical studio classrooms also contain separate student desks and chairs for students to gather in during lectures or demonstrations.

The physical classroom functions with social rules. This includes listening to others (instructor or peers), engaging in discussions, working independently on projects, or raising a hand for questions. Students formally address instructors with titles such as Mr., Mrs., Dr., or Professor.

In virtual studio classrooms, students need access to a computer, a scanner, a portable drafting table, and a camera. Unlike students in a physical classroom, virtual students typically work in a home office, dining room, public library, or even a coffee shop. In this case, the students rely on technology (online classroom software, computer, other equipment) to be present in the classroom. There are no classroom rules in the physical sense. The classroom rules are based on prompt return of emails, engagement in written discussions, or sending an instant message for questions. In my experience, 
Running head: ANALYZING STUDIO CLASSROOM PRACTICES AND CULTURE

students are also less aware of the social rules in the classroom meaning that students may send an email to their instructor with casual conversation or phone during non-office hours. Many students in the virtual classroom do not formally address instructors and simply refer to everyone by first name.

After reviewing the information gleaned from the interviews and observations, the following categories emerged: 1) studio practice, 2) critique, 3) studio culture, 4) collaboration, 5) outcomes, and 6) environment influence, impact, and control. Each category will be examined in detail in two sections, Physical Interior Design Studio Classroom and Virtual Interior Design Studio Classroom.

The following provides generalized definitions formulated with findings from the interviews and supported research. These categories are referenced in this section and beyond; therefore, the definitions are included to eliminate any confusion regarding the interpretation of the category.

1. Studio practice: In each classroom, there are distinct approaches and actions taken within the studio environment. "Students are presented with a design problem grounded in the realities of professional practice and are expected to work individually or in groups to solve it" (Cennamo, 2012, p. 842). Instructors use studio time to lecture, conduct discussions, demonstrate techniques, converse individually with students, or provide critiques.

2. Critique: Critique, or an assessment of the students' work, is offered via different avenues based on the environment. This one-way communication is typically a directive and requests that the project be modified or updated. Feedback can also provide affirmation of solid work. "It feeds forward, in that artists use insights from critique to 
Running head: ANALYZING STUDIO CLASSROOM PRACTICES AND CULTURE

make further adjustments to the specific project under discussion, to reject the suggested changes, or to apply new ideas to their future efforts (Soep, 2005, p. 40). Critiques can be provided individually or during a formal presentation. "At various points in the class, students present their work to faculty, peers, and occasionally guests for critiques that stimulate students' reflection on and discovery of their developing design knowledge through project reviews and student questioning" (Cennamo, 2012, p. 842). The delivery process of critiques differs in each environment, as well as how the student chooses to utilize the information.

3. Studio culture: The development of relationships based on interactions supports studio culture. Interaction, a two-way exchange between instructors and students, allows for often spontaneous communication. This exchange can happen outside of class or during class time, but typically does not provide instruction. Interaction is also a two-way exchange between students. This typically happens once instruction is complete, and students have time to work on their projects during classroom time. "The unplanned interactions that occurred within open studio hours were especially important in moving students' ideas forward when they were stuck" (Cennamo, 2012, p. 841). Studio culture typically grows organically and is mostly spearheaded by students.

4. Collaboration: This two-way exchange is a more formal and defined approach that occurs with instructor and student, or between peers. There is a common goal to seek out potential solutions, or solve a design problem; the exchange is meaningful and productive. "During collaboration, students actively learn from one another in a spontaneous and exploratory mode that fosters deep understanding of content, stimulates and motivates learning, and eliminates boredom" (Cho, 2016, p. 568). Sometimes 
Running head: ANALYZING STUDIO CLASSROOM PRACTICES AND CULTURE

instructors will assign group or team projects to encourage interaction between students. Students see the benefits of working together during the project as well as at the completion of the project.

5. Outcomes: With each interior design studio course, the student uses the design process to complete the project. The quality of work is based on a set of criteria established by the instructor or program. Typically, student work is evaluated based on research, creativity, design, presentation, and problem solving. Instructors may also consider participation (peer critiques) or team contributions.

6. Environment influence, impact, and control: The environment can dictate many aspects of the studio classroom when considering the physical and virtual classroom approach. Instructors must consider the method of information distribution, the method of evaluation, as well as type of communications. Students consider other factors such as location to campus, personal situations, and convenience.

In the following two sections, physical studio learning environment and virtual studio learning environment, the presence of the six categories that emerged from the interviews are analyzed.

\section{A. Physical Interior Design Studio Classroom}

\section{i. Studio practice.}

In discussing physical studio classrooms, a few instructors interviewed indicated that they meet once a week for four hours, however, a majority said they meet two to three times per week for several hours each time. Ankerson and Pable (2008) also found this in their research as mentioned earlier in Chapter 2: Physical Studio Learning Environment. The number and length of meetings appears to be institution specific. Many 
Running head: ANALYZING STUDIO CLASSROOM PRACTICES AND CULTURE

instructors interviewed referred to a "typical studio format." In this case, instructors use the first hour of class time to lecture or discuss topics, then allow the students to practice and apply these skills in the remaining class time. For example, the instructor could introduce the project parameters/requirements, or explain why a drawing is necessary, including the purpose of the symbols, the contractor/engineer/designer that would use it, or why it is important to communicate the information. It is also during this time that the students can receive direct guidance from the instructor. This could be a time when instructors discuss the project in detail. In the end, the instructor links the course project to the real world and indicates how the student designer would engage in the business environment.

Instructors Rob, Eric, and Ethan describe their approach to the studio sessions indicating that each uses approximately the first hour as instructional time, with the remaining time used for questions or meeting with students individually.

Typically, in a physical studio, I would do lecture for the first, depending on if it's early in the term or late in the term, for the first hour, half an hour to hour, depending on how much information I have to get out. That lecture would sometimes include some sort of demonstration. So, if I was doing a commercial design class or whatever I'd talk a bit about what the project is, what they're going to have to do, maybe do some board work [whiteboard] showing them design development or something like that, and then possibly some sort of software element that they're going to wind up using as well. And then I let them work, I would try to let them work, typically for at least half of the time that I was meeting per class. So maybe an hour, hour and a half lecture, and then an hour, 
Running head: ANALYZING STUDIO CLASSROOM PRACTICES AND CULTURE

hour and a half of studio if it was a three-hour term (Rob, Instructor, 20 years physical, 14 years virtual).

On ground it's, what I call the typical studio model. In other words, it usually starts with some sort of a brief lecture that talks about a concept or an idea that students can use broadly on their project or it can be very focused in terms of today we're going to learn about codes specific to your projects. And I usually try to do that for about the first hour or so (Eric, Instructor, 11 years physical, 11 years virtual).

In a physical classroom, I do have the advantage of creating more of a theater show, in a way. From beginning to end, I can proctor what can be delivered, knowing that many times, at least $20 \%$ of the class time is left to anything can happen. If the students are really prepared, I can advance more material. More often than not, the students are not fully prepared, so I have to put on the brakes, and then review past material before we can move on. For the most part, $80 \%$ of the class is pretty much guided (Ethan, Instructor, 11 years physical, 11 years virtual).

Students Anna and Casey find this same approach in their courses, as they describe the studio course with lecture or demonstrations during the first part of class time, with the remainder of the time used for individual questions.

I would say it's more lecture for the majority of the class, like lecture and then teach for the majority of the class and then maybe the last hour they go through 
Running head: ANALYZING STUDIO CLASSROOM PRACTICES AND CULTURE

and give individual responses (Anna, Student, at least one physical interior design studio course and at least one $100 \%$ virtual interior design studio course).

Always 6pm-7pm, she mainly just lectures whether it's like, if the next thing due is a reflected ceiling plan, she talks all about how to do it, what it is, what she's looking for, what her goals are. She breaks it down and she talks about it. Then from 7pm-7:30pm, she always gives us a break. That's normally when everyone goes and gets dinner. And then 730pm-9:00pm, we do these groups. So right now, from the beginning to finals, we're in three different groups so she spends 30 minutes each with each group and talks about what you've done, what you're turning in, how much do you have left on the project, if you have any questions, it's more like a three-on-one type of thing. She's done the same thing. So, it's kind of got a structure and I like that because you know what to expect (Casey, Student, at least one physical interior design studio course and at least one $100 \%$ virtual interior design studio course).

As indicated, during this time, the instructor also meets with each student individually at their desk/drafting table to discuss the work or project. This one-on-one time allows the instructor and student to work through the process of generating ideas, perfecting a skill, or providing clarification. Studio time allows students the time to work out design problems by applying different solutions and evaluating those solutions based on the project parameters. The project solution must meet the client requirements and project requirements. The instructor guides the student through potential project solutions by providing critiques, feedback, or reference to similar projects during individual 
Running head: ANALYZING STUDIO CLASSROOM PRACTICES AND CULTURE

evaluations. Instructor Emma describes the studio setting with the various communication techniques used:

In a physical classroom, being able to engage the students as a whole in discussion and for the lecturing part and talk that way as well as literally being there and being able to be one-on-one with them. I can see their projects. I can see their face. They can see my face. I like that aspect of it where you have that personal interaction either as a group or be one-on-one with a student in the studio (Emma, Instructor, 3 years physical, 10 years virtual).

Instructor Eric highlights how the one-on-one time is approached. This could include talking through the design solutions, sketching ideas with the student, guiding the student with potential ideas. These steps replicate the actions taken in the professional world with other designers or managers/directors.

Then it [studio time] gets into best critiques, and so for the remaining two hours I'm usually going from desk to desk spending time with each student. Looking at what they've done since our last meeting, what their progress is, talking about ideas how they can develop their ideas or challenging what they're doing to make their ideas stronger. Talking about examples. Sketching with them. Truly, it mimics professional studio when you're working with another designer almost. So, in the classroom I think of myself, as, almost like the lead designer that's working with a junior designer, kind of showing them or modeling a behavior for them about how to work through their project (Eric, Instructor, 11 years physical, 11 years virtual). 
Running head: ANALYZING STUDIO CLASSROOM PRACTICES AND CULTURE

The one-on-one time is quite beneficial as shown by Students Victoria and Maria below. Both students indicate that the instructor will help the student until full comprehension is gained. This individualized attention allows the student to move forward with their design.

It's a real small class, there's only four of us and she takes time every class session and sits down with each of us, okay, what's your deal? What's this, what's that? We can ask questions and that helped with doing the studio classes. Being able to specifically ask the question in class while you're doing something. You can be sitting there making something while she's talking to the other students and then when she comes and gets to you, you can be like "Okay, I'm doing this and I'm struggling with it. Help me." She can actually physically help you do some of this stuff over trying to direct you through words (Victoria, Student, at least one physical interior design studio course and at least one $100 \%$ virtual interior design studio course).

She actually goes around [to all students] and goes over the work, and she takes her time. If I need something and if I have a question for her, she'll take all the time and dedicate for my question until I understand it, until she knows she's helped me and that with all the classmates (Maria, Student, at least one physical interior design studio course and at least one $100 \%$ virtual interior design studio course). 
Running head: ANALYZING STUDIO CLASSROOM PRACTICES AND CULTURE

Instructors use the studio time to post/pin the student work to a presentation board. This process serves many purposes: the students practice presenting their work in a professional manner, the students learn how to use constructive criticism of their work, and the students learn how to provide thoughtful critiques to their peers. Students may discuss their work, or take questions from the instructor and peers. The instructor may also use the work as an example for other students to use as a guide. Student Leah describes as:

We have desk critiques and we also have group critiques. And that's where we basically just reflect and tell each other the different things that we like about each other and things we should change about our project (Leah, Student, at least one physical interior design studio course and at least one 100\% virtual interior design studio course).

If the instructor finds that they are fielding the same question or notices that all students lack a particular skill, the instructor may use studio time for demonstrations. Demonstrations can be completed in a variety of means including the use of vellum/pencil, the whiteboard, the computer monitor, or video. The instructor can access the best approach based on the skills they need to demonstrate. For example, when showing students how to manually draft lines, then the instructor would use vellum/pencil, or even the whiteboard. However, if the instructor wanted to show students how to color render a drawing, they may use vellum/markers or a computer with rendering software. In any case, the technique will dictate the approach. The techniques 
Running head: ANALYZING STUDIO CLASSROOM PRACTICES AND CULTURE

are then practiced by the students and incorporated into their current project. Instructor Ethan describes the approach:

If it is a drafting class, I give them more techniques. Even if I do not know the answer, we go online and we check for some new symbols, or something like that, and then we add them directly on the student work. Usually on tracing paper over the original work. (Ethan, Instructor, 11 years physical, 11 years virtual).

\section{ii. Critique.}

As indicated earlier, critiques are an important component of the studio. Students learn how to interpret and evaluate the critiques. Students must determine if the critique is valid and incorporate the critique into the project if it supports the project requirements. Again, this process replicates the real world, as the student must also take feedback from the client, an architect, or another designer. With the following, an instructor explains the physical studio classroom by discussing the pin-up critique process in detail. The instructor explains that critiques are a way for students to learn about their approach to their project. The critique pushes the student further with their design solutions by utilizing the details to inform their decision making about project revisions.

In a physical classroom, in a studio class, the first thing that we do when they walk in, the students, is give them pushpins and they pin up their work. If the class is very large, which has happened many times, what I do is warn the students every week that I might just pick some examples of the pinned-up work 
Running head: ANALYZING STUDIO CLASSROOM PRACTICES AND CULTURE

and discuss it, so that everybody can learn. And that they should not be taking it personal, the fact that I didn't get to review every single one. But, I need to do that warning. if a studio class is three hours long, the review of the work can take anywhere from half hour to 45 minutes. The second part of the class is I tell them they learn three ways. The first one is by doing the homework. The second time is by comparing their work against their peers, so they can see how they could have done things differently, or better. They get to see their work against everybody else's. Thirdly, I pick some student work, put it on the demo table, and continue working on it to push the learning a bit further (Ethan, Instructor, 11 years physical, 11 years virtual).

As mentioned earlier, the students receive individualized feedback from the instructor. To further connect the students to the real world, many instructors act as the design director when meeting with students and provide comments or suggestions. The critique process is a critical step in project development. The student learns the critique process, as well as learning that their first, second, or even third solution might not be the final solution. Although the design process is lengthy and incorporates many viewpoints, perspectives, and requirements, it is a process that must be taught properly, as well as followed, with each project while in school and thereafter.

The design process forces the student to think about the project. They must evaluate the potential solutions, review for project and client requirements, and use a discerning eye when analyzing their own work. This same course of action will be utilized in the professional world without the guidance of an instructor. The student must 
Running head: ANALYZING STUDIO CLASSROOM PRACTICES AND CULTURE

be able to push their own work to the next level. Instructors Rob and Eric outline this process of asking students to reflect upon their work and refine their work until the best solution is found.

I think in a physical classroom my most successful approaches are truly when I put the students on the spot, meaning I'm having them explain design ideas, having them explain why they did what they did in projects. When they've got an audience around them and they have to stop and think about what they're doing and walk through it a bit it makes them really have to dig deeper and think about why they did what they did. And so sometimes they'll be like, “Oh, I don't know why I even did, and I think I need to change that" (Rob, Instructor, 20 years physical, 14 years virtual).

I think actually in my mind, the physical approach of a desk critique is still probably the most beneficial because that is still how practice typically happens (Eric, Instructor, 11 years physical, 11 years virtual).

As expected, the critiques were conducted face-to-face with immediate response as instructor feedback was provided visually or verbally. Students find this approach beneficial. "I've gotten a lot more insight and more constructive criticism in the physical studio than I have online" (Elizabeth, Student, at least one physical interior design studio course and at least one 100\% virtual interior design studio course). Another student felt that the instructor critique was limited due to the classroom time. "I feel like you're only scratching the skin of the design in the sense that the instructor's time is far more divided, 
Running head: ANALYZING STUDIO CLASSROOM PRACTICES AND CULTURE

so he or she is only able to give you a limited amount of time in terms of feedback" (Maggie, Student, at least one physical interior design studio course and at least one $100 \%$ virtual interior design studio course). However, a majority of students felt more connected and engaged in the physical environment with the face-to-face critique.

\section{iii. Studio culture.}

Many instructors have noted that during this open time in the physical studio, the instructor may share personal professional experiences, or provide further explanation about the project or topic. The classroom appears to have allowances, but remains respectful and professional. The relationships between students and instructors develop over each session. In many cases, relationships continue to develop over many sessions as the students tend to be enrolled in courses together. As Instructor Eric explains, the personal experience adds to the studio time. Even if the discussion is limited to one student, the other students are listening and absorbing the information. The personal professional experiences contribute to strengthening a working relationship.

In a physical classroom I am constantly thinking about how do I improve the class? What things can I share? I'm looking for examples. I'm really sharing a lot of my personal experience with the students when I do desk critiques, and, from one student to the next that could be a very different personal experience but because everybody sits together in the classroom, all the students should be sort of listening to what I'm sharing with all of them (Eric, Instructor, 11 years physical, 11 years virtual). 
Running head: ANALYZING STUDIO CLASSROOM PRACTICES AND CULTURE

Students felt as if they had an informal connection with the instructor that created a non-threatening environment. Students also felt as if they had strong connections with peers. Not only did they seek out each other's help, but they also supported one another. Instructors felt as if the level of engagement was high with students in the same space. Student Victoria concurs as she describes the working relationship face-to-face and sideby-side.

I like when you're actually in studio, in class, I like the fact that they're more direct and can guide you a little bit better because they can see as you're working on something how to change it or help. They might be able to tell you, okay, when you're building it this way, let's do this or that to help make your project better and that's not quite as easy to do online (Victoria, Student, at least one physical interior design studio course and at least one 100\% virtual interior design studio course).

Instructors also felt that the studio course aligned with the profession as the culture that manifests supports the environment after graduation. Students are mimicking the skills (technical, communication, critical thinking) that they would use in professional work. Students also learn the social skills of working in groups or working with others; students will need to know how to communicate the critique of another's work in a professional setting. Lastly, students need to communicate their ideas via presentations, drawings, project notebooks, etc.

Instructor Ethan relates how studio time replicates the skills the students will use in the professional world. In this case, the instructor is comparing the physical studio 
Running head: ANALYZING STUDIO CLASSROOM PRACTICES AND CULTURE

against the virtual studio and suggests that the physical environment provides an advantage in skills practice.

You lose a little bit of the professional touch when you do it online, because you don't live in a bubble. After all, it is just the physicality that really gets you there. Being a professional, it's about how you conduct yourself in a classroom, how you prepare your material, how do you present (Ethan, Instructor, 11 years physical, 11 years virtual).

Instructor Andy also states that interaction is a skill that will be used in the professional environment.

So, on campus they get to collaborate with their peers in person, as they have to collaborate and interact with their instructor, just like they'll probably interact with their supervisor in the real world, they're interacting with their peers like they would interact with their colleagues in the real world (Andy, Instructor, 18 years physical, 12 years virtual).

Students also seek out others that are considered experts. Within the cohort, they have identified those with the strongest skills and ask for their help. As the following two students argue, each one has sought out help or guidance from a fellow classmate.

I think, for me, another advantage of on-ground is not only having that face time with the instructor, but also fellow students. I'm trying to improve my CAD skills, so I'm always one that has, "Oh, I'm helpless and I don't know how to solve it," and having other classmates jump in there and help me, and we give each other 
Running head: ANALYZING STUDIO CLASSROOM PRACTICES AND CULTURE

suggestions about where to go for textile samples and that sort of thing. Yeah, also being able to get that feedback from your fellow students (Clara, Student, at least one physical interior design studio course and at least one $100 \%$ virtual interior design studio course).

...inevitably there's somebody in your class that is better at one particular thing than you are. And there are go-to people in every single one of my classes for something or other. Like there's one CAD wizard in one of my studios every quarter (Katherine, Student, at least one physical interior design studio course and at least one $100 \%$ virtual interior design studio course).

With the students and instructors gathered together in the same physical studio, it is much easier to engage and maintain the students' attention. Instructors find this quite beneficial as they can adapt their approach based on student understanding of the material. It may be that the instructor needs to explain in another way, provide an example, present work from previous students, complete a demonstration, or simply encourage a discussion among the group to cement the learning. Instructors value the opportunity to modify the instructional plans to accommodate the student. They can identify the deficiencies quickly and address them just as quickly. Two instructors explain that the studio classroom is organic, adaptable, and impromptu. This allows the instructor to meet the needs of the students by accommodating different learning styles; the studio is not the rigid lecture classroom that other disciplines follow. Studio culture allows for spontaneous interactions and directions. 
Running head: ANALYZING STUDIO CLASSROOM PRACTICES AND CULTURE

I think for the physical classroom, it can be more organic so I can pull everybody together at the drop of a hat and say, let's all talk about something that just came up. And so, there are opportunities to learn more sporadically throughout the process as opposed to it being so structured. And I think in my mind, again, I feel like that's the value of education and teaching is that organic quality versus it being so structured that you're just following kind of a root path through a, you know, on a predetermined set of milestones (Eric, Instructor, 11 years physical, 11 years virtual).

In an on-campus environment. instructional strategies can be adapted on the fly, so if you have some students who cannot comprehend material via one instructional strategy then that instructional strategy can be altered to adapt to different learning style (Andy, Instructor, 18 years physical, 12 years virtual).

Students enjoy interacting with one another, thereby learning from one another. The Community of Inquiry framework indicates that students learn from three avenues: cognitive presence, instructor presence, and social presence. To summarize, the social presence is an imperative factor in learning as students are more apt to collaborate, express emotion, develop companionship, and have a sense of risk-free expression. It may take time to develop, however, and the studio environment supports this framework (Garrison, 2008). Student Maggie and Instructor Ginny describe how students learn from their peers in this social presence. 
Running head: ANALYZING STUDIO CLASSROOM PRACTICES AND CULTURE

First the physical studio classroom, what I like the most is my peer interaction. While you're looking at how other people are designing in the studio classroom, it kind of exposes you to different kinds of thinking, different kinds of creativity, and different kinds of, even, presentation styles. Just looking at other ... You learn a lot from your peers, I think, and studio in particular you learn a lot, because it's an entire project, and you kind of understand how people are thinking about the concepts, what other kind of ... What are the latest trends they are factoring into their design, and just the thinking process is clearer when you're doing it in classroom (Maggie, Student, at least one physical interior design studio course and at least one $100 \%$ virtual interior design studio course).

So, on ground, it's the impromptu, creative process where you can just kind of even flow, and just kind of push ideas back and forth, and just have those discussions. Plus, it's the peer-to-peer discussions that you miss online also. On ground, you're sitting next to somebody else, and you're watching what they're doing, and you're looking at their line weights, or you're looking at their design style, or you're looking at their selections, or whatever you're doing at that moment. And you're sort of ... That healthy competition, like "Oh, they're five days ahead of me!” (Ginny, Instructor, 9 years physical, 4 years virtual).

Student Leah indicates how the instructor presence provides an advantage as she is a kinesthetic learner. 
Running head: ANALYZING STUDIO CLASSROOM PRACTICES AND CULTURE

I believe that I really like from on ground studio classes the flexibility of having one-on-one teacher time and hands on teacher time because I'm more of a handson learner (Leah, Student, at least one physical interior design studio course and at least one $100 \%$ virtual interior design studio course).

Finally, as Instructor Ginny implies, students that invest more time in the projects will have better outcomes.

It's the culture, it truly is. So even in one school that I was teaching that was four hours a week, one day a week, that information wasn't as intense as the three day a week, four hours each day. I think it's the time invested, and the outcome gets better if you invest more time. And although you may not want to be there, but you're investing that time, so it's going to be better. when you opt to say "I'm going on ground," you're making it fit your schedule, and I think you're putting more effort into it (Ginny, Instructor, 9 years physical, 4 years virtual).

\section{iv. Collaboration.}

Collaboration (between instructor and student or between two peers) provides opportunities to develop communication skills, seek out potential solutions, or solve a design problem. This type of exchange is meaningful, productive, and essential to studio practice. As students work through a design problem in the physical studio, they may seek out others to work with in regard to weighing out the best options. "One thing I really loved about that on-ground class is the instructor made it very collaborative and the class actually did a lot of brainstorming” (Clara, Student, at least one physical interior design studio course and at least one 100\% virtual interior design studio course). 
Running head: ANALYZING STUDIO CLASSROOM PRACTICES AND CULTURE

To encourage this collaborative process, the instructors also create projects that must be completed in groups or teams. Instructor Sally provides an overview of the team project approach used.

I also had a lot of success with team projects in the on-ground classroom. I would randomly pick out of a hat three or four students per team, depending on the size of the class, and this I used mostly for advanced students maybe in their third or fourth year. And by teaming them up and actually having them envision their project as if it were a design firm they really got more excited about it, there was more interaction, more creativity would come out as a result and the students took the projects a lot more seriously that way too. They had a lot of pride in their work as they almost wanted their own little design firm. So, I had a lot of success with teaming (Sally, Instructor, 13 years physical, 12 years virtual).

Student Clara understands that collaboration is beneficial to the overall design solution. In this interview excerpt, the student recalls how her instructor approached a team project. The students collaborated at the project onset, but then completed the project individually. This student appreciated the collaborative effort with research, as she was new to the design process and approach.

One thing I really loved about that on-ground class is the instructor made it very collaborative and the class actually did a lot of brainstorming. It was our first studio class and, so, she sat down with us at the computer and when we looked at some examples of some Frank Lloyd Wright structures ... We were doing a design for a dome house and so we explored some dome designs together, we did a field 
Running head: ANALYZING STUDIO CLASSROOM PRACTICES AND CULTURE

trip together, and we all sat down and just collaborated on ideas for designing a residence that was a dome structure, and I thought that was a real-world experience. Sort of like a charrette. I don't know, I got a lot out of that (Clara, Student, at least one physical interior design studio course and at least one $100 \%$ virtual interior design studio course).

Collaboration also exists with others in the industry such as building contractors, engineers, furniture or cabinet manufacturers, other designers, or sales representatives. Many instructors invite these professionals to the studio classroom to talk about their experiences with designers, share their projects, or work with students. Instructors have also invited clients to the studio classroom to talk about their project needs and requirements. All of this is replicating the profession and provides opportunities for the students to practice their communication skills (both verbal and visual).

\section{v. Outcomes.}

With the students in the physical space, instructors can influence the outcomes. Instructors indicate that students can immediately apply their new knowledge from discussions, lectures, or demonstrations. And, when they do perform these new skills, they can ask for clarification during that same session should they not understand or perform the skill correctly.

What I see in the physical classroom, I would say that there tends to be more good work and strong work and a lot less mediocre and I think that's a virtue of the things we've talked about so far, you know, the ability to stop class and talk organically and the time you spend doing critiques and kind of those natural 
Running head: ANALYZING STUDIO CLASSROOM PRACTICES AND CULTURE

flowing conversations about things that don't seem to happen online even though you can do things like have a virtual conference and bring everybody together (Eric, Instructor, 11 years physical, 11 years virtual).

I think that could potentially influence the outcome of their work because in the on-campus classroom they are forced to stand there and be quiet and pay attention for the entire time that the instructor is providing the information, because it's a quiet learning environment they can receive all this information then go back to the table and immediately try it (Andy, Instructor, 18 years physical, 12 years virtual).

Students indicate that it is easier for them to understand the project or assignment requirements when they can see a physical example.

I'm a very hands-on person. I like to do hands-on projects and to see, I don't know, to have a more physical example of something. I think it's easier for me to understand. I'm a very distracted person, so I think it is a little bit harder on an online course (Maria, Student, at least one physical interior design studio course and at least one 100\% virtual interior design studio course).

Instructors indicate that design students need to understand how to conduct themselves professionally. By taking part in the studio environment fully, the student outcomes are stronger. Professionally prepared work is one component of the final outcome. Students are also required to present their final work to a group of students, instructors, or professionals. Instructor Ethan explains how the studio prepares the 
Running head: ANALYZING STUDIO CLASSROOM PRACTICES AND CULTURE

student for the professional world, not only in how the student should act in the classroom, but also how the student presents work. This particular instructor teaches at two different institutions; one is a CIDA (Council for Interior Design Accreditation) accredited program, the other is not. The CIDA Standards require students to practice presenting their work, hence the reference to "forcing of students" to present.

Being a professional, it's about how you conduct yourself in a classroom, how you prepare your material, how do you present. Presenting is a big part and I'm glad, as a part of a CIDA accredited school, we work really hard to keep that. I know not all departments online do that. That forcing the students to really present orally, and I think that's a very important part of being a professional. How do you present your work? I wish we did it, actually, in more classes. You have to choose your words carefully. You have to have poise in front of your audience. It forces you to dress differently. Sometimes you prepare your cue cards before you speak. You know, the whole thing (Ethan, Instructor, 11 years physical, 11 years virtual).

\section{vi. Environment influence, impact, and control.}

As indicated earlier, this category appears to demonstrate the most dominance in the overall research. The instructor has control over the time used during physical studio. As indicated thus far, the instructor can change direction depending on the student learning and project progress. Students that are behind or struggling are easy to identify. The instructor also can control how information is distributed. For example, if the instructor feels that it would be most important to show the drawing prior to discussing it, 
Running head: ANALYZING STUDIO CLASSROOM PRACTICES AND CULTURE

then they control the flow of the studio time. This can also be applied to the course design, as the instructor is in control of how the students digest the information. Indicated below, the physical environment allows them to quickly identify potential issues or generate engagement.

On-campus I can walk around and immediately notice areas for improvement and call those to the attention of the student immediately before they complete the entire drawing. And so, I can help them direct by the deficiencies right away. And then when they turn in their final assignment there will be fewer errors (Andy, Instructor, 18 years physical, 12 years virtual).

Instructors also find that with face-to-face instruction, they know when their students are not focused, engaged, or when students do not attend class. It is much easier to reach out to students in this environment and instructors can get them back on track more quickly.

In a physical environment if they're sitting in the back of the room and not engaging you can at least go back there, sit with them, talk with them, try and figure it out, see if you can get them to engage (Rob, Instructor, 20 years physical, 14 years virtual).

Instructors indicate a few disadvantages to the physical studio environment that include the time between studio meeting times and the controlled environment. Students may not reach out to their instructor until the next formal meeting time, or students may miss a class. These instructors explain the drawbacks of nonattendance: 
Running head: ANALYZING STUDIO CLASSROOM PRACTICES AND CULTURE

In my experience, with both physical and virtual classrooms, is attendance. So, in a physical classroom if a student is not in attendance, there is absolutely nothing you can do to interact. There's no way to interact or help that student (George, Instructor, 26 years physical, 12 years virtual).

The difficulties in the on-ground classroom would be I guess its pros and cons but I would say timing. If you're teaching a class that meets only twice a week, then the students are kind of left on their own without online help and on ground class they're left on their own until they meet again the following week. So. if they have questions or things in the interim, they kind of lose some time in that respect. So. keeping that continuity is a little hard in an on-ground classroom (Sally, Instructor, 13 years physical, 12 years virtual).

The physical environment may or may not please all users and their requirements or needs when considering the noise level, air temperature, or equipment. This instructor highlights their experience:

Whereas on the on-campus school environment it's a controlled environment, so there is no distraction, there is no noise. They have a quiet environment, they have a drafting table in good condition, with the necessary equipment (Andy, Instructor, 18 years physical, 12 years virtual).

Only a few instructors and students indicated that distractions could pose issues with the physical environment. The physical space could also have issues that prevent 
Running head: ANALYZING STUDIO CLASSROOM PRACTICES AND CULTURE

student attention to details. Such issues could include high traffic hallways, noisy HVAC systems, other students in the studio, or the size of the classroom. The students and instructors do not have control over these issues.

This student and instructor indicate the positives and negatives of the physical environment.

With the physical studio, what I dislike is sometimes the fact that it is a larger class, or just the overwhelming environment of the studio. A lot of students, a lot of work everywhere (Elizabeth, Student, at least one physical interior design studio course and at least one $100 \%$ virtual interior design studio course).

There also can be a lot of distractions in an on-ground classroom. You're on a campus where there's a lot of outside activities happening, where students are going from class to class, they have to be disciplined enough to keep their school work going even though they're having a job fair happening downstairs, and there are guest speakers coming in, there's a party down the hall for someone, there are a lot of distractions that way. So, although you have a focus for your time for the class, when everyone's in person on campus, the campus activity can be something you have to work around. So, I would say that can be kind of difficult (Sally, Instructor, 13 years physical, 12 years virtual).

Overall, it appears as if the physical studio environment supports the research regarding the studio space with the opportunity to engage with each other, collaborate, and create meaningful, supportive relationships. Although, instructors and students 
Running head: ANALYZING STUDIO CLASSROOM PRACTICES AND CULTURE

agreed that there are a few disadvantages to the physical studio environment, overall, the organic, impromptu gatherings and face-to-face critiques support the learning.

\section{B. Virtual Interior Design Studio Classroom}

\section{i. Studio practice.}

In my experience, virtual studio classroom lectures are provided in written form in the virtual classroom. The instructor does not provide a verbal lecture. Instructors can add information to the "course master" or "course shell." Instructors that are tech savvy or more experienced with the learning management system tend to add to the provided course. On occasion, instructors host a non-mandatory live session with students for an hour or so each week. During this time, the instructor may review the upcoming week, review project requirements, or take questions.

So then, I would say, “Okay, it's going to be from this time to this time, once a week." Maybe a couple people showed up because they were interested in something but it was depending on the class I had. I have three or four people out of an enrollment of 10 or 12 which is pretty good considering the nature of the online classes. They aren't just affected. They don't want to do it. They don't show up. When they turn in their stuff and you say, "Okay, you know what, I explained this and that's why I opened the session. I explained how to do this." I started recording those and posting it and people used to just wait for the recording instead of updating the live sessions. It's always a struggle in finding the right way (Ryan, Instructor, 11 years physical, 3 years virtual). 
Running head: ANALYZING STUDIO CLASSROOM PRACTICES AND CULTURE

Two instructors describe the structure of the virtual studio classroom including written lecture, videos, and course project. Course projects are provided in the virtual classroom and some instructors do present their own work as examples.

Virtual, the class is much more structured. They're [the students] given a lot more information in lecture as well as assigned reading and then they are given assignments. They have assignments that they work towards. Preliminary assignments. Then usually they build towards a final project just like a regular [physical] studio class would do (Emma, Instructor, 3 years physical, 10 years virtual).

In the virtual world, that same type of presence is there. There is a lecture, a written lecture, that the students would have to read through. There would be written assignments. There would be an interactive session where ... Well, again, a synchronous interactive session where the students are presented with additional notes and ideas and examples. Sometimes that's in a video form. It is always with a written or verbal along with visual indicators (George, Instructor, 26 years physical, 12 years virtual).

Student Elizabeth indicates how some instructors add to the existing virtual studio by including voiceovers of the assignments or lecture.

It also helps too I've noticed more and more in the online classes the instructors will voiceover and show you the program through a video. So, it's basically the same thing trying to get that physical. (Elizabeth, Student, at least one physical 
Running head: ANALYZING STUDIO CLASSROOM PRACTICES AND CULTURE

interior design studio course and at least one $100 \%$ virtual interior design studio course).

Unlike the physical studio, there is no unknown element or mystery to the virtual studio. In the physical studio, instructors change their teaching styles, their approaches, or embrace spontaneous moments, such as an opportunity to relay their personal experiences. Instructors have a good idea of how their session will progress, and the competencies they will cover, however, the day to day strategies are unscripted. The virtual studio is opposite, as the course is prescribed. The instructor may not know how the students will perform or how the students will absorb the lectures and tutorials, but the students will be at the same place in the project design process all at the same time. Although there are due dates for assignments or milestones within a project, the students never meet with their instructor in a physical space. Unlike meeting together for 4-12 hours per week in the physical studio, the virtual student determines the day they want to work or the number of hours they need to complete their tasks or projects. Without the typical classroom time that is found in physical studio classrooms, virtual students must reach out to the instructor when they need help or guidance. This is very different from the physical studio where instructors require students to continue to refine their work under their guidance. In the virtual studio, the students typically only complete the number of process drawings required in the assignment instructions. These actions, unfortunately, undermine the structure and learning outcomes of the studio classroom. In some cases, even though revisions are suggested, students are not required to incorporate the suggestions or justify why the suggestions did or did not support the overall project goals. Student Maria explains the checklist approach of completing the work step-by- 
Running head: ANALYZING STUDIO CLASSROOM PRACTICES AND CULTURE

step, then completing the participation portion by looking at peers' work. For

participation, the student would provide a written critique of the work reviewed.

That's what I like about the online environment, they put the instructions of the online course, they [instructors] put step by step and they also want to make sure we participate and that we check on other classmates after doing our work. And that's when I realize I've done some work, that after I'm done with it and after I turned them in, whenever the participation part, I get to see what were my errors or what were my, I don't know, what were my advantages. And that's good, because I think I can compare my work to others. And we see when ... Like what's to get better in our next assignment (Maria, Student, at least one physical interior design studio course and at least one $100 \%$ virtual interior design studio course).

In some cases, students will revise work based on instructor comments, but generally only when required by the instructor or in some cases when required to receive a higher grade on an assignment. Without the continuous interaction between instructors and students as in the physical studio, the design projects in the virtual studio become a back and forth dialogue instead of one created with a collaborative spirit. Both students below concur that the instructor provides the framework and the needed revisions for a final submit.

For the Lighting Design with this instructor, she broke it down by each week was a specific part or section of the final. So, let's say, there's ten pages. Week One would be page one. Week Two would be two, three, four. And she mainly broke it 
Running head: ANALYZING STUDIO CLASSROOM PRACTICES AND CULTURE

down so that, when it came to your final, you just edit all of her comments and her suggestions, and then you plug it into a more design style, professional booklet, and you turn it in (Casey, Student, at least one physical interior design studio course and at least one $100 \%$ virtual interior design studio course).

For my online classes, definitely like, all through environmental design every time I turn something in, she'll send it back and be like, "you need to do this, this and this" and that's exactly what should be happening in the on campus (Anna, Student, at least one physical interior design studio course and at least one $100 \%$ virtual interior design studio course).

If the student needs to reach out to the instructor, they could post the question in the virtual classroom discussion board, send an email, or, in some cases, send a text. Although it is recommended that all communications stay in the virtual classroom, a few instructors do allow students to use email and phone for classroom type questions. As expected, all instructors encourage students to use email for all personal questions or situations. In most cases, virtual instructors are also required to provide at least three virtual office hours each week in that the expectation there is an instant reply to the student via the discussion board post, a question thread post, or email. In my experience, it is rare that a student requests an appointment via phone. Student Victoria confirms the communication styles used in the virtual learning environment:

Online it's more of an email and it's when the instructor is available. When you're online, I can take a picture of it or I can email when I'm in the process of doing something and go "Hey, I have a problem with this. Can you suggest something?" 
Running head: ANALYZING STUDIO CLASSROOM PRACTICES AND CULTURE

They can email you but it's not always right then, they'll get to it when they're online which could be in two hours, it could be the next day (Victoria, Student, at least one physical interior design studio course and at least one $100 \%$ virtual interior design studio course).

It should also be noted that this delayed response, from either the instructor or the student, can limit creativity and solutions. There is a certain rhythm established during a brainstorming session that is live and continuous. When students submit work and wait a day or two to receive comments, then wait another day or two to review, the momentum is lost. Camaraderie has not been generated. The project becomes a task or a step in a process and not a creative phase within the design process.

\section{ii. Critique.}

Unlike the physical classroom, group presentations or critiques in the virtual classroom are rare. Most generally, students post their assignment to the open discussion board (meaning that all students in the course can view). The students review the work of at least two peers and post written critiques of the work. The instructor, on the other hand, typically posts a written critique and/or an audio/video critique. The students do view other work, and comment on their peers' work via the discussion thread, but there is not a live gathering of students, instructors, or jurors where all students are listening and learning at the same time.

Face-to-face critiques were not found often in the virtual studio. A few instructors engaged with their students via Skype, however, a majority of the feedback provided was limited to written or personalized/individualized pre-recorded audio/video files. No 
Running head: ANALYZING STUDIO CLASSROOM PRACTICES AND CULTURE

student interviewed recorded a critique of their peers' work even though the task is relatively easy and not time consuming. With the examples below, the instructors describe how they use software or systems to provide recorded critiques or live conversations.

I find that what works so well with on ground and you can't replicate $100 \%$ what you do on ground online, the next best thing I find are the videos. Students find them incredibly helpful. They're usually very thankful for them. That really helps them to see and to hear. It's my way of recreating what I teach in the live studio, but via online (George, Instructor, 26 years physical, 12 years virtual).

There might be videos that support what we want them to do. But then I am just reviewing their assignment post and sharing feedback, in you know, some manner with them but there really isn't exchange of back and forth to any extent. Sometimes there is, rarely, like if I post feedback to a student in the online classroom rarely do they respond with questions or ideas other than saying like, thanks for the feedback, I'll appropriate that in my next post. So, there is ... the interaction or the interplay is completely different in my mind in the two scenarios (Eric, Instructor, 11 years physical, 11 years virtual).

We use Jing [screencapture software]. I think that's great, because they can hear my voice, and they can hear the inflection, and I'm sort of a positive person, so I could be ripping the stuff to shreds, but at the same time, you're being positive (Ginny, Instructor, 9 years physical, 4 years virtual). 
Running head: ANALYZING STUDIO CLASSROOM PRACTICES AND CULTURE

I always try to imagine myself as having a conversation with them, even though it is only uni-directional. Almost as if you were an actor in front of a camera. They say you need to fall in love with the camera, right? Whatever that means. I try to be that relaxed. Of course, there are days and days, but I think that makes a difference (Ethan, Instructor, 11 years physical, 11 years virtual).

Mostly written. Taking twenty students and creating a video and responding back to them or one by one communicating with them in a different format would be tough. When I stated the drafting course, they were not many programs that could be utilized for online. Later on, they offered me a program that you could go and record your voice on the lines. I'm not sure what it's called. So, you click on the drawing and you read your comments. Students will go back and click on that button next to the area that your commenting on and listen to your voice (Bill, Instructor, 32 years physical, 5 years virtual).

Students also appreciate the audio/video feedback created by the instructors. "To me, I think the most effective style that I've experienced as far as providing feedback for the students are the ones [instructors] who give audio feedback" (Katherine, Student, at least one physical interior design studio course and at least one $100 \%$ virtual interior design studio course). Instructors provide screenshot videos so that students can see the instructor indicate areas of the drawing or presentation while discussing. This personalized video provides the students with the exact area of concern as well as areas that are strong. This video emulates the desk critique in the physical classroom, as Student Elizabeth indicates. 
Running head: ANALYZING STUDIO CLASSROOM PRACTICES AND CULTURE

It also helps too I've noticed more and more in the online classes the instructors will voice over and show you the program through a video. So, it's basically the same thing trying to get that physical ... They do very well trying to help you out virtually (Elizabeth, Student, at least one physical interior design studio course and at least one 100\% virtual interior design studio course).

Students have indicated that they receive more attention via the virtual environment than in the physical studio. This could be dependent on the instructor and instructor involvement or dedication. In some cases, it could be dependent on the number of students in the course. Both students below reference the same instructor. Her level and number of responses (feedback) could be greater than other instructors. In any case, the instructor is required to respond to each student post in the virtual classroom, therefore, the perception of instructor feedback could be higher when compared to the number of times an instructor meets with a student individually during the physical classroom studio.

For the online classes I seem to get feedback way more often. Like way more often than I do for a campus class. I actually have a class right now, lighting design, and that class I never really feel like I know what is going on and I'm actually there with her (Anna, Student, at least one physical interior design studio course and at least one $100 \%$ virtual interior design studio course).

I did have my Lighting Design professor last quarter ... I emailed her something. I think it was she texted me, and then we were texting back and forth and then she said, "Let me just call you." And then we had a live conversation that way 
Running head: ANALYZING STUDIO CLASSROOM PRACTICES AND CULTURE

(Katherine, Student, at least one physical interior design studio course and at least one $100 \%$ virtual interior design studio course).

However, one instructor indicated that some students may not provide useful critiques because they are unsure of the concepts or do not understand the concepts themselves. Therefore, the critiques are too general or not helpful. In the end, students are required to critique the work of others, but it is the responsibility of the student to provide substantial critiques. Students do not receive participation points if the critique is not thoughtful and meaningful. The requirement forces the students to engage, but, again, the level of engagement is student dependent.

We have similar cases where some students do want to get a check off for participation. I think that many students simply don't have enough knowledge. I think that maybe they're struggling themselves to understand the concept, and I think that some may be intimidated by providing feedback for their peers because they don't fully understand the material itself. And I think that's sometimes why their responses are brief. I don't think it's necessarily because they are being lazy, I think sometimes it's because they feel awkward providing feedback something like an instructor would do when they don't fully understand the material (Andy, Instructor, 18 years physical, 12 years virtual).

This instructor requires that students reply to two students, but they also must read and review all comments so that the student is exposed to more work and more instructor and student critiques. 
Running head: ANALYZING STUDIO CLASSROOM PRACTICES AND CULTURE

I try to make it a little more relevant and to have only responding to one person but making sure that they read more than one or two replies and comply. That's what I do. It works because they say, "Oh, I just learned from such and such. That they did that. They also struggled with this and for that." It creates a little sense of community in the discussion (Ryan, Instructor 4, 11 years physical, 3 years virtual).

In regard to students providing critiques of peers' work, Bill explains that it may be easier for students to complete due to the virtual environment. Students can find it challenging to be completely honest when in the same room face-to-face with peers.

An advantage that I see in online courses is the students are more receptive to critique each other because they are not sitting face-to-face with a friend. When it comes to criticizing or making comments about each other's work, I think online they do a better job than face-to-face (Bill, Instructor, 32 years physical, 5 years virtual).

I think because you're not face-to-face with people ... I know one part of the online environment where you have to provide critique or feedback on another student's work. It's actually kind of somewhat helpful that they're not sitting in front of you when you really want to give them some constructive feedback (Katherine, Student, at least one physical interior design studio course and at least one $100 \%$ virtual interior design studio course). 
Running head: ANALYZING STUDIO CLASSROOM PRACTICES AND CULTURE

\section{iii. Studio culture.}

As indicated in the physical studio classroom, studio culture is an important aspect as students learn from the instructor, learn from one another, push each other, and complete comprehensive projects based on many critiques and revisions. Instructors do recognize that the virtual environment does not allow for relationship building. The lack of relationship building can be detrimental to student learning and does not necessarily support the shift from student to professional. Instructor Ethan shares how the virtual environment does not allow for a warm and welcoming atmosphere even with thoughtfully prepared videos.

Online would be not seeing the student in person, because you get so much more out of a regular conversation. Even the way I gesticulate, or move my hands, or body language. You're missing all that. You try to convey a warm and welcoming atmosphere as you speak, but it's not the same when I do videos for them online (Ethan, Instructor, 11 years physical, 11 years virtual).

Students also do not initiate peer contact or establish relationships. Many stated that they recognized names from prior courses, but they did not reach out to others for guidance or support. Instructors have tried to create the opportunity for students to reach out, however, this appears to be unsuccessful. Both the instructor and student below indicate that initiating or building relationships is not common in the virtual environment.

I've tried setting up little peer groups too, to kind of get that happening online, but you know what, you get the people that want to do it, you get the people that 
Running head: ANALYZING STUDIO CLASSROOM PRACTICES AND CULTURE

don't, and chances are, if you set up a group of five, two are going to actually do it (Ginny, Instructor, 9 years physical, 4 years virtual).

Other than that, I won't reach out to people in the online environment unless I have to. And I think that kind of does take away from the personal experience of being one on one with a group of students, because you chit chat and talk amongst yourselves sometimes and it takes the creative talk out of it, I guess you could say (Anna, Student, at least one physical interior design studio course and at least one $100 \%$ virtual interior design studio course).

In the physical studio, students ask questions of the instructor during open studio. This is similar in the virtual environment as most students contact the instructor directly. One student indicated that she felt more comfortable in the virtual studio classroom. "I actually feel online that it's better. I actually interact more with my instructors. This online class now, I've probably spoken to this instructor three times as much as I have with my physical instructor" (Elizabeth, Student, at least one physical interior design studio course and at least one $100 \%$ virtual interior design studio course). A majority of the students agreed that the interactions within the virtual classroom were with the instructor only. Both instructors and students agree that the written or video critiques are quite helpful because they can be reviewed as many times as needed. With a live discussion, a student may forget to take notes or write down a particular suggested revision or solution.

Instructor Emma indicates how she approaches communicating with students via the virtual classroom by creating "screenshare" videos or critique videos directed at the 
Running head: ANALYZING STUDIO CLASSROOM PRACTICES AND CULTURE

students. The instructor walks through the project components while discussing the design issues that need to be solved or technical issues that need to be corrected.

Then I can look at that work and make comments, but what I do is I use video, so that they can literally see just I can on the on ground, I can give them the work, but I can look at it and point things out and make comments, make suggestions, things that are good, things that are, things that need improvement, so they can digitally see as they hear my voice, point some things out and basically a little bit more personal instruction that way (Emma, Instructor, 3 years physical, 10 years virtual).

Student Anna indicates that the recorded session with the professor is beneficial because it can be reviewed instead of a live conversation where a student may have missed a note or comment from the instructor.

When you're talking to an online professor it's there in black and white, you can see it. You know wherever they respond you can re-read you know, but if you miss something that your instructor says in class or you don't note it down, that could lead to deductions in points because you spoke it and you didn't write it (Anna, Student, at least one physical interior design studio course and at least one $100 \%$ virtual interior design studio course).

However, instructors also recognize that the process is more difficult than the physical environment and that students may miss the benefits of the studio interaction. Virtual students are good at taking directions, however, they are not necessarily good at interacting and debating/justifying potential solutions. Students are required to submit a 
Running head: ANALYZING STUDIO CLASSROOM PRACTICES AND CULTURE

justification of the choices they make; students are not required to submit an analysis of the critiques they receive. Instructor Eric explains how students in the virtual environment tend to complete their projects independently, without the support, guidance, or critique from other students. Each student tends to approach the project on their own, moving through the steps to completion individually. The design process can be messy with multiple solutions, options, or thoughts that may not work. The virtual student does not appear to experience this.

And, in the online environment, I think the idea is similar to that, in terms of students are directed to read feedback that is given to their classmates so that they learn from that but, to be honest, I don't think that happens. So, I think that's a very, linear process. Like, they're going along on their own projects, on their own paths and not really watching what others are doing. And the reason I say that is when I look at the feedback that they leave for their peers, there isn't a lot of critical content in there even though that is expected. It's really limited and unstoppable and so I don't know that they, in my opinion ... it's just a very different experience where in the physical classroom it seems like it's more organic in terms of students will talk to each other more naturally than happens in the online environment (Eric, Instructor, 11 years physical, 11 years virtual).

A student explains how she felt in the online course by comparing herself to the characters in a television series, Girlboss. The main character created an online business; she regularly held a virtual conference where all participants attended via computer. No one was together in the same physical space. 
Running head: ANALYZING STUDIO CLASSROOM PRACTICES AND CULTURE

Sometimes I feel like I'm in the series Girlboss - where they are all sitting around the conference table as screens (Maria, Student, at least one physical interior design studio course and at least one 100\% virtual interior design studio course).

That healthy competition, you get on ground, because you're in this culture. You're in this environment where people are aware of one-another. Versus online, I know everyone posts comments and posts interim progress shots, but you still don't have that ... You're in your own office. Somebody might be like an hour away, five states away ... But you don't have that connection (Ginny, Instructor, 9 years physical, 4 years virtual).

Instructor Andy suggests that virtual students do not have as many opportunities to practice professional attributes such as oral communication (either via conversation or formal presentation).

Online I think it's uniquely different, online they have to read materials on their own, they have to digest the information, they have to use problem solving, they have to work independently, try to come up with solutions, And those are skills that they are practicing in the online classroom that they're going to use in the real world once they get a job. So, I think it's different between on campus and online but I think that in both cases they're learning something valuable (Andy, Instructor, 18 years physical, 12 years virtual). 
Running head: ANALYZING STUDIO CLASSROOM PRACTICES AND CULTURE

Lastly, Instructor Eric sums up the virtual studio classroom by referring to himself as a "facilitator" when present in the virtual studio. As a facilitator, he guides the students through the course, but does not feel a connection or relationship with the virtual students. There is not a sense of cohesiveness in working together to solve the problem; there is a sense of directing the students to completion.

Well, I think it is pretty clear, at least it feels like to me, that on ground I truly feel like and I think I'm viewed as an educator versus online I'm viewed as a facilitator. So, I'm hoping someone gets through the process ... I'm facilitating that process online versus, not sure how else to explain that, other than like in the classroom you're really responsible for educating as well as facilitating, I guess is maybe now that I think about it. So, in a physical classroom I am constantly thinking about how do I improve the class? What things can I share? I'm looking for examples. I'm really sharing a lot of my personal experience with the students when I do desk critiques, and, from one student to the next that could be a very different personal experience but because everybody sits together in the classroom, all the students should be sort of listening to what I'm sharing with all of them (Eric, Instructor, 11 years physical, 11 years virtual).

\section{iv. Collaboration.}

Due to the virtual environment and the asynchronous approach to the classroom, collaboration with peers, as well as between instructor and student can be quite challenging. However, in the current global marketplace, it is a required skill of students. "With the global market trend and the advancement of technology, collaboration in a 
Running head: ANALYZING STUDIO CLASSROOM PRACTICES AND CULTURE

technology-mediated work environment has become common among designers" (Cho, 2016, p. 569). If students are motivated to engage with one another, or with the instructor, then collaboration is possible. Instructor Emma explains the approach in the virtual environment.

There's collaboration hopefully within the [physical] classroom where students can get that same studio type environment, but it's virtual where they're looking at a student's work because they post their work digital and then they can comment on each other's work (Emma, Instructor, 3 years physical, 10 years virtual).

However, most of the time, the student is more concerned with completing the next task instead of working with others. Many blame the virtual environment or lack of time. Both Students Clara and Katherine describe the challenges of working with teams virtually.

Well, I had a group project one time in an online class. And it took us 10 days to all sort of link up and get in touch with each other by email, so that just kind of posed a timing problem (Clara, Student, at least one physical interior design studio course and at least one $100 \%$ virtual interior design studio course).

Group projects are difficult online. They're difficult on-ground as well, just because as a student everybody has such different schedules. It's very difficult to find time to actually get together and work together. Online is even a little harder because you don't have that face-to-face contact (Katherine, Student, at least one 
Running head: ANALYZING STUDIO CLASSROOM PRACTICES AND CULTURE

physical interior design studio course and at least one $100 \%$ virtual interior design studio course)

Students do see the benefit of collaboration, but they may not understand the full scope of those benefits due to the limited practice in the virtual environment. "Being able to collaborate with each other might be kind of nice" (Clara, Student, at least one physical interior design studio course and at least one 100\% virtual interior design studio course).

Instructors also see the lack of connection between peers, or even the connections between the project milestones. The instructor must rely on the student to further inquire about the project if there are any misunderstandings. If the student corrects their work, the instructor can see the revision, but does not know, unless the students inquires further, that the student understands the purpose of the revision. "I can see the benefit of that [providing a set of parameters as a check list], but then, where is the collaboration and where is the thought process? We just told you, do one, two, three, four, not necessarily are they making the connection. Do they know why, they only do one, two, three, and four?” (Ginny, Instructor, 9 years physical, 4 years virtual).

Just as the with the students of the physical studio, it is imperative for virtual students to collaborate with industry professionals and clients. On occasion, the instructors will host times for the professionals to speak to the students. During the Virtual Career Week, guests will speak for thirty to sixty minutes about a particular project, or how they collaborate with designers. A majority of the time, the instructor acts as the client with student projects. 
Running head: ANALYZING STUDIO CLASSROOM PRACTICES AND CULTURE

\section{v. Outcomes.}

With all the obstacles and differences between the virtual studio classroom and the physical studio classroom, there are instructors that feel students can obtain similar educational results in the virtual environment. "The only reason I teach in a virtual environment is because I have seen that for students who are interested and interact with the instructor you can produce the exact same results that you can produce in an onground environment" (George, Instructor, 26 years physical, 12 years virtual). By this, the instructor implies that the success of the student is based on their proactive actions and their willingness to learn in a different environment. The success of the student is also based on the dedication of the instructor and their willingness to modify their teaching strategies to accommodate the virtual environment.

Students appreciate the directness of critiques in the virtual environment that allow them to produce quality work.

I would have to say I'm actually prouder of my online work for some reason. I don't know, I feel it's a lot more focused, it's straight to the point. If I have something to fix I go back and fix it exactly what the instructor said and for a physical class sometimes I feel that the attention is so divided because it's a classroom full of different kids, so I feel like sometimes I don't get that criticism that I feel I should and when the project does come to complete, I'm criticized on something that I thought twice about. And on an online I don't necessarily think twice (Elizabeth, Student, at least one physical interior design studio course and at least one $100 \%$ virtual interior design studio course). 
Running head: ANALYZING STUDIO CLASSROOM PRACTICES AND CULTURE

Instructors in the virtual environment have found that virtual students tend to also have other responsibilities such as work, family, and other obligations. This can be true of those in the physical studio, however, the attention students give virtual courses can be overrun by their other responsibilities. The virtual work can be hurried or incomplete, as detailed by Instructors Emma and Eric.

Then you factor in the fact that it's online and if you're not savvy with that, there's an issue. If you have other personal challenges, which I found more online students had additional issues that they were dealing with, other obstacles. If you can get though that, then yes, your work as you move forward is equal if not better than what you get on ground. (Emma, Instructor, 3 years physical, 10 years virtual)

If they're trying to balance jobs and, you know, all sorts of other responsibilities in their life, that's reflected in their work. So, I don't know that maybe that's the best student to be online. I would say when I compare what I see online which is a few good things and a lot of mediocre work to what I see in the physical classroom, I would say that there tends to be more good work and strong work and a lot less mediocre and I think that's a virtue of the things we've talked about so far, you know, the ability to stop class and talk organically and the time you spend doing critiques and kind of those natural flowing conversations about things that don't seem to happen online even though you can do things like have a virtual conference and bring everybody together. Like, those things just don't 
Running head: ANALYZING STUDIO CLASSROOM PRACTICES AND CULTURE

seem to, in my mind, in my experience, work as well as physical classroom (Eric, Instructor, 11 years physical, 11 years virtual).

As indicated earlier, formal presentations are an important component of the final outcomes. Many virtual students do not practice this skill, or, if required, only do so a few times in the program. Virtual students are required to present their senior thesis project as well as their portfolio via a live video conference to instructors. With each student presentation, two or three instructors provide live feedback. The instructor informs the student at the beginning of the presentation session that it will be submitted as an assignment prior to the formal presentation. Students, however are sometimes unsure of how to present the work without much verbal presentation practice. In regard to formal presentations, Student Katherine does not remember formal presentations required by any virtual course. Instructor Andy provides an alternative option allowed for formal presentations.

Online, I don't think I have. You mean like do some sort of video or audio? (Katherine, Student, at least one physical interior design studio course and at least one $100 \%$ virtual interior design studio course).

Online? The only way that they're really presenting their work is posting it in the discussion forum, and I provide feedback in the forum, so then their peers can be engaged and in the learning process I'm providing feedback as well. So that is really the only way that the work is presented (Andy, Instructor, 18 years physical, 12 years virtual). 
Running head: ANALYZING STUDIO CLASSROOM PRACTICES AND CULTURE

A few instructors believe that the work virtual students produce can be compared equally to that of physical studio students. Again, in my experience, the students that produce quality work are those that value the critique, ask questions, and continue to revise and rework projects based on feedback. Instructors Rob, Emma, George, and Ethan recount their experiences:

I see outstanding work. When I used to teach on ground I'd have some students that were just amazing and some students that did not have design skills or talent. And then I see the same thing online as well, where you've got some people that just blow you away with their ideas, and some people that just maybe it's not the right path for them to take for a career choice (Rob, Instructor, 20 years physical, 14 years virtual).

I think the online, believe it or not, I think is a better real-world experience than on ground. The reason I think that is when I was teaching as an adjunct ... I went to a portfolio review during ASID Week. I was floored at what I was seeing, the quality of what I was seeing, and the fact that it was all digital. We're in a digital world. We do business virtually now. Everything goes digitally now. Nobody brings big sets of CDs and does things like that. In that respect, I see a difference because in my beginning students, some of them don't even know how to use PowerPoint. They don't really know how to scan. They don't know how to scan and merge (Emma, Instructor, 3 years physical, 10 years virtual).

The only reason I teach in a virtual environment is because I have seen that for students who are interested and interact with the instructor you can produce the 
Running head: ANALYZING STUDIO CLASSROOM PRACTICES AND CULTURE

exact same results that you can produce in an on-ground environment (George, Instructor, 26 years physical, 12 years virtual).

No. Interestingly, our students, and this is kudos, pats on the back for us online. We're doing a phenomenal job preparing our students, the ones that really want to learn. I mean, the ones that really take this seriously. Nothing to compare with other students that go on-ground. They get quality education (Ethan, Instructor, 11 years physical, 11 years virtual).

Despite some of the pitfalls of the virtual learning environment, instructors continue to teach in this environment because of the opportunity to work with many instructors and students across the globe, the desire to stay current with technology, the development of alternative avenues for students, the persistence of wanting to create the next session with higher quality, or the advantage of the convenience/flexible schedule. "Online seems to be the way of the future, brick and mortar education and institutions are dwindling while online increases so you move forward or get left behind" (Emma, Instructor, 3 years physical; 10 years virtual). Eric, Instructor, indicated that he started teaching in the virtual world because of the possibilities. "At first, I believed in the potential, I enjoyed teaching, and I needed the income. I was working several adjunct positions to cobble together a teaching career and this became steady work when enrollments were high" (Eric, Instructor. 11 years physical; 11 years virtual). However, he has stated that his enthusiasm for the virtual interior design studio classroom has waned over the years. "There is a constant attempt to improve courses for students and to prepare students for careers. I suppose that sort of "can do" attitude and the desire to 
Running head: ANALYZING STUDIO CLASSROOM PRACTICES AND CULTURE

teach and help students keeps me going, for now" (Eric, Instructor, 11 years physical; 11 years virtual).

\section{vi. Environment influence, impact, and control.}

In regard to the environment influence, impact, and control, the most compelling findings concerned the lack of professionalism, lack of interaction, increase in independent study type habits, and the lack of exploring design solutions within the virtual environment.

Instructors have indicated that virtual studio students could need time to adjust to a career in the physical environment. Although virtual interior design students are required to take a Professional Practices course, the students do not practice the skills in the physical work environment. These skills could include professional dress, professional conversations, and professional interactions regarding design projects.

Instructor Ryan tries to elevate the conversation and classroom experience to prepare the students for the professional world, whereas Student Casey indicates that the virtual environment allows her to not be professional in regard to dress.

What the online class is missing and hard to ... there's always that question. I keep thinking of how to find the way to lead a better experience but the students that have graduated from a fully online, they will need a little time to adjust, to adapt to working with other people. Probably, the discipline of the two ... the professionalism aspect of the program that you're required to graduate from the very simple thing of showing up on time and staying for an entire class and your behavior and all that. Whereas, in an online process, you may be by your swimming pool in shorts and it doesn't matter if you even comb your hair, right? 
Running head: ANALYZING STUDIO CLASSROOM PRACTICES AND CULTURE

There's no interaction with other people. That's probably the thing that is hard to replace but I don't think it's dramatic as the end of the world. I think that they will need some time to adapt to work with people with real clients, with colleagues and in a team environment, because you know, as interior designers or architects, we work with a lot of people. We don't work alone, normally (Ryan, Instructor, 11 years physical, 3 years virtual).

What I love about online is I have more freedom. I don't have to go to class, I don't have to interact with a bunch of people, I can be in my pajamas, I could be on vacation and no one knows that I'm getting my work done (Casey, Student, at least one physical interior design studio course and at least one $100 \%$ virtual interior design studio course).

Although there is constant communication between the virtual instructor and virtual student, the students are responsible for the time and effort they contribute. The independent study type format is completely contradictory to the studio format. Within the physical studio, interior design students are encouraged to work independently with their final design solutions, however, are not encouraged to work throughout a project entirely independently. Again, the virtual environment can prevent students from working collaboratively, contradicting the typical physical studio foundation as explained by both Instructor George and Student Casey.

Now, in the physical classroom, I feel that the live interaction helps prepare students better for networking opportunities and interaction with other humans, which is vital for their success. In the online environment, students can go 
Running head: ANALYZING STUDIO CLASSROOM PRACTICES AND CULTURE

through an entire degree program never having to seriously interact with anybody outside of that virtual classroom (George, Instructor, 26 years physical, 12 years virtual).

Where online, I don't talk to anybody except for in the participation discussion points. However, I know you're supposed to comment back, but not many people respond back to your comments. And then same with the professors when they just response, that's kind of the only interaction (Casey, Student, at least one physical interior design studio course and at least one 100\% virtual interior design studio course).

With the structure of the virtual classroom, students can complete work independently and this can cause an issue for the instructor. Instructor Ginny provides a comment on how challenging it can be to work with virtual students. When not in the same space, the student can continue to work on the project whether they are headed in the right or wrong direction. Student Clara views working independently in a different light as she views independent work as a benefit to her schedule and her best working hours.

Online, you have to be so prepared, because they're reading this information, you're not there at their beck and call, interacting so clearly as you would if you had four hours of time together. So, preparing on ground versus online, I would just say you have to be more detailed online than you do on ground, but I think the benefit of on ground is that you have some fluidity with the project, so you can allow the students to come and go and let them explore a little bit more, 
Running head: ANALYZING STUDIO CLASSROOM PRACTICES AND CULTURE

versus online, if they start to explore and veer a rabbit trail, you're like, "Get back here!" Because you don't know when the next time you're going contact them, or when they're going contact you is going to be, there could be a deadline, and you're like, “All right, you really went off” Versus on ground, if they start rabbittrailing, let them go, you can always reel them back in when you see them (Ginny, Instructor, 9 years physical, 4 years virtual).

I think, for me, being able to set my own schedule, not being confined to the classroom for four hours at a certain time and if I need to work in the morning or in the middle of the night, you know, it's certainly nice to be able to work that around my schedule. I think the communication is just on ground, it was a bit better but that's just a matter of logistics (Clara, Student, at least one physical interior design studio course and at least one $100 \%$ virtual interior design studio course).

When students work independently, there is also a greater chance for missed learning opportunities or students pursuing incorrect or impossible design solutions. With the checklist approach, students do not elevate their design solutions. The prescriptive approach is linear and does not allow for the design process to work most advantageously. The virtual student, explained below, misses the opportunity to interact with them.

In physical, it's that ability to be creative and to explore, and that ability to just have that impromptu design session. And I think Skype actually opens the doors 
Running head: ANALYZING STUDIO CLASSROOM PRACTICES AND CULTURE

for that online, but you still can't get your hand on their piece of paper and take that one piece of line and extend it to become a curve, or take that line ... You don't have that impromptu, that physical interaction. Thats what you miss in the online education. You can try, and Ive tried it with the videos, and I've tried it with the Skype, and I've tried moving my cameras so they can see what I'm drawing, sending them pictures, but you just don't have that online (Ginny, Instructor, 9 years physical, 4 years virtual).

In the online classroom, you really cannot do that. The students are doing their assignment, they're scanning them, turning them in, at that point you can find all those problems you didn't have the opportunity as the students were drawing it to intervene. So that's a limitation of the online classroom versus on campus (Andy, Instructor, 18 years physical, 12 years virtual).

A few instructors have indicated that the use of a blended classroom would be the most beneficial if a complete physical classroom program was not available. This would allow for the students to receive the benefit of physically being together, yet also provide the benefit of videos, tutorials, or examples that they could view during open studio time, or after official studio time. The instructors provide ideas for modifications to the $100 \%$ virtual approach.

I think, if I could just reiterate, I'm not against online education, but I think that it's important that we identify who it makes the most sense for. And how does each scenario benefit the student the most. And I actually think that somewhere in 
Running head: ANALYZING STUDIO CLASSROOM PRACTICES AND CULTURE

the middle, the combination of physical and virtual is probably the happy medium that we haven't arrived at yet in either type of institution. I think there is a way to incorporate the benefits of online learning in the physical studio (Eric, Instructor, 11 years physical, 11 years virtual).

What I'm seeing, the future of education more and more is a hybrid system. Even if you teach in on-ground, in an on-ground environment, I always prepare a website, and I put their material that they can see during the week, before we meet the next time. It works two ways. For the students that are overachievers, they can prepare ahead of time. For the students that need extra hand-holding, they can play, and pause (Ginny, Instructor, 9 years physical, 4 years virtual).

It's been a really positive and pleasing finding for me to find out that you can do so much. And I think as we go ahead, we're going to have technologies that are maybe even going to be able to bridge that gap even more. We have more virtual reality, we have the changes in cap technology that we use in design is constantly changing. We have better communication methods, Skype and other things that are happening. And who knows what's going to happen in the future. I think it's all very positive to know that there are so many options now in education (Ethan, Instructor, 11 years physical, 11 years virtual).

Students indicate that the motivation behind enrolling in virtual studio classes is due to flexible schedules. Unlike the physical studio student, the virtual student is not required to attend the physical studio classroom meetings. As mentioned earlier, the 
Running head: ANALYZING STUDIO CLASSROOM PRACTICES AND CULTURE

physical studio student could meet with their instructor from 8-12 hours per week. Again, this practice of students working on their own time without direction or interaction from the instructor or other students does not support studio learning. Virtual students see this as a benefit, but as a studio component, it is detrimental. The goals of the virtual students are based on schedule and dedication of time instead of the learning. Students Anna, Katherine, and Instructor Ginny agree that virtual studio courses are quicker and allow more flexibility. The students also indicate that the virtual studio courses are quicker due to this particular program's schedule. Physical studio courses are completed in 11 weeks, whereas the virtual studio courses are completed in 5-1/2 weeks. Therefore, the students tend to register for two virtual studio courses during the same time as registering for one physical studio course.

I would say an advantage for being online, is that you get done quicker, it is a lot of work, but you get done with the class quicker and you can move into another online class and get two finished in the same time it takes to get one campus class done. Which is really, really helpful. For me as a mom anyway. But then the drawbacks of not actually going to the class is more along the lines of that personal, you know, talking to your classmates, you know, face to face one on one time with your instructor (Anna, Student, at least one physical interior design studio course and at least one $100 \%$ virtual interior design studio course).

What I like about online, well, to be honest the .... The thing I like most about the online classes is you can get through them quickly. You can see, you can look ahead and look at assignments and often work ahead a little bit easier than in on- 
Running head: ANALYZING STUDIO CLASSROOM PRACTICES AND CULTURE

ground classes (Katherine, Student, at least one physical interior design studio course and at least one $100 \%$ virtual interior design studio course).

And I feel like online, you're just kind of putting ... You do an online thing because of time or location or schedule, and you fit it in when you can (Ginny, Instructor, 9 years physical, 4 years virtual).

The instructors also recognize the flexibility of virtual studio courses in regards to meeting times.

Online, you could choose any hour of the day that you want to work on it. So that's a benefit, it's the flexibility with the schedule (Ginny, Instructor, 9 years physical, 4 years virtual).

Virtual students are less likely to revise their work in any stage of the design process. This could be due to the limited time in the accelerated virtual courses, or to the structure of the virtual classroom. Again, due to the shorter timeframe of the virtual studio classroom, and the course design, a majority of the students tend to be focused on the steps to completing a project instead of focusing on completing the project with totality. However, for some students, the virtual environment is beneficial. Students Elizabeth and Maria explain that the virtual course appears to be more focused and organized.

I have to say online personally more focused. That's an advantage. I'm a lot more focused. There's no physical class to say hi to a few friends or maybe get a little 
Running head: ANALYZING STUDIO CLASSROOM PRACTICES AND CULTURE

off track. Because online it's you and that computer. So, I'm a lot more focused online (Elizabeth, Student, at least one physical interior design studio course and at least one $100 \%$ virtual interior design studio course).

I like about online classes is that I have a more organized schedule. I decide when to do physical classes and my online classes I can do them whenever I, ...

Obviously before the due date of the assignments, but I know when to do it and I don't know. I think that's a better way to organize as if I had another class on campus, you know what I mean? (Maria, Student, at least one physical interior design studio course and at least one $100 \%$ virtual interior design studio course).

Utilizing the information from this chapter, a table was created to allow for direct comparisons pf the physical interior design studio classroom and the virtual interior design studio classroom.

Table 1: Comparison of Physical and Virtual Studio Classrooms

\begin{tabular}{|l|l|}
\hline $\begin{array}{l}\text { Physical Interior Design Studio } \\
\text { Classroom }\end{array}$ & $\begin{array}{l}\text { Virtual Interior Design Studio } \\
\text { Classroom }\end{array}$ \\
\hline & \\
\hline $\begin{array}{l}\text { Physical classrooms were equipped } \\
\text { with drafting tables, chairs, and } \\
\text { computers for students; } \\
\text { whiteboards, projector, and } \\
\text { presentation area for instructor. }\end{array}$ & $\begin{array}{l}\text { Virtual classrooms required } \\
\text { students to possess computer, } \\
\text { scanner, printer, camera, and } \\
\text { portable drafting table. }\end{array}$ \\
\hline $\begin{array}{l}\text { Enrollment in the physical } \\
\text { classroom was between 14-16 } \\
\text { students. }\end{array}$ & $\begin{array}{l}\text { Enrollment in the virtual classroom } \\
\text { was between 18-25 students. }\end{array}$ \\
\hline
\end{tabular}


Running head: ANALYZING STUDIO CLASSROOM PRACTICES AND CULTURE

\begin{tabular}{|c|c|}
\hline $\begin{array}{l}\text { Instructors and students met in the } \\
\text { studio classroom between } 4-12 \\
\text { hours per week. }\end{array}$ & $\begin{array}{l}\text { Instructors and students typically } \\
\text { did not meet synchronously. If so, } \\
\text { on a limited basis. }\end{array}$ \\
\hline $\begin{array}{l}\text { Instructors provided lecture, } \\
\text { demonstrations, or discussions. } \\
\text { Then, students applied skills during } \\
\text { same studio class time. }\end{array}$ & $\begin{array}{l}\text { "Course master" or "course shell" } \\
\text { with written lectures, video } \\
\text { demonstrations, or discussion } \\
\text { threads were provided within the } \\
\text { virtual classroom. }\end{array}$ \\
\hline $\begin{array}{l}\text { Students received synchronous } \\
\text { one-on-one instruction. }\end{array}$ & $\begin{array}{l}\text { Students received one-on-one } \\
\text { instruction typically via written } \\
\text { notes or screencapture video/audio. }\end{array}$ \\
\hline $\begin{array}{l}\text { Critiques were provided face-to- } \\
\text { face during the class time by the } \\
\text { instructor or peers. }\end{array}$ & $\begin{array}{l}\text { Critiques were provided via the } \\
\text { discussion thread by the instructor } \\
\text { or peers. }\end{array}$ \\
\hline $\begin{array}{l}\text { Studio culture developed } \\
\text { organically; typically, student } \\
\text { driven. }\end{array}$ & $\begin{array}{l}\text { Student culture did not appear to } \\
\text { develop. }\end{array}$ \\
\hline $\begin{array}{l}\text { Students interacted informally and } \\
\text { learned from one another. }\end{array}$ & $\begin{array}{l}\text { Students did not appear to interact } \\
\text { beyond the classroom framework. }\end{array}$ \\
\hline $\begin{array}{l}\text { Formal collaboration opportunities } \\
\text { were provided. }\end{array}$ & $\begin{array}{l}\text { Formal collaboration opportunities } \\
\text { were provided. }\end{array}$ \\
\hline $\begin{array}{l}\text { Students presented work orally and } \\
\text { provided justification for design } \\
\text { solutions. }\end{array}$ & $\begin{array}{l}\text { Students presented work via } \\
\text { discussion thread with written } \\
\text { justification for design solution. } \\
\text { There were a few courses that } \\
\text { required oral presentation. }\end{array}$ \\
\hline $\begin{array}{l}\text { Physical classroom allowed } \\
\text { opportunity for meaningful, } \\
\text { supportive relationships. }\end{array}$ & $\begin{array}{l}\text { Virtual classroom allowed } \\
\text { opportunity for instructors and } \\
\text { students to interact. }\end{array}$ \\
\hline $\begin{array}{l}\text { Industry professionals or jurors } \\
\text { attended the class sessions via face- } \\
\text { to-face. }\end{array}$ & $\begin{array}{l}\text { Industry professionals or jurors } \\
\text { attended the class sessions via } \\
\text { webinar or recordings. }\end{array}$ \\
\hline
\end{tabular}


Running head: ANALYZING STUDIO CLASSROOM PRACTICES AND CULTURE

\section{Chapter Five: Discussion}

As indicated earlier, the studio as a learning environment provides the optimum space for the interior design student. Throughout this research and findings, it was shown that there were few similarities and critical differences when students participated in physical interior design studio classrooms versus virtual interior design studio classrooms. There were many factors that contributed to successful outcomes, however, the most prominent appeared to be the development of the culture within the studio. This organic evolution of the student dynamic supported student growth and development in becoming an interior designer. When comparing the physical interior design studio classroom with the virtual interior design studio classroom, there were five major limitations in the virtual environment:

A. Limited collaborative interaction among faculty, students, project clients, and experts

B. Limited creativity associated with the fluid and open-ended nature of stimulation, trials and exploration in the design process

C. Limited personal and individualized interaction in building engaged relationships and networks

D. Limited teaching and learning expectations for iterative on-going reflection and continuing improvements in projects evolving in time

E. Limited investment in building a studio culture with real-time presence and interaction among a tightly formed group of 16 or less colleagues to address dynamic complexities in the problem-solving design process 
Running head: ANALYZING STUDIO CLASSROOM PRACTICES AND CULTURE

\section{A. Limited collaborative interaction among faculty, students, project clients, and experts}

Collaboration was indicated in various ways in the physical studio classroom as students worked together in team or group projects. Typically, students completed projects together from beginning to end, however, in some cases, the instructor asked the students to research together, then solve the design problem individually.

Collaborating as a team was not as evident in the virtual classroom. Instructors indicated that they tried to assign group projects, but the students claimed scheduling issues, different time zones, etc. prevented the groups from working together. Instructors appeared to have stopped requiring team projects after a few attempts.

Although the amount of collaboration time was not measured in either environment, the physical studio classroom provided more opportunities for ongoing and interactive collaboration. The physical space of the studio allowed teams to gather together on a regular basis with a pre-determined class schedule. "In interactive and collaborative instructional contexts, individuals have an opportunity for perspective taking and reflective thinking that may lead to higher levels of cognitive, social, and moral development, as well as self-esteem" (Kvan, 2008, p. 196). This can then lead to an environment that is perceived as safe where students actively engage with each other (Kvan, 2008). Due to the schedule limitations of virtual students, as indicated by both instructors and students, synchronous and interactive virtual collaboration was more challenging to plan, thereby collaborative opportunities were not as prevalent.

Issacson (2017), author of The Innovators, stated that creativity is taught through collaboration. Throughout the book, he highlighted many technology-focused projects 
Running head: ANALYZING STUDIO CLASSROOM PRACTICES AND CULTURE

and analyzed the success. He concluded that collaboration was vital to any project's favorable outcomes. Although not directly related to the studio environment, his summation can be applied in this context. "First and foremost is that creativity is a collaborative process. Innovation comes from teams more often than from the lightbulb moments of lone geniuses" (Issacson, 2017, p. 479).

Due to the lack of collaboration on projects it was difficult to distinguish if the students in the virtual studio truly understood the creative process. Physical classroom students had the opportunity to explore more options with the guidance of the instructor, however, the virtual classroom students lost this opportunity when instructors provided limited group work.

In the industry, students are expected to work together, and they must also work with other professionals in the industry after graduation, including but not limited to, building contractors, engineers, manufacturers, or other designers. And, designers also

need to work with their clients. In the physical environment, there appeared to be several opportunities to work with others in the many capacities. In the virtual environment, the opportunity of working with other disciplines, as well as clients, was limited.

\section{B. Limited creativity associated with the fluid and open-ended nature of stimulation, trials and exploration in the design process}

Although creativity was discussed as a collaborative effort, the limitation of the design process, or not using the process fully, could also affect creativity. Due to the asynchronous environment, virtual instructors indicate that it was challenging to reach students in the virtual classroom. It could be difficult to know when a student was at a stopping point, needed direction, or needed further explanation or instruction. With 
Running head: ANALYZING STUDIO CLASSROOM PRACTICES AND CULTURE

physical studio students, it could be much easier to focus on the students' needs. By evaluating the body language, facial expressions, or actions in class, the instructor could quickly address issues. The lack of synchronous face-to-face classroom time could limit the project outcomes as students may not fully develop an idea/solution, approach the project in the best way, or complete the research needed for the problem. Instructors also had difficulty knowing how far they could push the student when seeking or evaluating project solutions. Without the base of a relationship, it was possible that the instructor did not guide the student to their full abilities.

Instructor Bill asked during the interview, "How do you teach creativity?" The instructor could explain the design process and guide the student through the process, and in the end the student could understand how to approach future projects by understanding that constant reflection and revisions are necessary to provide the best outcomes. No project will take the same path from beginning to end, however, with the physical studio experience, the student should be prepared for the profession and the projects they would encounter.

When the virtual studio students were focused on the step-by-step process of completing the task or project, the freedom to explore many solutions diminished. In the virtual studio, the projects tended to take a linear path from start to finish and with limited time, disallowing the investigation of multiple options.

There appeared to be a disconnect between the process and importance of revisions with the virtual students. Students learned technical skills in this virtual classroom, however, as indicated earlier, these same virtual students missed the opportunity to observe and work through the design process with others, a critical 
Running head: ANALYZING STUDIO CLASSROOM PRACTICES AND CULTURE

component of the physical studio experience. These virtual students could choose to read critiques, view a video critique, and/or incorporate the feedback into the design. The virtual student final project was complete and presentable when taking the technical skills into consideration, and the project could also appear complete in regards to the final solution. However, it is unknown if this best solution was based on multiple configurations since the preliminary drawings were not visible.

The virtual student was not exposed to alternate solutions (precedents, other students in class) unless they completed additional research or reviewed their peers' work. This research showed that virtual studio students had a choice to participate in the discussion as the only requirements were the points attributed to their critique with a rubric. If the student wanted the points, they often would complete the critique; if the points were not important, they may not complete the critique. Physical studio students, on the other hand, were required to participate in group critiques as a component of the studio classroom. Again, the process to the outcome did not support the studio approach. Outcomes appeared to be similar - both instructors and students agree - however, the process taken in the two environments was quite different. To learn from one another was an additional major component of the physical studio experience that was diminished within the virtual environment.

Referring back to Social Learning Theory (see Chapter 2), Bandura emphasized human interaction, observation, and modeling as key characteristics. With these virtual students, the social learning is absent.

\section{Limited personal and individualized interaction in building engaged relationships and networks}


Running head: ANALYZING STUDIO CLASSROOM PRACTICES AND CULTURE

Some virtual instructors have conducted telephone or Skype conversations. In most instances, this was only when the student was experiencing difficulties. The student or instructor could request the meeting. There was typically no live feedback or critique via telephone or Skype; this action was reserved for a student that was struggling, not posting work, or failed to understand the course content. The instructors mainly relied on written critique or recorded audio/video critiques. On occasion, an instructor may have met with a student via telephone to discuss a senior project or portfolio. However, this was not common practice. Instructors have indicated that it takes extra time to create response videos/screen captures, and many students did not view or access them.

(Instructors had the capability to see students' log-in time when accessing the course.) If a student did not try to improve their work or themselves, the instructor tended to stop going above and beyond the requirements of their teaching duties. Finding a common time to meet individually with 15 or more students in a given week could also pose challenges. Many virtual students did not want to meet with the instructor as they would rather work through the course at their own pace with the content provided.

Today, it is still necessary to develop new instruments and methods to facilitate the design of learning processes in a virtual learning environment (virtual pin-up, virtual jury, virtual desk critic), to elaborate organizational strategies that encourage interaction between different actors (inside and outside academia), to create procedures to build knowledge collectively, to organize communication protocols in order to show the design results to different audiences and to manage repositories with quality content (Masdeu, 2017, p. 18). 
Running head: ANALYZING STUDIO CLASSROOM PRACTICES AND CULTURE

Unlike the physical classroom, virtual students had limited live personal interaction with other students and experience of community. The student goals appeared to be different for the virtual learner. For example, virtual students had the choice to reach out to others in the classroom. They were not forced to sit next to someone and converse. Virtual students tended to reach out to the instructor with questions or they sought answers via online resources. These actions did not support the purpose or intent of studio, and the potential sense of community was lost.

As indicated with the virtual classroom, the interaction was limited to written thread discussions, audio recordings, screenshot recordings, and in some cases live communication. Although these communication techniques supported the creation of connections, it was challenging to build and sustain meaningful relationships. Not only was the interaction limited, the students and instructors were typically only together for one course in the program. On occasion, instructors could teach a variety of courses and students could appear on an instructor's roster in more than one course. Students that took more than one course with the same instructor adapted to the course faster as they knew the expectations and teaching style within the first week. This was not a surprise, however, and this could also be seen in the physical classroom. This circumstance of students taking different courses with the same instructor more than once was a rare occurrence in the virtual studio and, as a result, the program did not reap the benefit of an established relationship.

During interviews, Instructor Eric identified his role as an "educator" in the physical studio, however, used the term "facilitator" when present in the virtual studio. (See Virtual Interior Design Studio Classroom, Studio culture for interview excerpt.) As 
Running head: ANALYZING STUDIO CLASSROOM PRACTICES AND CULTURE

an "educator," this instructor developed relationships, shared personal experiences, and treated the student as a whole. As a "facilitator," this instructor believed he did not have the opportunity to develop relationships in the virtual classroom. Personal experiences were shared but within the discussion threads or with an audio clip-somewhat different than live presentations or interactions. With this relationship base, it could be challenging to consider the student fully, as interactions were limited to discussion threads, not four hours per session in a physical classroom together.

This instructor found the value in relationship building with students. With these relationships, it could be easier to provide critiques that the student understands, or have a broader scope of the student goals. The relationship building was a two-way process; the virtual instructor must be engaged as well as the virtual student. If either did not go above and beyond the requirements of the course, then the instructor could always act as the "facilitator."

There did appear to be an internal struggle with the instructors as they wanted to provide a quality education and experience, but also knew that the results rested in the hands of the students. There was only so much an instructor can do from afar. Many virtual students wanted to start new careers, change careers, or enhance another degree. In most cases, the students were working full time, or were stay at home mothers with no child care options. Although they all had a personal reason to be in a design program, their time constraints may not have allowed for the personal interactions needed in such a degree. The virtual studio classroom allowed the student to determine their personal schedule. However, the strategy of independent work directly opposed the principles of the studio model. 
Running head: ANALYZING STUDIO CLASSROOM PRACTICES AND CULTURE

Although the virtual courses were pre-packaged in the sense that the online lectures were complete, the textbook readings were assigned, and the course projects were defined, it appeared as if the instructor managed the course similar to an independent study with 15 or more students in each section. Each student post in the virtual classroom was addressed. Student posts could range from questions, to discussion question responses, to assignment submissions. It was found that instructors needed to repeat the same set of instructions or clarifications to each student. Therefore, the instructors developed videos and/or written instructions that addressed common issues that could be placed at the introduction of an assignment or as a response to a student post. In either case, neither were solely individualized responses to the student. This could be perceived as a cold approach and thus not contribute to relationship building with the student. Many instructors also used programmed keyboard shortcuts (similar to copy/paste, but with only one keystroke) to instruct students. For example, if many students were having issues with proper citation format, the instructor may have used the same verbiage in response to many students. Again, this could appear more "robot-like" and take away from a personal approach and relationship building. These step-by-step actions completed by the instructor created the "facilitator" approach.

Instructional videos or general announcements could be time saving and allowed the virtual instructor to spend more time on the critical aspects of the course such as direct feedback to assignments. However, unlike the physical classroom when one student asks questions, the entire group of students hear the instructor response. a majority of virtual students only viewed the comments to their work and did not visit virtual instructor comments to other students. Again, this undermines the studio model as 
Running head: ANALYZING STUDIO CLASSROOM PRACTICES AND CULTURE

students were only viewing their own work and not learning from others. The students were required, in most cases, to provide comments on and critiques of others' work, but on a rare occasion would the critiquing student view the same work again to see if the student modified or revised the work. The instructor was the only one to look at a student's work from beginning to end. Most likely, students were unaware of their peers' progress with a project.

\section{Limited teaching and learning expectations for iterative on-going reflection and continuing improvements in projects evolving in time}

The most favored reason that students registered for virtual studio courses stemmed from convenience. These students preferred virtual courses due to the demands of full-time jobs, child and family care, or the distance to a campus. At times, virtual students allowed these demands to impede their academic schedules and progression within the program. Instructors have indicated that the relationship they developed with their virtual students typically was caused by an emergency. For example, virtual students asked for extra time on a project assignment because a child was sick or they needed to work overtime. This type of behavior did not seem to be as widespread in the physical classroom. The resident student had a different viewpoint of the physical class. Although physical classroom instructors had experienced students with personal issues, these issues appeared to be more prevalent in the virtual classroom.

There was a generalized perception that online courses were easier to complete. Due to the many home remodeling television shows and networks, there was also a generalized perception that interior design was a profession that was fun and easy. Many 
Running head: ANALYZING STUDIO CLASSROOM PRACTICES AND CULTURE

virtual students indicated that they wanted to start a new career, or change their career, but had not researched the roles and responsibilities of an interior designer.

And, with this misconception of easy coursework, the virtual student did not understand the time required to generate design projects with reflection or refinement of their work. Lacking the physical studio as a reference, the virtual student was unaware that students of the physical studio dedicate at least 12 hours per week to their work (actual physical studio class time). In many cases, the physical student dedicates more time per week as students remain in the physical studio beyond the scheduled meeting times.

The constant interaction with the instructor or peers provides a real-time exchange of ideas and solutions. Although not attending the physical studio classroom provided an option for the virtual student to advance their education, the student lost the opportunity to be immersed in an environment that thrives on learning and working with others. The behavior of discipline is modeled and virtual students fail to witness this when working from home.

\section{E. Limited investment in building a studio culture with real-time presence and interaction among a tightly formed group of 16 or less colleagues to address dynamic complexities in the problem-solving design process}

With the independent study style of the virtual studio courses, students could find the courses to be more challenging than physical studio courses as the students were asked to decipher online lectures, textbook readings, instructional videos, and project requirements. The audio clips, online tutorials, and asynchronous feedback could or could not provide the answer the student needs. 
Running head: ANALYZING STUDIO CLASSROOM PRACTICES AND CULTURE

Although each instructor in the physical environment had their own approach to the management of the studio, the studio model was followed. For example, instructors utilized the time in the classroom to provide instruction, critiques, guidance, and realworld experiences. There was a live, organic, fluid approach to the distribution of information. Interaction in the physical classroom was face-to-face, thereby promoting relationship building between instructors and students, and between students and their peers. The nature of the interaction appeared to cement this successful approach when evaluating the use of the studio model.

The maximum number of students enrolled in physical studio courses is typically 16 thereby allowing this small group to develop working and social relationships. Due to the use of cohorts, this group also moves through the program together from studio course to studio course. By building this sense of comfort, the physical students feel unencumbered to make mistakes, experiment with potential design solutions, and achieve success with the others in the physical studio classroom. This network of support is imperative so as to develop the collaborative sprit and healthy competitiveness that occurs in the physical studio classroom.

Instructors of the physical studio classroom provided feedback about the projects in real time. When engaging in this manner, this allowed the student to assess their work against the project requirements and execute changes, when necessary. It was the constant interaction between the instructor and student that assisted in producing a successful outcome. The virtual studio classroom also provided a time for students to assess their work. However, without the face-to-face commentary, the virtual students did 
Running head: ANALYZING STUDIO CLASSROOM PRACTICES AND CULTURE

not experience the live interaction of working together to solve the design problem. The exchange was delayed due to the discussions posted in the virtual classroom.

With the physical environment studio classroom, the instructors used the traditional studio approach with the sessions. All physical classroom instructors that facilitated in the virtual classroom, however, appeared to approach the virtual studio differently. There was no model, framework, or tradition for the virtual studio classroom. Instructors lost the ability to create a fluid approach and tried to recreate the personal interactions with written or recorded critiques of student work. This one-way communication did not allow for the fundamental approach to the physical studio practice. Instructors tried to replicate the physical studio experience in the virtual classroom by creating video feedback, video tutorials, and written critiques. This asynchronous approach was a one-way conversation. The virtual student had the choice to view, read, or even ignore the information provided. The instructor did not know the actions taken by the student. In many instances, it was apparent when students did not read the text, online lecture, written critique, or view a recorded video critique; their work was not revised, or not revised well, and repeated student questions which were addressed had no action taken. This loss of studio culture development or social learning did not allow for the virtual students to benefit from the studio culture that is cultivated in the physical studio.

In the physical classroom, the instructor controlled the flow of the course; the instructor understood the best approach to the presentation order of information. For example, the instructors discussed the techniques, the purpose of the technique, and then demonstrated how to complete or utilize the techniques. With this approach in the virtual 
Running head: ANALYZING STUDIO CLASSROOM PRACTICES AND CULTURE

asynchronous course, the instructor lost control of the student absorption of information.

With a virtual course, the student could choose how to digest the information. They could skip online lectures, view all demonstrations at one time, or access the course topics out of order from the course schedule. Of course, the physical classroom students also had the option to read ahead in the textbook, but they must follow the schedule of the live (in class) lectures, discussions, and demonstrations.

\section{F. Other Aspects for Consideration}

Other aspects of this study that did not emerge from the interviews, but should also be taken into consideration include dedication of instructor and student, technical skills and design process, and course design.

\section{i. Dedication of instructor and student.}

Dedication of the instructor was not a prominent aspect in the research. Those interviewed were full-time instructors and adjunct instructors. The preparation time, institutional support, course load, appointment requirements, and salary/benefits are different between these two groups but not examined in this study.

As indicated in the previous section, the willingness for instructors to identify and know how to facilitate courses in each environment could also be attributed to the success of the course. The virtual studio classroom could require more time in course planning for the instructors. The instructor could add information to the pre-packaged online course by creating video lectures or demonstrations, written lectures, and other supporting materials, readings, or videos. The instructor had to be available more hours or at different times of the day to accommodate students in various time zones. 
Running head: ANALYZING STUDIO CLASSROOM PRACTICES AND CULTURE

Instructors that went above and beyond the requirements of the classroom or the requirements for instruction typically embraced the virtual component and the nuance of technology.

Instructors had to think about the competencies of the course and the structure of the assignments. For example, in a physical course, the instructor could meet with students individually during studio time to discuss their work. In the virtual environment, the instructor would need to set up time via Skype or another live screen sharing software that would allow discussion of their work. This could take much more time than the 3-4 studio hours and much more effort in scheduling the many individual meetings each week. The time it takes to review student work could be similar in both the physical and virtual classroom. However, with the virtual component, the instructor had to take extra time to scan, download/upload files, add comments electronically, create response videos, etc.

The dedication and effort could also fall on the student. The virtual student would be expected to be somewhat technologically savvy to scan and merge drawings, download/upload files, or learn software programs to support their virtual experience.

If the student completed the course by checking off the requirements, they would obviously not gain the same results as the student that constantly revised their work, researched precedents, or engaged fully in the design process. In the physical studio, the instructor and the student reviewed the work together, or the conversation between the two pushed the student to the next level. This instantaneous interaction promoted the elevation of work. In the virtual studio classroom, the immediate interaction and perhaps the relationship was not as strong. 
Running head: ANALYZING STUDIO CLASSROOM PRACTICES AND CULTURE

\section{ii. Technical skills and design process.}

Although not prevalent in the findings, it was also imperative to note the difference between students learning the skills needed in the profession versus the process of working through a design project and a formal solution.

In the physical studio, students were constantly interacting with one another or with the instructor. The studio space could be lively with many conversations, or on the other hand, a place of tranquil work with everyone in deep concentration. In either case, the students were surrounded by other people and could reach out to ask for assistance, contemplate design solutions with another, or confirm that their solution was viable. Working together led to multiple solutions and sparked creativity. These interactions cemented the student learning as well as replicates the professional world. "Students actively learn from one another in a spontaneous and exploratory mode that fosters deep understanding of content, stimulates and motivates learning, and eliminates boredom (Bowen, 2012)" (Cho, Cho, et al, 2016, p. 568).

The culture of the physical studio developed organically over the session and could continue into multiple sessions as many of the students stayed together in the original cohort. The instructor and students developed relationships; these relationships were considered both professional and personal. For example, it would not be uncommon for the instructor to talk to the student about their family, their past projects, or their plans for the weekend. Students were the same in that they shared details about their personal lives with the instructor or other students. The physical studio became a place for this extended family to gather. Students learned to rely on each other, push each other, and 
Running head: ANALYZING STUDIO CLASSROOM PRACTICES AND CULTURE

support each other with every project. A certain bond was formed. The experience was a rite of passage.

Even though the student design project contained the same parameters and requirements for each student, the project outcomes could be different. Each student progressed through the design process differently. Some could experience road blocks; others could rely on past experiences and solve a problem easily. Each student designer had his/her own style, approach, and personal stamp. In any case, the project results would be different. All would meet the project requirements, but the outcomes would be unique to the student and their strengths.

In the virtual situation, this sense of community was lost as students worked independently. They typically did not form a bond with others thereby decreasing the opportunity for natural relationships to develop. The students only reached out when they were stuck or in need of further clarification. There was limited collaboration of ideas, reviewing others' work intently, or sharing of sources. However, in a global market, students should be able to work together with others in many situations.

For effective collaboration in a technology-mediated learning environment (TMLE), collaborators should have certain skills, such as effective communication, positive attitudes, or technology skills. These skills cannot be developed immediately, so they must be incubated through practice; therefore, educators should consider technology-mediated collaboration activities in design studio for students' smooth transition to their future professional practice (Cho, Cho, et al, 2016, p. 569). 
Running head: ANALYZING STUDIO CLASSROOM PRACTICES AND CULTURE

This led back to skills. Did students learn the same skills in the physical and virtual studio classroom? In regard to technical skills and the phases of the design process, yes. In regard to the sense of community and supporting one another, working through projects together late at night, etc., no. To thoroughly understand the profession and gain experience needed in the professional world, students should have the opportunity to work together (in a community, or collaboratively). On the surface, when comparing projects completed in the virtual studio and the physical studio, the technical outcomes would be quite similar. However, what was not visible was the process. The interactions, the creativity, and the reflection on work was not present in the virtual studio projects.

\section{iii. Course design.}

The last aspect from the research that did not fully develop was the overall virtual course design. Many of the instructors indicated that they needed to modify the prepackaged course, or they felt constrained by the course parameters. Perhaps more focus should have been placed on virtual course design. Instead of forcing a square peg into a round hole, the course should be created to support the studio approach and student learning outcomes. As indicated prior, this research found that these particular courses were designed to support the institution demands. For example, the assignments were required to be graded within 48 hours. Not only did this dictate the number of assignments each week, but is also provided a falsehood that the assignment was complete and in no need of reflection.

With all this said, the 5 prominent factors identified at the beginning of this chapter, could be addressed in the virtual learning environment with different 
Running head: ANALYZING STUDIO CLASSROOM PRACTICES AND CULTURE

instructional strategies, approaches, and technologies. The course design/instructional design could be modified in the virtual learning studio as indicated below. These suggestions have not been implemented in any virtual interior design studio classroom from this study.

A. Limited collaborative interaction among faculty, students, project clients, and experts

The use of videoconferencing or other collaborative tools could be incorporated into the course and assignment instructions. There are also many technologies that allow virtual connection and collaboration in classrooms; these include Adobe Connect, WebEx, Google Classroom, and Zoom. With these videoconferencing applications, a group of students could gather together and the videoconference could stay open for many hours. These applications are flexible in that several students could be in one location and connect to others in different physical locations, or all students could be in different physical locations and connect via the application. The instructor would have control of the meeting time and length.

This approach would need further investigation, as Rehn, et al (2016) suggests, instructors must be cognizant of the design of their courses with the inclusion of videoconferencing. "We suggest that a complete paradigm shift is required whereby teachers think about the affordances of a videoconference and then design their courses to exploit these innovative aspects" (Rehn, et al, 2016, p. 314). Rehn, et al (2016) further explains that technology cannot create a successful course nor create a sense of presence, but it is the instructors and their 
Running head: ANALYZING STUDIO CLASSROOM PRACTICES AND CULTURE

adaption to the virtual environment. Students would also need to adapt to the virtual environment, as they would be required to reach out to students virtually. B. Limited creativity associated with the fluid and open-ended nature of stimulation, trials and exploration in the design process

The approach to the critiques (both pin-up and desk) could be modified to allow the students to submit work without a grade. Many of the virtual studio issues revolved around limited use of studio traditions and limited interactions. The courses are organized by session week or by module, and interviewed instructors indicated that grades of each assignment are due within 48 hours of the assignment submission. This forces the instructor and the student to move forward from the graded assignment thereby hindering the studio approach. With the graded assignment, this indicates to the student that this design step is complete, and there is no need to return or revise the work that is already graded. However, this manner of thought process is not replicated in the physical classroom, or the professional world as designers are constantly revising work based on client preferences or needs, furniture/fixture/material availability, modifications to the built environment, and so on. The organization of the course and the forced grading defines the interactions with the instructor and student.

It could be beneficial for students to submit work without a graded rubric for a "virtual desk crit." With this process, the student could submit their work to the instructor and have an individual review with the instructor. This non-graded approach would allow the student the freedom to make mistakes, think creatively, and potentially try different or unique solutions knowing that the submit would 
Running head: ANALYZING STUDIO CLASSROOM PRACTICES AND CULTURE

not be graded. The "pin-up critique" could also be possible via the videoconferencing applications.

C. Limited personal and individualized interaction in building engaged relationships and networks

Although it may take more dedication of both the instructor and student, assignments may need to be modified to include synchronous interaction. Instructors and students could meet via videoconferencing, share the project via desktop, and conduct a meaningful interaction as if they were in the same physical space.

Collaborative approaches could also provide student to student personal interaction. In a similar approach, students could interact with one another using collaborative tools (written or video) to solve a design problem together. This would allow the students to practice working in teams to complete group projects. D. Limited teaching and learning expectations for iterative on-going reflection and continuing improvements in projects evolving in time

As found in this research, many students have many demands such as fulltime jobs, families, etc., and prefer online courses due to the flexibility. The requirements of the course could be identified the first few days of the course start including the expected hours an assignment or research should demand. This could assist the student with time management and allow more opportunities to reach out to others, when needed. 
Running head: ANALYZING STUDIO CLASSROOM PRACTICES AND CULTURE

E. Limited investment in building a studio culture with real-time presence and interaction among a tightly formed group of 16 or less colleagues to address dynamic complexities in the problem-solving design process

Lastly, this factor is far more complex than the first four, and would need more research. This study reveals that the studio culture cannot be identically cultivated in both environments with the same approaches. With course design in mind, other studies with modified course material, course organization, or course technology would need to be investigated.

A research future study with the above suggestions would be necessary to determine the best instructional strategies and approaches. Again, not only would the outcomes of the courses need to be evaluated, but also the experience.

\section{G. Limitations of Study}

Based on the previous section, "F, Other Aspects to Consider," it may have been beneficial to inquire about course design from both the instructor and student perspectives. A few interview questions such as how course design influences the student participation, or the student expectations could be included. This could have yielded information about the amount of work expected, or how the work would be approached in both the physical studio classroom and virtual studio classroom. When students attend the physical studio classroom, since the instructor and the students are together, the instructor knows the number of hours a student has worked on a project, the number of revisions or modifications the student has made to their work, the points where the student lost their way with the project, or when the student was frustrated or pleased 
Running head: ANALYZING STUDIO CLASSROOM PRACTICES AND CULTURE

with a solution. With virtual students, the instructor does not witness any of this. The instructor must rely on the student to ask for assistance, or wait for the student to submit their work to the online discussion for critique. Unless the instructor asks for specific information, such as the number of hours dedicated to the project, or where the student felt lost, the particulars are not known.

Another interview question could have targeted the number of hours each week the instructor and student dedicate to the course. With the virtual studio classroom, the instructor can see the number of minutes a student has accessed the online classroom for required readings, review of project information, viewing of recorded lectures or tutorials, etc. However, the instructor does not know how much time the student spends on work not completed in the virtual studio classroom. The estimated time spent on projects in both classrooms could have been useful for comparison.

In regards to interviewees and the interview records, the following information was not documented:

1. The number of physical studio or virtual studio courses that instructors facilitated or students participated in

2. The sequence of courses (virtual studio course prior to physical studio course or vice versa)

3. The success of the student in regards to graduation or employment after graduation as the students in the study were sophomore to senior Lastly, the students in this study were all enrolled at the same institution, but different physical campuses. Although students from the physical campus have access to the virtual studio courses, the number of students that had both virtual and physical studio 
Running head: ANALYZING STUDIO CLASSROOM PRACTICES AND CULTURE

experience was restricted. Instructors had a variety of physical studio experiences from different institutions, however, a majority of the virtual studio experiences were from one institution. When (and if) other institutions offer virtual interior design studio courses, this study could be replicated with another set of students.

\section{H. Final thoughts}

\section{i. Advantages and Disadvantages}

With the findings and research limitations taken into consideration, how do students of both the virtual and physical environments differ in project outcomes and professional preparation?

While virtual environments have the potential be a productive learning space with the current technologies available, the examined virtual interior design studio environment did not live up to the rich experiences, practices, or culture of the physical environment.

The student of the physical studio classroom had more experience when considering the studio culture, collaboration, and design processing. The physical studio environment allowed the student to produce quality work for their portfolios as well as allowed the student to be exposed to the expected design firm atmosphere of collaboration. These students also had the opportunity to go on extemporaneous field trips and meet with design professionals, sales representatives, architects, and others faceto-face to engage in professional discussions.

Instructors also invited clients to the physical classroom so that students could conduct live interviews. The student of the virtual studio classroom had more experience 
Running head: ANALYZING STUDIO CLASSROOM PRACTICES AND CULTURE

when considering online learning computer skills, communicating via multiple media outputs, and communicating with instructors with diverse backgrounds. Virtual students attended design professional presentations via webinars. A few instructors briefly mentioned the global aspect to virtual learning environments.

There were particular advantages and exposure to experiences in each environment. For the design profession, the students from the physical environment appeared to have more exposure to the profession.

\section{ii. Beyond Classroom Influences}

The one-on-one interviews from this research focused on the classroom environment. Critical interview comments were not as forthcoming as expected. Therefore, these last paragraphs address the other factors that could be of influence. Although not a direct result of this research, I would be remiss to not include the experiences I have encountered over the past twelve years as an instructor within the physical and virtual interior design studio programs.

The institution referenced in the research that provides the $100 \%$ virtual interior design undergraduate degree is a for-profit institution. The students interviewed were enrolled at the institution as students in an on-ground (physical) program with access to virtual courses, and several of the instructors had experience at this institution as a fulltime or part-time employee. Many of the instructors also had experience from other institutions.

As an instructor with experiences at both a for-profit and a private residentstudent institution, I believe the goals of the for-profit institution were quite different. In this specific program, the focus was on the number of students enrolled in the program. 
Running head: ANALYZING STUDIO CLASSROOM PRACTICES AND CULTURE

Not only were the course enrollment numbers higher, the entrance standards of the students were lower. Typical private or public institutions that utilize physical studio classrooms enroll 15 students, whereas the virtual studio classroom in this study allowed 20-25 students per course. The management of 10 additional students in a physical studio is challenging; it becomes even more so in the virtual studio. The students enrolled in this virtual program also had lower GPA requirements than public or private schools, and did not require a design portfolio for admission to the professional program — common in face-to-face programs.

This virtual program marketed itself as utilizing asynchronous teaching methods thereby creating a student expectation that they could complete the work individually anytime, anywhere. From this research, it was found that studio culture cannot be cultivated in an asynchronous environment. Although instructors in the program provided many opportunities such as workshops, activities, or speaker series events for the students outside of the classroom, student attendance was sparse. I built an online resource center to house items such as portfolio gallery, professional dress/etiquette, "to the trade" sources - mainly topics that would arise during a studio lecture or informal chat. Many students did not attend these events or use the resource center as this was beyond the expectations of the degree.

Many instructors and students experienced frustration with the virtual studio classroom; I believe the frustration was due to several reasons. First, the instructors of the virtual environment had teaching experience originating from the physical environment. After many years of teaching in the physical studio, they had certain 
Running head: ANALYZING STUDIO CLASSROOM PRACTICES AND CULTURE

expectations from students as well as an expected standard of quality from student design project work.

Second, even though students may have had one or two physical design classes, they may not have had a full understanding of how to translate these skills from the physical studio culture into the virtual environment. The reference to a physical studio was not strong enough for the students to understand how the virtual studio should function. Students were frustrated because they were following the steps provided, but the outcomes or instructor expectations of quality and competence did not match. No one had explained "studio culture" to the virtual students. Due to the high enrollment, course overload, low instructor compensation and high instructor responsibilities, there was not much time or reward for instructors to develop the deep, meaningful relationships so essential in the traditional physical studio classroom. The students were completing their work in a step-by-step checklist manner and the instructors responded to the student work in a step-by-step manner. In many cases, the instructors provided thoughtful and thorough comments and/or critiques, however, the student was able to make the choice to incorporate suggestions into their design. The asynchronous approach made it difficult and challenging to create the supportive studio environment expected in a design program.

Third, the virtual studio environment did not create the same learning experience. The course design did not support the design process, the informal collaboration, or the studio culture. Instructors were required to provide a grade for the assignment within 48 hours. This signals to the student that the assignment was complete, and they should move on to the next assignment thereby not encouraging the continued revisions and 
Running head: ANALYZING STUDIO CLASSROOM PRACTICES AND CULTURE

improvement expected. This requirement did not allow students to fully develop as a student or as an emerging design professional.

I also believe that the virtual studio classroom environment was not created to support the outcomes desired. Instructors of the virtual studio were upset and frustrated that students did not produce work that was expected, but students did not have a virtual studio environment that was designed to support the outcomes desired. The virtual studio was not created to support the informal collaboration, building of relationships, or the studio culture that was demanded for a successful environment. The virtual studio classroom was a framework established and could not be changed or modified. However, in the end, what the virtual instructors desired for student studio work had been different than what the students were providing. Yes, technically, the acceptable work was completed well, but the process and culture were quite different between the two environments.

In addition to the non-supportive environment, faculty received salaries lower than the industry average. Research and scholarship were not promoted or supported. Instructors also facilitated courses back-to-back on multi-track course enrollments. This type of treadmill production of student credit hours is severely taxing on instructors.

Within the recent years, the online interior design program was accredited by a design organization. Because accreditation standards evolve and the accreditation agency encourages programs to exceed minimum standards, it will be of interest to follow accreditation of programs in the future with the $100 \%$ a virtual delivery given my assessment of the differences between the physical and virtual studio classroom discussed in this study. 
Running head: ANALYZING STUDIO CLASSROOM PRACTICES AND CULTURE

I believe faculty are placed in a challenging and difficult ethical situation as students are not ready for the demands of the program due to program expectations were not communicated well by the admission representatives. Instructors assumed high expectations and demands extending beyond the time spent in the classroom. However, is it also my belief that the instructors of this environment did the best they could with the conditions that were provided. In the end, any of these factors could impact the quality of the education.

\section{Conclusion}

The interior design studio is the backbone of interior design education. Students learn by doing, develop relationships with instructors and peers, and collaborate. With the lack of collaboration, limited creative process, limited personal interaction, environmental influences, lack of structure, and difference in instructional strategies, it appears that the current virtual studio classroom does not meet the established physical studio classroom approach and quality standards. These virtual students are learning the design process steps, technical skills, and digital presentation skills, however, without the experience of the physical studio classroom, they lose the benefits of this established learning strategy. The virtual student experience does not practice project exploration thereby diminishing their skills in finding the best solution. One of the outcomes of this

research raises critical questions about the virtual studio classroom in that it did not create or sustain the studio culture as developed in the physical studio classroom.

Technology has allowed virtual learning and the opportunity for students to learn within a non-traditional environment. However, conducting virtual studio classes needs 
Running head: ANALYZING STUDIO CLASSROOM PRACTICES AND CULTURE

to be rigorously evaluated and reconstructed to improve practices for both students and instructors. Mechanisms of the virtual studio classroom analyzed in this study did not replicate the same learning outcomes in the physical studio classroom. Creative methods for design instruction should continue to evolve with best teaching practices.

This study did not consider hybrid or blended courses. In these cases, the students would meet both in the physical classroom and virtual classroom throughout each session. Many studies have been completed investigating the benefits and disadvantages to this approach in non-studio courses, with only a few studies focusing on the studio approach. More research in this area would be quite beneficial. Experimenting with different technology (learning management systems, collaborative communication tools such as hangouts, chat rooms, blogs, videoconferencing, etc.) may provide other areas for instructors and students to connect on a deeper level than this research indicates.

Examining the professional advancement of instructors with experiences in both the physical and virtual design studios would be beneficial for future studies, too. These instructors would have the experiences to share that would create the best environments for learning.

In summary, established course design, studio practices, and the use of collaborative technology were not implemented to produce the experiential learning outcomes of real-time intensive studio culture. Specifically, the study found serious limitations in (1) Collaborative interaction among faculty, students, project clients, and experts, (2) Creativity associated with the fluid and open-ended nature of stimulation, trials and exploration in the design process, (3) Personal and individualized interaction in building engaged relationships and networks, (4) Teaching and learning expectations for 
Running head: ANALYZING STUDIO CLASSROOM PRACTICES AND CULTURE

iterative on-going reflection and continuing improvements in projects evolving in time, and (5) Investment in building studio culture with real-time presence and interaction among a tightly formed group of 16 or less colleagues to address dynamic complexities in the problem-solving design process.

This research indicates that the virtual studio classroom in the current analyzed format had critical limitations in its pedagogical infrastructure as documented in teaching and experiential learning outcomes. To benefit in the potential future for the depth of intensive studio learning in a virtual format, it is recommended that the virtual studio classroom be approached in a way that would emphasize collaboration, creativity, personal interaction, teaching and learning expectations for continuing improvements, and an investment in a studio culture for students to flourish. 
Running head: ANALYZING STUDIO CLASSROOM PRACTICES AND CULTURE

\section{References}

Al-Qawasmi, J., Vasquez, V. G. P., \& Center for the Study of Architecture in the Arab Region. (2006). Changing trends in architectural design education. Morocco: The Center for the Study of Architecture in the Arab Region (CSAAR).

Ankerson, K. S., \& Pable, J. (2008). Interior design: Practical strategies for teaching and learning. New York: Fairchild Books.

Babbie, E. R., \& Babbie, E. R. (1999). The basics of social research. Belmont, Calif: Wadsworth Pub.

Bandura, A. (1977). Social learning theory. Englewood Cliffs, NJ: Prentice-Hall.

Bender, D. M., \& Vredevoogd, J. D. (2006). Using Online Education Technologies to Support Studio Instruction. Educational Technology \& Society, (9)4, 114-122.

Blumer, H. (January 01, 1969). Symbolic interactionism: Perspective and method. Berkeley: University of California Press.

Cennamo, K., \& Brandt, C. (October 01, 2012). The "right kind of telling": Knowledge building in the academic design studio. Educational Technology Research and Development, (60)5, 839-858.

Charmaz, K. (2006). Constructing grounded theory: A practical guide through qualitative analysis. London: Sage Publications.

Cho, J. Y., \& Cho, M. (2014). Student perceptions and performance in online and offline collaboration in an interior design studio. International Journal of Technology 
Running head: ANALYZING STUDIO CLASSROOM PRACTICES AND CULTURE

and Design Education, 24(4), 473-491. doi:10.1007/s10798-014-9265-0

Cho, J. Y., Cho, M.-H., \& Kozinets, N. (2016). Does the medium matter in collaboration? Using visually supported collaboration technology in an interior design studio. International Journal of Technology and Design Education, 26(4), 567586.

Cho, J. Y., \& Schwarz, B. (2015). Aesthetic Theory and Interior Design Pedagogy. The Handbook of Interior Design, 478-496.

Creswell, J. W. (2009). Research design: Qualitative, quantitative, and mixed methods approaches. Los Angeles: Sage.

Creswell, J. W., \& Creswell, J. W. (2013). Qualitative inquiry \& research design: Choosing among five approaches. Thousand Oaks: Sage Publications.

Crotty, M. (1998). The foundations of social research: Meaning and perspective in the research process. London: Sage Publications.

Cuff, D. (1992). Architecture: The story of practice. Cambridge, MA: The MIT Press. deMunck, Victor C. \& Sobo, Elisa J. (Eds) (1998). Using methods in the field: a practical introduction and casebook. Walnut Creek, CA: AltaMira Press.

Department of Architecture. (n.d.). Retrieved from http://www.memphis.edu/architecture/docs/studio.culture.pdf

Design, U. A. (n.d.). Architecture School Admissions - UCLA. Retrieved from 
Running head: ANALYZING STUDIO CLASSROOM PRACTICES AND CULTURE

http://www.aud.ucla.edu/admissions/admissions.html

Dewey, J. (1933). How we think: A restatement of the relation of reflective thinking to the educative process. Boston, Mass: Heath.

Fusch, P. I., \& Ness, L. R. (January 01, 2015). Are we there yet? Data saturation in Qualitative research. Qualitative Report, 20, 9, 1408-1416.

Garrison, D. R., \& Vaughan, N. D. (2008). Blended learning in higher education: Framework, principles, and guidelines. San Francisco, CA: Jossey-Bass.

Ghaziani, R., Montazami, A., \& Bufton, F. (2013, April). Architectural Design Pedagogy: Improving Student Learning Outcomes. Paper presented at AAE Conference, Nottingham Trent University, UK. Retrieved from https://architecturaleducators.wordpress.com/conference-2013/conference-2013papers/

Groat, L. N., \& Wang, D. (2002). Architectural research methods. New York: J. Wiley.

Haythornthwaite, C., \& Kazmer, M. (2004). Learning, Culture and Community in Online Education. New York: Peter Lang.

Hill, J. R., Song, L., \& West, R. E. (January 01, 2009). Social Learning Theory and WebBased Learning Environments: A Review of Research and Discussion of Implications. American Journal of Distance Education, 23, 2, 88-103. 
Running head: ANALYZING STUDIO CLASSROOM PRACTICES AND CULTURE

Imel, S., \& ERIC Clearinghouse on Adult, Career, and Vocational Education. (2002). Adult learning in cohort groups. Columbus, OH: ERIC Clearinghouse on Adult, Career, and Vocational Education, Center on Education and Training for Employment, College of Education, the Ohio State University.

Isaacson, W., \& Boutsikaris, D. (2017). The innovators: How a group of hackers, geniuses, and geeks created the digital revolution. Riverside: Simon \& Schuster.

Kvan, T. (2001). The pedagogy of virtual design studios. Automation in Construction, (10), 345-353.

Konkel, M. T. (2014). Build-to-Learn: An Examination of Pedagogical Practices in Interior Design Education. Journal of Interior Design, (39)2, 1-16.

Kuhn, S. (2001). Learning from the Architecture Studio: Implications for Project-Based Pedagogy. International Journal of Engineering Education, (17), 349-352.

Masdeu, M., \& Fuses, J. (2017). Reconceptualizing the design studio in architectural education: Distance learning and blended learning as transformation factors. Archnet-ijar, 11, 2, 6-23.

Maxwell, J. A. (2005). Qualitative research design: An interactive approach. Thousand Oaks: SAGE Publisher.

May, B. A. (2017). Lessons in Diversity: Origins of Interior Decoration Education in the United States, 1870-1930. Journal of Interior Design, (42)3, 5-28.

McWhinnie, L., \& Peterson, J.F. (2017) Evolving pedagogy: Is studio a state of mind?, 
Running head: ANALYZING STUDIO CLASSROOM PRACTICES AND CULTURE Design Management Academy Conference, Hong Kong, 2017.

Nikanjam, S., Hassanpour, B., \& Ani, A. (2016). Exploration of Influential Factors on First Year Architecture Students' Productivity. International Journal of Social, Behavioral, Educational, Economic, Business and Industrial Engineering, 10(5), 1565-1570.

Ockman, J., \& Williamson, R. (2012). Architecture school: Three centuries of educating architects in North America. Cambridge, Mass: MIT Press.

Rehn, N., Maor, D., \& McConney, A. (2016). Investigating teacher presence in courses using synchronous videoconferencing. Taylor \& Francis.

Salaana, J. M. (2009). The Coding manual for qualitative researchers. Place of publication: Sage.

Sawyer, R. K. (2017). Teaching creativity in art and design studio classes: A systematic literature review. Educational Research Review, 22, 99-113.

Schon, D. A. (1987). Educating the Reflective Practitioner: Toward a New Design for Teaching and Learning in the Professions. John Wiley \& Sons.

Soep, E. (2005, September). Critique: Where Art Meets Assessment. Phi Delta Kappan Magazine, 87(1), 38-63.

Spellman-Cann, S., Luong, E, Hendricks, C., \& Roberts, V. (2016). In Kilgore, W. \& Hack Williams, W. (Eds.), Humanizing online teaching and learning, (pp. 111- 
Running head: ANALYZING STUDIO CLASSROOM PRACTICES AND CULTURE

131). CreateSpace Independent Publishing Platform.

Tongco, M. D. C. (2007). Purposive Sampling as a Tool for Informant Selection. University of Hawaii at Manoa.

Tumusiime, H. (2013, April). Learning in architecture: Students' perceptions of the Architecture Studio. Paper presented at AAE Conference, Nottingham Trent University, UK. Retrieved from https://architecturaleducators.wordpress.com/conference-2013/conference-2013papers/

Williams, K. (2017). Using social learning theory to engage adults through extension education. NACTA Journal, 61(3), 263-264. 
Running head: ANALYZING STUDIO CLASSROOM PRACTICES AND CULTURE

\section{Appendices}

Appendix A

Discussion Guides for In-Depth Interviews

\section{In-Depth Interview Discussion Guide - Instructors}

\section{Introduction to the study}

a. A research project examining instructor and student experiences in physical and virtual interior design studio classrooms

b. Explain why this group of people was selected

c. Thank the participant for agreeing to the interview

\section{Questions}

a. Based on answers, ask for clarification. Prompts could include, "Could you describe further?"

i. How many years have you been teaching physical studio courses? And virtual studio courses?

ii. How do you conduct the physical/virtual studio courses? What techniques do you use?

iii. What are the most successful approaches to physical studio courses? And virtual studio courses?

iv. What are the difficulties with physical studio courses? And virtual studio courses?

v. How does the classroom environment dictate your approach to the class?

vi. Do you see a difference in quality of work between the two environments? 
Running head: ANALYZING STUDIO CLASSROOM PRACTICES AND CULTURE

\section{In-Depth Interview Discussion Guide - Students}

\section{Introduction to the study}

a. A research project examining instructor and student experiences in physical and virtual interior design studio classrooms

b. Explain why this group of people was selected

c. Thank the participant for agreeing to the interview

\section{Questions}

a. Based on answers, ask for clarification. Prompts could include, "Could you describe further?"

i. What do you like about physical studio courses? And virtual studio courses?

ii. What do you dislike about physical studio courses? And virtual studio courses?

iii. How do you interact with your instructor? And peers?

iv. What are the advantages with the physical studio course? And the virtual studio course?

v. What are the disadvantages with the physical studio course? And virtual studio course?

vi. How do you plan/prepare for the physical studio course? And the virtual student course?

vii. Were you proud of your work in both environments? 
Running head: ANALYZING STUDIO CLASSROOM PRACTICES AND CULTURE

\section{APPENDIX B \\ Full Listing of Categories and Codes}

Studio Practice (Instructor - Physical) - 20 codes

Course strategies, instructor availability, full attention, face-to-face, live demonstrations, lecture $\mathrm{prep} / \mathrm{mental}$ prep, personal contact, attendance, mimics professional studio, students fully prepared, classroom not pre-loaded, videos assist, cohorts, field trips, instant application of skills, prep time consuming, demonstrations, centralized environment, necessary equipment, classroom strategies can be modified

Studio Practice (Instructor - Virtual) - 21 codes Definition of instruction, instructor availability, recorded demonstrations, addressing student struggles, content pre-loaded, records content accessed, course strategies, instructor synchronous, time to gather thoughts, access to all, all content available, student savviness with technology, prepare for global world, communicate digitally, instructor invested time, personal attention, independent course, topic communication only, student misunderstandings, lack of professionalism, web field trips

Studio Practice (Student - Physical) - 13 codes Instructor availability, limited to class time, student learning strategies, large class overwhelms, personal, instructor strategies, schedule, course structure, benefits of studio, discussions, engaged, instant/real time, audio instructions

Studio Practice (Student - Virtual) - 13 codes Instructor availability, asynchronous, student learning strategies, expectations, course availability, coursework preparation, lack of personal experience, not engaged, student preparation, experience of student, not real time, different instructors, written instructions

Critique (Instructor - Physical) - 5 codes

Instructor feedback, instant feedback, formal presentations, pin-ups, desk critiques

Critique (Instructor - Virtual) - 6 codes

Interpretation of critique, instructor feedback, instructor feedback via video, majority feedback/no exchange, limitations to synchronous feedback, written or video feedback only

Critique (Student - Physical) - 5 codes

Instructor individual feedback, formal presentations, pin-ups, desk critique, reaction to presentations

Critique (Student - Virtual) - 5 codes

No formal presentations, instructor feedback written, audio feedback, easier to critique others, written feedback

Studio Culture (Instructor - Physical) - 13 codes 
Running head: ANALYZING STUDIO CLASSROOM PRACTICES AND CULTURE

Personal interaction, live interaction, genuine, 'educator,' personal experiences, 'organic,' 'fluid,' peer-to-peer interaction, healthy competition, aware of one another, build relationships, engagement extends beyond class time, high sense of comfort

Studio Culture (Instructor - Virtual) - 8 codes

Live interaction, non-personal, 'facilitator,' independent study, lack of personal contact, missing connection with peers, difficult to build relationships, low sense of safety

Studio Culture (Student - Physical) - 5 codes

Direct interaction, instructor interaction, peer interaction, peer interaction casual/extend beyond classroom, reach out to others for help

Studio Culture (Student - Virtua) - 8 codes

Instructor interaction, student/peer interaction, comfort level of students, comfort level of instructors, student support of one another in class, variety of interactions, peer discussions, hesitant to reach out

Collaboration (Instructor - Physical) - 5 codes

Collaborative, group examples, team projects, organized teams, learn from others

Collaboration (Instructor - Virtual) - 5 codes

Missing connection with peers, not much instructor collaboration -formal, team projects challenging, beneficial but challenging, must provide more time than on ground

Collaboration (Student - Physical) - 2 codes

Team projects, collaboration

Collaboration (Student - Virtual) - 2 codes

Limited collaboration, collaboration challenging

Outcomes (Instructor - Physical) - 7 codes

Addressing student struggles, allow exploration, develop student creativity, course outcomes, high percent of student success, hands on, caliber of student

Outcomes (Instructor - Virtual) - 7 codes

Outcomes, exploration is difficult to manage, technical skills, step-by-step instructions, limited time for creativity, caliber of student, low percent of student success

Outcomes (Student - Physical) - 4 codes

Projects/outcomes, outcomes, hands on learning, hard copy/hand to paper

Outcomes (Student - Virtual) - 3 codes

Outcomes, virtual copy, work ahead

Environment Influence/Impact/Control (Instructor - Physical) - 4 codes

Distractions, more dedicated, forced to attend studio, classroom maintenance 
Running head: ANALYZING STUDIO CLASSROOM PRACTICES AND CULTURE

Environment Influence/Impact/Control (Instructor - Virtual) - 5 codes Flexibility, work from home, cannot determine proper equipment, cannot determine student issue when missing, student perceived benefit

Environment Influence/Impact/Control (Student - Physical) - 3 codes Prefer over virtual, students not paying attention, course overloads distractions

Environment Influence/Impact/Control (Student - Virtual) - 7 codes Convenience, student perceived limitations, content focused/no distractions, forced schedule, expedited, flexible, can lead to frustration 
Running head: ANALYZING STUDIO CLASSROOM PRACTICES AND CULTURE

\section{VITA}

Lori Kinley has an undergraduate BS degree in Advertising from Bradley University, an undergraduate BA degree in Art/Interior Design from Anderson University, and a graduate MA degree in Historic Preservation from Savannah College of Art and Design. She started her second career 12 years ago when she began teaching interior design courses in the physical and virtual classrooms. Lori currently lives in South Carolina with her husband, two sons, and two dogs. 